Florida International University FIU Digital Commons

FIU Electronic Theses and Dissertations

University Graduate School

$11-21-2003$

\title{
Economic analysis of the Florida Everglades restoration
}

Jeffrey Robert Czajkowski

Florida International University

DOI: $10.25148 /$ etd.FI14061580

Follow this and additional works at: https://digitalcommons.fiu.edu/etd

Part of the Environmental Indicators and Impact Assessment Commons

\section{Recommended Citation}

Czajkowski, Jeffrey Robert, "Economic analysis of the Florida Everglades restoration" (2003). FIU Electronic Theses and Dissertations. 2704.

https://digitalcommons.fiu.edu/etd/2704

This work is brought to you for free and open access by the University Graduate School at FIU Digital Commons. It has been accepted for inclusion in FIU Electronic Theses and Dissertations by an authorized administrator of FIU Digital Commons. For more information, please contact dcc@fiu.edu. 
FLORIDA INTERNATIONAL UNIVERSITY

Miami, Florida

ECONOMIC ANALYSIS OF

THE FLORIDA EVERGLADES RESTORATION

A thesis submitted in partial fulfillment of the

requirements for the degree of

MASTER OF SCIENCE

in

ENVIRONMENTAL AND URBAN SYSTEMS

by

Jeffrey Robert Czajkowski

2004 
To: Dean Vish Prasad

College of Engineering

This thesis, written by Jeffrey Robert Czajkowski, and entitled Economic Analysis of the Florida Everglades Restoration, having been approved in respect to style and intellectual content, is referred to you for judgment.

We have read this thesis and recommend that it be approved.

Mahadev G. Bhat

Grace M. Johns

Walter Z. Tang, Major Professor

Date of Defense: November 21, 2003

The thesis of Jeffrey Robert Czajkowski is approved.

Dean Vish Prasad College of Engineering

Dean Douglas Wartzok University Graduate School

Florida International University, 2004 
(c) Copyright 2004 by Jeffrey Robert Czajkowski

All rights reserved. 


\section{DEDICATION}

I dedicate this thesis to all of those who have helped me reach this point in my education through their support and encouragement - my parents, family, friends, teachers, colleagues, classmates and of course my little Miami Beach clan - Miryam, Bruno, and Chimpun. 


\section{ACKNOWLEDGMENTS}

I wish to thank the members of my committee, Mahadev G. Bhat, Grace M. Johns, and Walter Z. Tang, for their time and guidance in this endeavor, without their assistance, effort, and prodding this would not have been possible. I would especially like to thank my major professor, Walter Z. Tang, for all of his time, effort, support, and guidance and whose vision of the shared knowledge between environmental engineering and economics made this research effort a reality. I also wish to thank the FIU faculty in the departments of Civil and Environmental Engineering and Economics for imparting their knowledge. Finally, I wish to thank the Environmental Protection Agency for their financial support in the backing of my graduate education. 


\section{ABSTRACT OF THE THESIS \\ ECONOMIC ANALYSIS OF \\ THE FLORIDA EVERGLADES RESTORATION}

by

Jeffrey Robert Czajkowski

Florida International University, 2004

Miami, Florida

Professor Walter Z. Tang, Major Professor

An economic valuation methodology was developed in order to monetarily quantify the benefits resulting from the Indian River Lagoon - South (IRLS) \$995 million Everglades restoration project. Service flows of the IRLS were identified and their associated economic baseline values were estimated utilizing existing research. A water quality baseline for the IRLS was also established and compared with the best available standards. Benefits accruing beyond the baseline values given the completion of the IRLS restoration were estimated via benefit transfer to be approximately $\$ 159$ million annually, importantly factoring in the established IRLS water quality baseline.

Given these benefit results of a lower bound estimate, the project was determined not to be economically feasible, i.e., NPV $<\$ 0$, via a cost-benefit analysis. However, Monte Carlo analyses provided further insights into the probability of an economically feasible restoration (36\%) given the uncertainty surrounding the benefit estimation, as well as specific variables to focus on to improve this probability. This research highlights the potential significant economic value of the IRLS and the importance of properly estimating this value given the magnitude of costs. 
1 INTRODUCTION 1

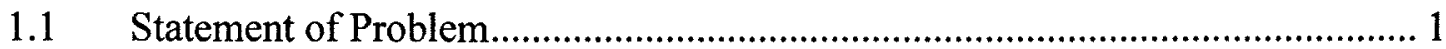

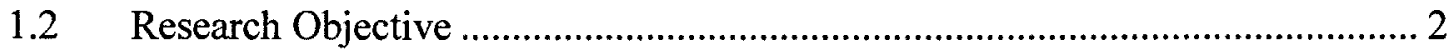

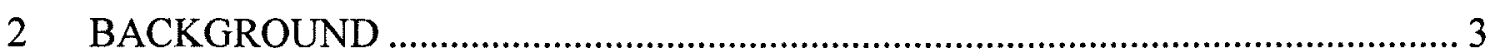

2.1 Economically Valuing Natural Resources ..................................................... 3

2.1.1 What is Meant By Economic Value...................................................... 3

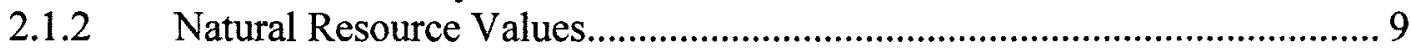

2.1.3 Market Failure for Natural Resources...................................................... 10

2.1.4 Natural Resource Economic Valuation Techniques ................................ 11

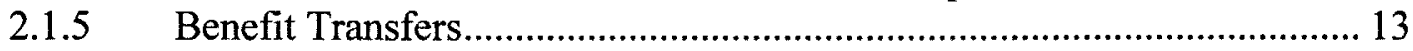

2.2 An Economic Valuation Focus on Water ..................................................... 14

2.2.1 Framework for Valuing Water.......................................................... 14

2.2.2 Water Quantity Benefit Estimation................................................... 17

2.2.2.1 Estimating Municipal Benefits ........................................................... 18

2.2.2.2 Estimating Commercial and Industrial Benefits ................................ 22

2.2.2.3 Estimating Agricultural Benefits ......................................................... 24

2.2.2.4 Estimating Hydroelectric Power Benefits.......................................... 27

2.2.2.5 Estimating Recreation Benefits..................................................... 27

2.2.2.6 Estimating Ecological Function Benefits............................................ 29

2.2.3 Water Quality Benefit Estimation....................................................... 32

2.2.3.1 Estimating Municipal Benefits ......................................................... 32

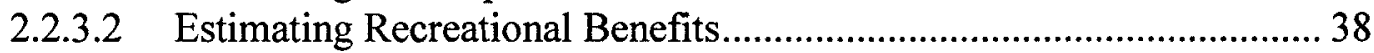

2.2.3.3 Estimating Agricultural Benefits ..................................................... 52

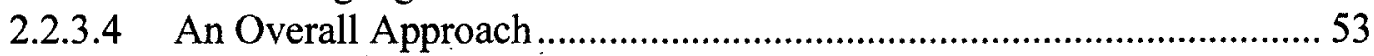

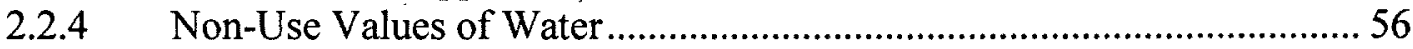

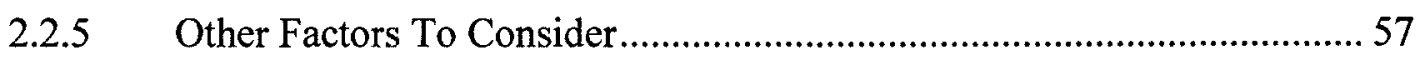

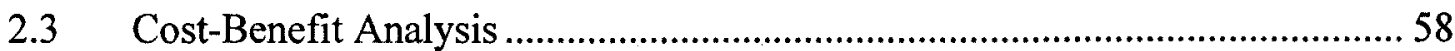

2.4 Indian River Lagoon South Project Overview.............................................. 61

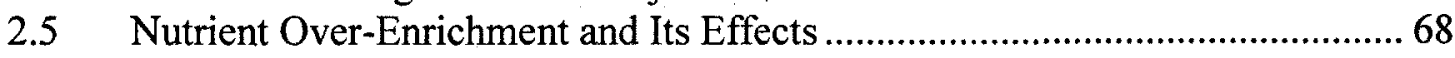

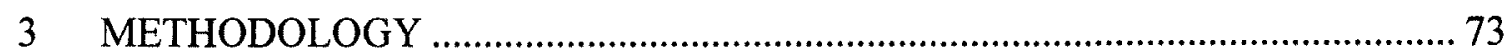

3.1 Overall Methodology Approach ………........................................................ 73

3.2 Identifying the Service Flows ……................................................................ 75

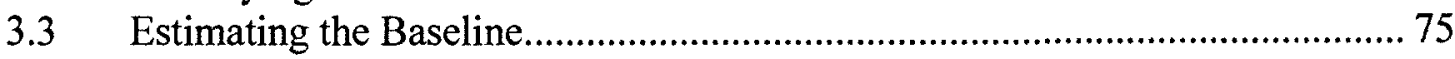

3.3.1 Market Direct Use Valuation ................................................................. 76

3.3.2 Nonmarket Passive Use Valuation........................................................... 79

3.3.3 Nonmarket Direct Use Valuation........................................................ 81 


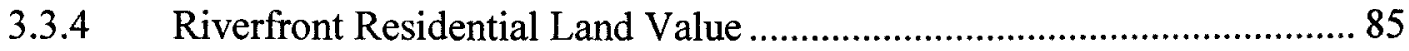

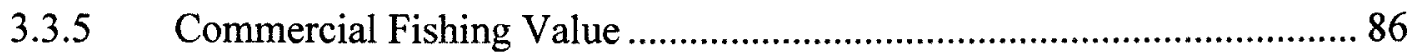

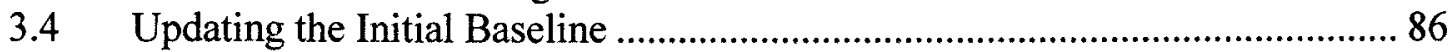

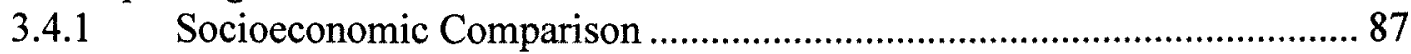

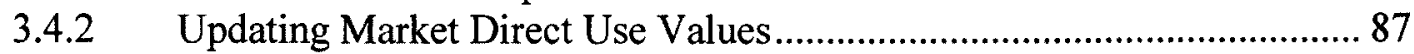

3.4.3 Updating Nonmarket Passive Use Values ................................................ 90

3.4.4 Updating Nonmarket Direct Use Values .............................................. 93

3.4.5 Updating Riverfront Residential Land Value ......................................... 94

3.4.6 Updating Commercial Fishing Values................................................... 94

3.5 Additional Baseline Values To Be Addressed...............................................95

3.6 Water Quality Baseline Assessment .............................................................. 96

3.7 Impact Assessment to Updated Baseline Estimate ........................................... 98

3.7.1 Market Direct Use Impacted Benefits................................................... 100

3.7.2 Nonmarket Direct and Passive Use Impacted Benefits ......................... 103

3.8 Cost-Benefit Analysis .................................................................................... 109

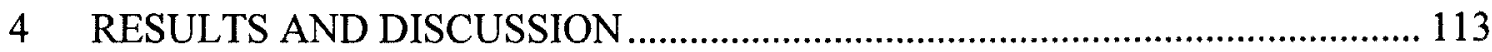

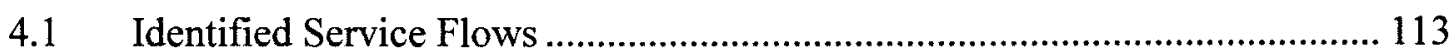

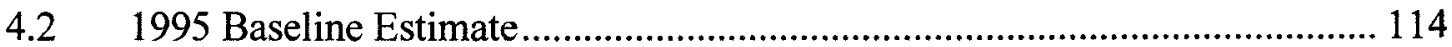

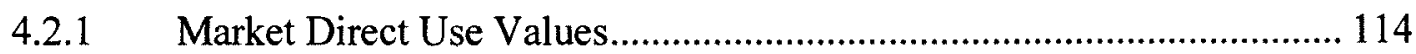

4.2.2 Nonmarket Passive Use Values ........................................................... 118

4.2.3 Nonmarket Direct Use Values .......................................................... 119

4.2.4 Riverfront Residential Land Values.................................................. 121

4.2.5 Commercial Fishing Value ................................................................... 122

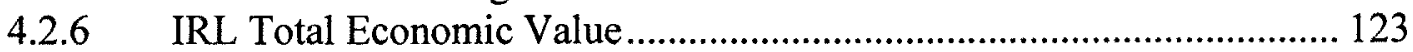

4.3 Updated Baseline Estimate .......................................................................... 123

4.3.1 Socioeconomic Comparison .......................................................... 124

4.3.2 Updated Market Direct Use Values ....................................................... 126

4.3.3 Updated Nonmarket Passive Use Values............................................. 128

4.3.4 Updated Nonmarket Direct Use Values.............................................. 128

4.3.5 Updated Riverfront Residential Land Value......................................... 129

4.3.6 Updated Commercial Fishing Values ................................................. 129

4.3.7 IRLS Total Economic Value.............................................................. 130

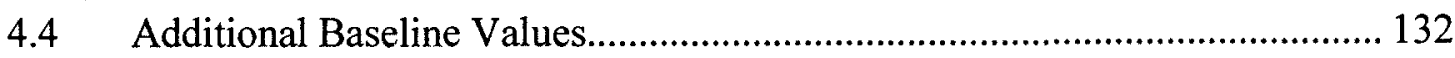

4.5 Water Quality Baseline Assessment .......................................................... 134

4.6 Estimated Market Direct Use Benefits ......................................................... 139

4.7 Estimated Nonmarket Direct and Passive Use Benefits ................................ 142

4.8 Total Estimated IRLS Benefits ................................................................ 146

$4.9 \quad$ Cost-Benefit Analysis .............................................................................. 149

5 CONCLUSIONS \& FUTURE RESEARCH ................................................. 156

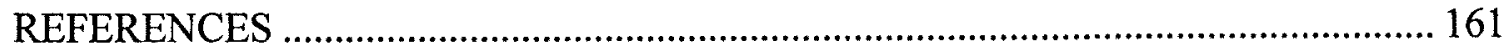




\section{LIST OF TABLES}

TABLE

PAGE

Table 2.1: Techniques for Natural Resource Economic Valuation 12

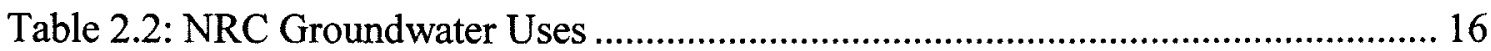

Table 2.3: Water Quantity Impact Considerations ...................................................... 17

Table 2.4: EPA Designated Use Scoring Categorization.................................................. 45

Table 2.5 : Iterative Choice WTP Results .................................................................... 47

Table 2.6 : Boatable, Fishable, Swimmable WTP …....................................................... 49

Table 2.7: Combined Revealed \& Stated Preference Study Results .............................. 51

Table 2.8: Estimated Initial Costs for IRLS Construction Features ...............................65

Table 2.9: Identified IRLS Environmental Quality Benefits .......................................6 66

Table 2.10: Identified IRLS National Economic Development Benefits ......................... 66

Table 2.11: Identified IRLS Regional Economic Development Benefits.......................67

Table 2.12: Florida Designated Uses of Water ............................................................ 72

Table 2.13: Nutrient Standards by Designated Use ....................................................... 73

Table 3.1: IRLS Restoration Activities Affect On Water Quality.................................. 104

Table 3.2: Benefit-Cost Analysis Overview ................................................................ 112

Table 4.1: IRL Resident Market Direct Use Value for Boating ................................... 115

Table 4.2: IRL Non-Resident Market Direct Use Value for Swimming ........................ 116

Table 4.3: IRL Resident Nonmarket Passive Use Values.......................................... 118

Table 4.4: IRL Non-Resident Nonmarket Passive Use Values .................................... 119

Table 4.5: Total IRL Nonmarket Direct Use Value.................................................... 119

Table 4.6: IRL Capitalized Market Value of Riverfront Land ................................... 121 
Table 4.7: IRL 1995 Total Economic Value

Table 4.8: Resident Socioeconomic Characteristic Comparison..................................... 124

Table 4.9: Non-Resident Socioeconomic Characteristic Comparison............................ 125

Table 4.10: IRLS Resident Market Direct Use Values................................................ 126

Table 4.11: IRLS Non-Resident Market Direct Use Values.......................................... 127

Table 4.12: IRLS Resident \& Non-Resident Nonmarket Passive Use Values ............... 128

Table 4.13: IRLS Resident Nonmarket Direct Use Values ....................................... 129

Table 4.14: IRLS Resident Riverfront Land Values................................................... 129

Table 4.15: IRLS Total Baseline Value for 1995 \& 2001 ............................................. 130

Table 4.16: Updated Baseline with Additional Values................................................... 133

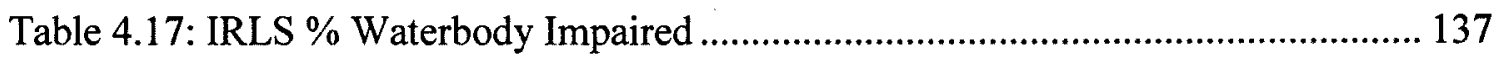

Table 4.18: Detailed IRLS Assessed Waterbodies .................................................... 138

Table 4.19: Resident Estimated IRLS Market Direct Use Benefits............................... 140

Table 4.20: Non-Resident Estimated IRLS Market Direct Use Benefits ........................ 141

Table 4.21: IRLS Resident Nonmarket Passive Use Value Benefits.............................. 142

Table 4.22: IRLS Non-Resident Nonmarket Passive Use Value Benefits ..................... 143

Table 4.23: IRLS Resident Nonmarket Direct Use Benefits ......................................... 144

Table 4.24: IRLS Non-Resident Nonmarket Direct Use Benefits.................................. 145

Table 4.25: Total IRLS Estimated Benefits............................................................. 146

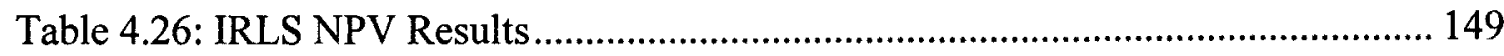

Table 4.27: Monte Carlo Base Case Summary Statistics ........................................... 152

Table 4.28: Monte Carlo Fixed Analysis Summary Statistics..................................... 154 


\section{LIST OF FIGURES}

FIGURE

PAGE

Figure 2.1: Total Marshallian WTP - Market and Nonmarket..................................... 6

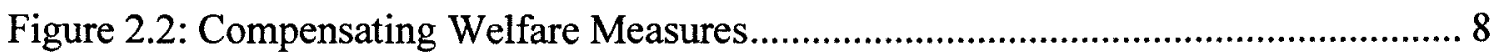

Figure 2.3: Total Economic Value Framework ...................................................... 10

Figure 2.4: Conceptual Framework for Water Valuation ............................................. 16

Figure 2.5: Florida Water Withdrawals in million gallons per day .............................. 18

Figure 2.6: Techniques for Measuring Recreational Benefits ........................................... 38

Figure 2.7: Iterative Choice Scenario - Cost of Living vs. Water Quality........................ 48

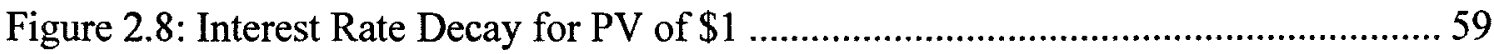

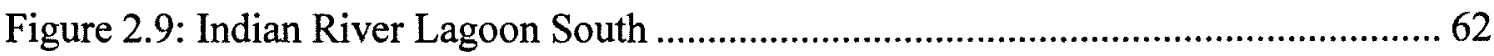

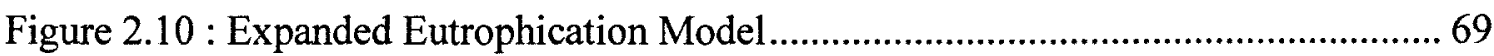

Figure 2.11: Total Nitrogen Concentration Classification............................................... 71

Figure 2.12: Total Phosphorus Concentration Classification ........................................ 71

Figure 3.1: Measuring the Benefit of the IRLS Restoration............................................ 74

Figure 3.2: Apogee Research RUM Iterative Process ....................................................... 84

Figure 3.3: Recreational Value Change Due to Quality Improvement............................. 99

Figure 3.4: Diminishing Marginal Returns for WQ Improvement ................................ 102

Figure 3.5: Nonmarket Direct \& Passive Use WTP Values .......................................... 104

Figure 3.6: Net Benefits of IRLS Restoration ....................................................... 110

Figure 4.1: IRL Total Resident Market Direct Use Values ......................................... 115

Figure 4.2: IRL Total Non-Resident Market Direct Use Values ................................. 117

Figure 4.3: IRL Total Resident \& Non-resident Market Direct Use Value.................... 117 
Figure 4.4: IRL Nonmarket Access Values Per Angler............................................... 120

Figure 4.5: IRL Total Annualized Value of Riverfront Land ...................................... 122

Figure 4.6: 1995 to 2002 IRL Adult Population Growth Rates.................................... 131

Figure 4.7: Resident Added Nonmarket Direct Use Values ...................................... 132

Figure 4.8: Non-resident Added Nonmarket Direct Use Values .................................. 133

Figure 4.9: IRLS Total Phosphorus Concentration Baseline ........................................ 135

Figure 4.10: IRLS Total Nitrogen Concentration Baseline ...................................... 135

Figure 4.11: Use Values as a $\%$ of $\$ 344$ million Total Baseline ................................... 147

Figure 4.12: Use Values as a $\%$ of $\$ 159$ million Total Benefits..................................... 147

Figure 4.13: IRLS PV of Cumulative Costs \& Benefits................................................. 150

Figure 4.14: IRLS Monte Carlo NPV Histogram ................................................... 151

Figure 4.15: Monte Carlo NPV with One Random Variable...................................... 153

Figure 4:16: Monte Carlo Histogram Results Varying Time ....................................... 155 
The inherent politics of environmental restoration efforts command numerous tradeoffs to be made so that the optimal balance between ecosystem restoration and economic development can be attained. Economic theory allows for the quantification of a restoration project's benefits and therefore the proper evaluation of tradeoffs for a taxpayer funded restoration investment. "The intelligent and ultimately successful management of any system requires quantification of benefits and costs in order to properly evaluate the tradeoffs involved in different courses of action." (Arrow et al., 2000). One such restoration effort is the South Florida Ecosystem Restoration Program which has been allocated approximately $\$ 8$ billion in federal and state government funding across 68 major components in order to achieve its overarching objectives of mitigating the hydrology and water quality; restoring, preserving, and protecting natural habitats; and fostering compatibility of the built and natural systems (SFERTF, 2000).

\subsection{Statement of Problem}

As any proposed government project is an investment of public funds, monetized project costs and benefits should be compared in order to determine whether the expenditure is justified as well as maximized. However, to date, an economic analysis allowing for the monetization of project benefits has not been conducted for any component of the restoration effort. Citing the inherent difficulty, controversial nature, and expense of determining total monetized environmental costs and benefits, the Central and Southern Florida Project Comprehensive Review Study (CERP) decided instead to use cost effectiveness and incremental cost analysis evaluation procedures to compare the 
costs and non-monetized benefits of the restoration effort (USACE/SFWMD, 1999). Without such an analysis of monetized benefits and costs, the proper evaluation of tradeoffs involved in different courses of action becomes nearly impossible and therefore the optimal balance between ecosystem restoration and economic development may not be achieved. In addition, the future economic benefit of the proposed $\$ 8$ billion investment will remain relatively unknown.

\subsection{Research Objective}

The purpose of this research effort is to develop an economic valuation methodology that allows for the monetary quantification of South Florida Ecosystem Restoration project benefits, specifically focusing on the Indian River Lagoon - South (IRLS) restoration component. Existing economic research on the Indian River Lagoon (IRL) was utilized as a baseline for this effort. The derived benefits were compared to proposed IRLS costs, where applicable, as part of a project benefit-cost analysis. The following research questions and hypotheses were addressed:

Question \# 1: $\quad$ Can the water quantity and/or water quality benefits derived from the IRLS restoration effort be monetized?

Question \#2: Will monetized benefits facilitate the evaluation of restoration tradeoffs by providing better information to decision makers?

Hypothesis \# 1: Water quantity and/or water quality benefits derived from the IRLS restoration effort can be monetized.

Hypothesis \#2: $\quad$ Monetized benefits will facilitate the evaluation of restoration tradeoffs and provide better information to decision makers. 


\subsection{Economically Valuing Natural Resources}

From an economic viewpoint, natural resources provide us with numerous service flows on a daily basis (Hanley et al., 1997). Some of these service flows are straightforward and immediately life sustaining such as the air that we breathe, the water that we drink, and much of the food that we eat. While others are more intricate in that they are a factor in a product that we consume such as the oil in the cars that we drive or the timber used to build our homes. In whatever way these service flows are experienced they are valuable to us nonetheless, and therefore natural resources can be deemed valuable assets. Changes to these service flows, brought about by a public policy initiative, firm activity, or individual actions, will consequently create benefits and costs to any relevant parties (Freeman, 1993). As we live in an economically based society it is in our best interests to economically value these benefits and costs in order to guide decision making processes for resource allocation.

\subsubsection{What is Meant By Economic Value}

Economic value ${ }^{1}$ has its foundations in neoclassical welfare theory, and hence is directly related to the concept of human welfare (Bockstael et al, 2000). Welfare theory has two overarching premises: 1) the ultimate objective of any economic activity is to

\footnotetext{
${ }^{1}$ Economic value is only one of many possible definitions of value and it is therefore not meant to apply to all policy-making questions. However, it is essential when considering the tradeoffs involved in allocating resources and/or conducting benefit-cost analyses (King, Mazzotta, 2002). A more detailed discussion of economic value and its relation to other non-economic measures of value is given by Sagoff (2000).
} 
increase the welfare of each individual, and therefore the welfare of the society as a whole; and 2) that individuals best understand their own welfare given a situation and/or choice. Bundles of goods that are made up of market goods and services, an individual's possible use of time, and government and environmental service flows can represent our society. Every day, individuals make choices between these different bundles of goods, where a higher value of welfare is implied for a bundle of goods when it is chosen over another bundle. Therefore, it is logical that when a natural resource service flow is changed, its economic value can be determined by measuring the effect on welfare (Freeman, 1993).

The effect on welfare is measured by willingness-to-pay (WTP) ${ }^{2}$, where WTP is the maximum amount an individual would pay in order to maintain a particular level of utility. That is, following economic consumer choice theory, each individual is assumed to have a known, well-defined, and consistent ordering of his or her preferences, which allows them to choose between bundles of goods. Preferences are ordinally represented via utility functions, where the most preferred bundle has the highest level of utility. Therefore, consumers will maximize their utility in order to obtain their most preferred bundle of goods. By the concept of substitutability, when the quantity of some good of a maximized bundle is reduced, it is possible for the consumer to receive more of some other good in the bundle in order to offset the initial reduction and remain at the same maximized utility. Substitutability indicates that consumers are able to make trade-offs

\footnotetext{
${ }^{2}$ Willingness to accept (WTA) is another measure that indicates economic value
} 
between goods, and these tradeoffs reveal how consumers value goods relative to each other. WTP provides a measure of the trade-off value by indicating the maximum amount an individual would pay in order to be as well-off without the change to his utility. For a natural resource, this can be thought of as the maximum amount a consumer would pay in order to achieve an improvement or prevent a decline in natural resource quality. A demand curve is obtained through a consumer's utility maximization and the height of this demand curve at any point indicates a consumer's marginal WTP, while the area under the demand curve represents total WTP (Freeman 2003); (Ortolano, 1997).

More explicitly the traditional consumer's problem of maximizing utility subject to a budget constraint is given by:

$$
\operatorname{Max} U(X) \text { subject to } Y=\Sigma p_{i} x_{i}
$$

where:

$$
\begin{aligned}
& \mathrm{U}=\text { utility } \\
& \mathrm{X}=\text { vector of quantities of goods } \\
& \mathrm{Y}=\text { income } \\
& \mathrm{p}_{\mathrm{i}}=\text { price of good } \mathrm{i} \\
& \mathrm{X}_{\mathrm{i}}=\text { quantity of good } \mathrm{i}
\end{aligned}
$$

The solution to this maximization problem leads to a set of ordinary demand functions, $x_{i}(p, y)$, where the optimal amount demanded, $x_{i}$, is a decreasing function of its price (holding y constant) and an increasing function of income (holding $\mathrm{p}_{\mathrm{i}}$ constant). This ordinary demand solution is known as the Marshallian demand function, and is shown to be downward sloping when quantity demanded is plotted against its own price holding income and prices of all other goods constant. The area under the Marshallian demand curve represents total WTP. However, the total WTP can be separated into its market 
value and its nonmarket, or consumer surplus (CS), value. The market value is the area under the demand curve and below the price and can be thought of as the minimum amount that people who buy the good are willing to pay for it. The nonmarket value is the area under the demand curve and above the price and can be thought of as the net benefit to consumers as it is the amount they are willing to pay above the market price. Total WTP, separated into its market and nonmarket values is depicted below:

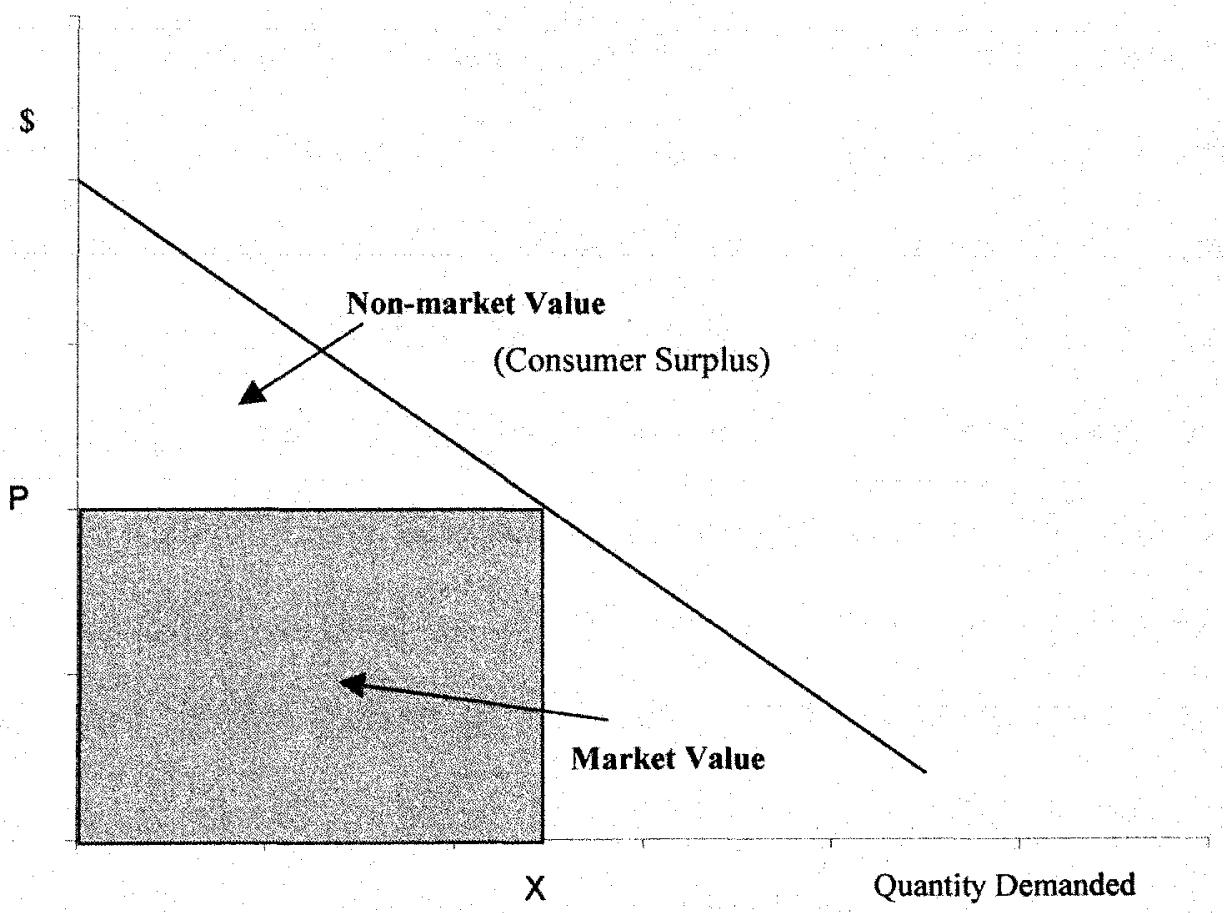

Figure 2.1: Total Marshallian WTP - Market and Nonmarket

Alternatively, the consumer's choice problem can be thought of as one where the consumer is minimizing the total expenditures necessary for achieving a specified level of utility:

$$
\text { Min } \mathrm{e}(\mathrm{p}, \mathrm{u})=\Sigma \mathrm{p}_{\mathrm{i}} \mathrm{x}_{\mathrm{i}} \text { subject to } \mathrm{U}(\mathrm{X})=\mathrm{U}^{\mathrm{M}}
$$

where: $\quad \mathrm{e}=$ dollar expenditure 
$\mathrm{p}=$ vector of prices

$\mathrm{U}^{\mathrm{M}}=$ maximum level of utility

The solution to this minimization problem also leads to a set of demand functions but conditional on prices and utility, i.e., $\mathbf{x}_{\mathbf{i}}(\mathrm{P}, \mathrm{U})$. "These are so-called Hicks-compensated demand functions which show the quantities consumed at various prices assuming that income is adjusted (compensated), so that utility is held constant" (Freeman, 2003). As defined above, WTP indicates the maximum amount an individual would pay in order to be as well-off without the change to his utility, i.e., keeping utility constant. Therefore, it follows that "the theoretically correct welfare measures are defined by the Hicksian demand relationships" (Ward \& Duffield, 1992). The area under the Hicksian demand curve still represents total WTP, however the nonmarket value of WTP is now given by compensating variation (CV) or equivalent variation (EV), rather than the Marshallian CS. Given a quantity increase of some good, the CV can be defined as "the amount, paid or received, that would make the individual just as well off after the change as before the change", and the EV defined as "the amount, paid or received, that would make the individual just as well off before the change as after the change" (Ward \& Duffield, 1992). A graphical comparison of $\mathrm{CS}, \mathrm{CV}$, and $\mathrm{EV}$ is given in the figure 2.2 below and as can be seen from the figure, the CS WTP value is bounded below by the CV WTP, and bounded above by the EV WTP. Therefore, how one is modeling the consumer choice problem can potentially give three separate values for WTP and the welfare effect. Furthermore, even though the Hicksian demands are the theoretically correct welfare measures, they are based on unobservable demand functions, while the Marshallian demand is more readily observable but flawed as a welfare measure (Freeman, 2003). 


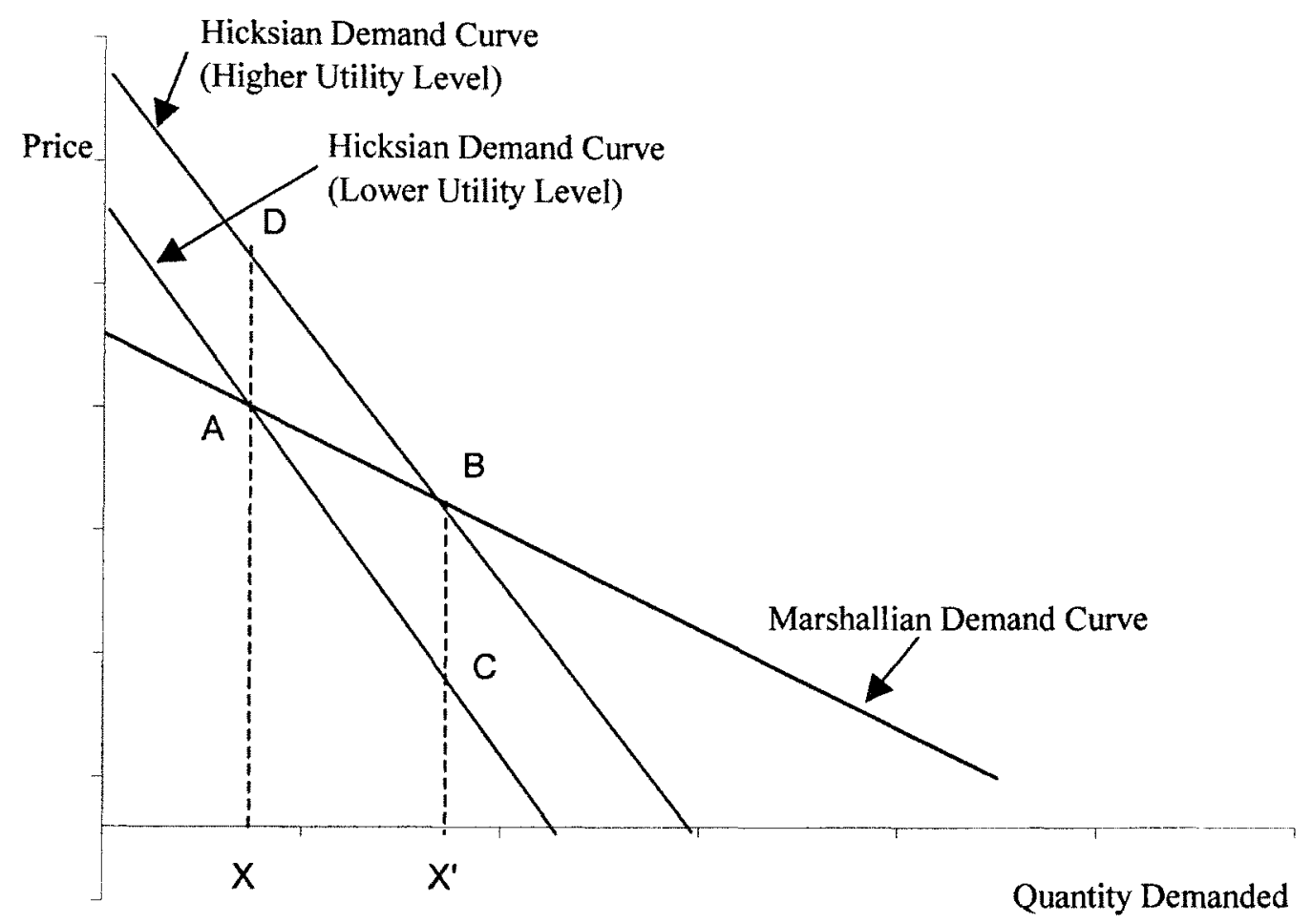

(Source: Ward \& Duffield, 1992)

where:

$$
\begin{aligned}
& C S=\left\{X, A, B, X^{\prime}\right\} \\
& C V=\left\{X, A, C, X^{\prime}\right\} \\
& E V=\left\{X, D, B, X^{\prime}\right\}
\end{aligned}
$$

Figure 2.2: Compensating Welfare Measures

The question for an applied welfare analysis given the above information is which is the appropriate WTP value measurement to use? A possible solution to this issue is related to the choice of the form of the utility function, e.g., quasi-linear utility functions will give equivalent $\mathrm{CS}, \mathrm{CV}$, and $\mathrm{EV}$ values as income effects are nullified. A more in-depth discussion on this issue is given by Freeman (2003). For purposes of this analysis, it is enough to know that WTP is the proper value to be obtained for measuring welfare effects, and that differences may exist in the WTP value obtained depending upon the 
approach used. Studies cited in the literature review use both the Marshallian and Hicksian WTP value derivations.

\subsubsection{Natural Resource Values}

The total economic value of a natural resource at its highest level consists of its use and non-use values, with various breakdowns given below this highest level. Freeman (2003) discussed four classifications of natural resource values; services people value due to use or non-use of the resource, whether the service flows affect humans directly or indirectly, the market or nonmarket economic channel through which human well-being is affected, and the type of natural resource media such as water quality. Leeworthy and Wiley (2003) further expanded on direct use values between consumptive and non-consumptive. For purposes of this study:

$\begin{array}{cc}\text { Total Environmental Restoration } \\ \text { Economic Valuation }\end{array} \quad=\quad \begin{gathered}\text { Use Values (Direct and Indirect) } \\ \text { Non-Use Values }\end{gathered}$

and the use and non-use values will be expanded further as depicted in the following total economic value framework of figure 2.3 below. Where direct use value is the contribution an environmental asset makes to current production or consumption. Indirect use values are the benefits derived from the services a natural resource provides in support of current production or consumption. Option value is the premium consumers are willing to pay to have an unutilized natural resource available in the future. And existence value is given by the satisfaction of knowing a natural resource exists, even thought there may be no intention of ever using it (Munasinghe, 1993). The distinction between market and nonmarket values was given above in section 2.1.1. 


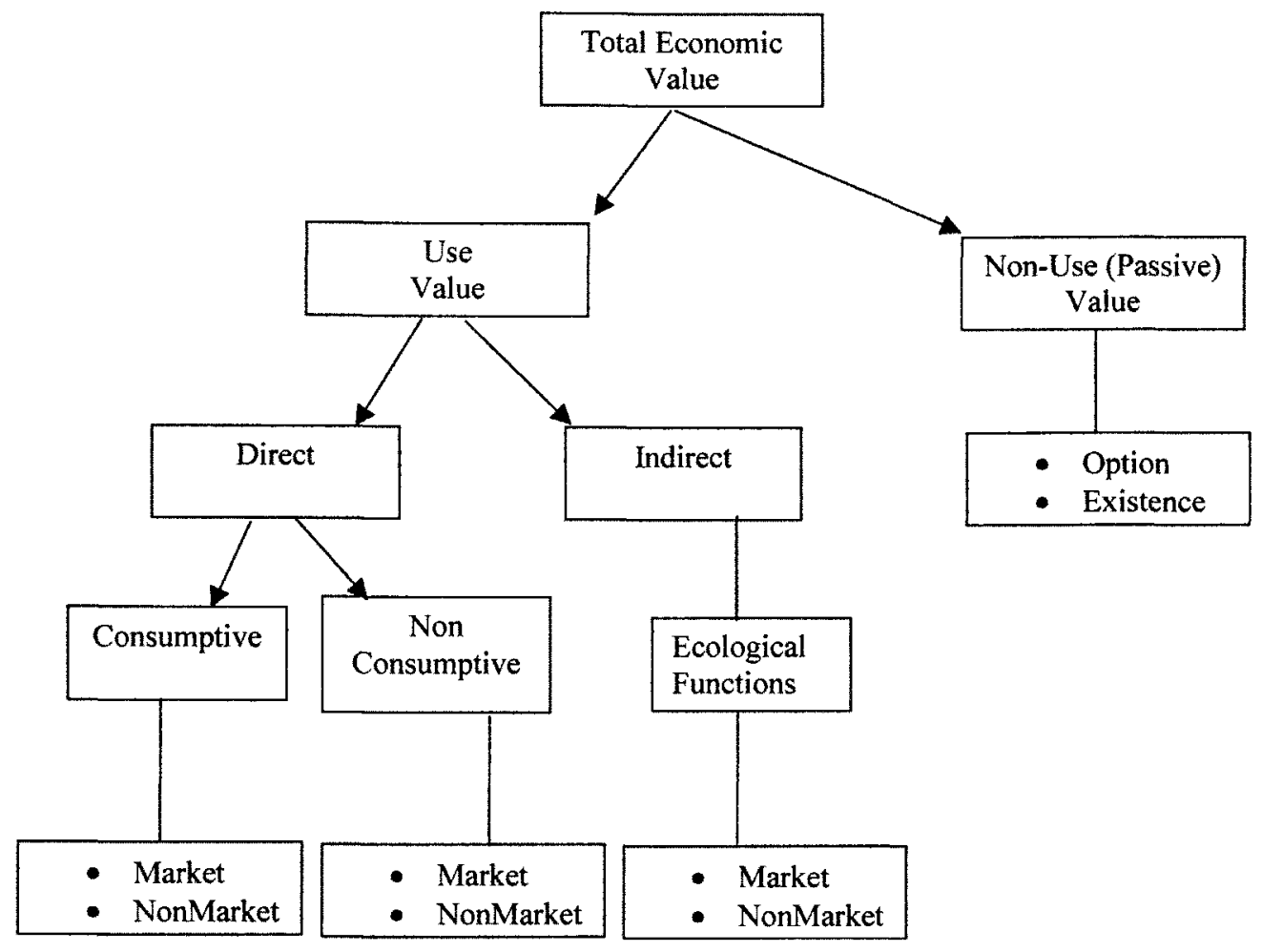

Figure 2.3: Total Economic Value Framework

\subsubsection{Market Failure for Natural Resources}

For natural resources the traditional concept of a good bought and sold in a marketplace often fails, indicating that other economic "imperfect market"3 value measures need to be defined. An efficient market system is defined as one that adheres to the concept of Pareto optimality, i.e., the impossibility of reallocating resources to make one person in the economy better off without making someone else worse off. Natural

${ }^{3}$ These imperfect market values are often times called nonmarket values, however to avoid confusion with nonmarket values defined in section 2.1.1, imperfect market value terminology was used instead. 
resource markets fail this condition of Pareto optimality due to the following reasons (Hanley et al., 1997); (Ortolano, 1997):

1) Incomplete markets - Markets are complete when a well-defined set of property rights exists with the properties of universality, exclusivity, transferability, and enforceability. As a well-defined set of property rights does not exist for environmental resources, they are incomplete.

2) Externalities - An externality exists when a market price does not incorporate all relevant supply and demand information. This insufficient information causes inefficient supply or demand to occur.

3) Non-exclusion and the commons - This occurs when there is rival consumption of a resource, but no way to exclude one party from consuming. This can lead to the exploitation of the resource.

4) Non-rivalry and public goods - A public good is one where its consumption is non-rival and non-excludable. One person's consumption does not reduce another's. This leads to the free rider problem.

5) Non-convexities - Implies that there may be more than one level of optimal allocation of resources.

6) Asymmetric information - Full information about a transaction does not exist for both parties involved.

\subsubsection{Natural Resource Economic Valuation Techniques}

Market data can be utilized to estimate economic values (WTP) for natural resources when applicable. However, as natural resources are often times unable to be 
represented as a market good as discussed in the previous section, imperfect market value techniques, such as revealed (observed) and stated (hypothetical) preferences, are employed to elicit the natural resource's economic value. Revealed preference methods estimate WTP from the observations of behavior in the markets for some related goods, while stated preferences estimate WTP from responses to hypothetical scenarios via a particular survey format. The following table classifies the various techniques:

Table 2.1: Techniques for Natural Resource Economic Valuation

\begin{tabular}{|l|l|l|}
\hline Preference Type & Revealed & Stated \\
\hline Market Type & Conventional and Surrogate & Hypothetical \\
\hline Technique & Conjoint Analysis \\
\cline { 2 - 2 } & Market Prices & $\begin{array}{l}\text { - Choice experiments } \\
\text { - Paired comparisons }\end{array}$ \\
\cline { 2 - 2 } & - Pedonic Pricing & Contingent Ranking \\
\cline { 2 - 3 } & Averting Behavior & Contingent / \\
\cline { 2 - 3 } & Random utility / discrete \\
choice models & conjoint rating \\
\cline { 2 - 3 } & Production functions & Contingent Valuation \\
\hline
\end{tabular}

(Source: Adapted from Pearce \& Seccombe-Hett, 2000)

Some of these revealed and stated preference techniques are briefly introduced below (Ortolano, 1997); (Farber and Griner, 2000); and (Carson, 2000).

1) Revealed Preferences:

a. Avoidance (Defensive) Expenditures - Benefits are assumed to be equal to the costs people would incur to avoid damages caused by lost service flows of the ecosystem.

b. Hedonic Pricing - Underlying assumption to this method is that the price of a market good is a function of its inherent characteristics. Assessing variations 
in property values based on environmental qualities such as proximity to an opens space is used to derive benefit value of the environmental service flow.

c. Production Function - As changes to environmental service flows effect volume, cost, and other factors of inputs to production, benefits are derived from the resulting changes to revenues and price data for that associated industry.

d. Travel Cost - Total use costs of an environmental service flow, including transportation costs, opportunity costs, and use fees are used as a proxy of the benefit of the service flow.

2) Stated Preferences:

a. Conjoint Analysis (CJ) - Respondents are given a set of hypothetical scenarios of at least 2 different attributes, and they are asked to rank, rate, or choose among them. Their selections reveal their preference ordering which allows for the WTP value estimation.

b. Contingent Valuation (CVM) - Respondents are given a hypothetical scenario and are asked to explicitly state how they would act contingent on being place in that scenario. This hypothetical observed action is the WTP value.

\subsubsection{Benefit Transfers}

The above-mentioned techniques would be used for primary research efforts. However, the practice of benefit transfers is a practical way to evaluate management and policy impacts when primary research is not possible or justified because of budget constraints, time limitations, or resource impacts that are expected to be low or 
insignificant. The four major types of benefit transfers that may be employed are single point estimate, average value, demand function, and meta regression analysis benefit function (Rosenberger \& Loomis, 2001).

\subsection{An Economic Valuation Focus on Water}

Getting the water right, i.e., mitigating the hydrology and water quality, represents the majority of the CERP components and costs ${ }^{4}$. More importantly, the IRLS is considered to be a water quantity and water quality related project (IRLS project overview is given in Section 2.4). Therefore, the literature review on economically valuing natural resources is centered on the valuation of water.

\subsubsection{Framework for Valuing Water}

Changes to service flows, whether brought about by a public policy initiative, firm activity, or individual actions, consequently create benefits and costs to any relevant parties (Freeman, 1993). Hence, understanding the changes to service flows is the foundation for estimating benefits and cost values. Before analyzing the magnitude of change, the service flows themselves must be identified. The question then becomes what service flows are provided by water? Water is a life-sustaining element and essential for all living organisms. However, water also offers value beyond its priceless life-sustenance, providing service flows to households, industries, agricultural, and

\footnotetext{
${ }^{4}$ Exact cost estimates broken down by the three main goals of the CERP are not readily available. However, through analysis of projects listed on www.evergladesplan.org and a request for additional funding listed in SFERTF, 2000 a range of $68-90 \%$ of the total $\$ 7.8$ billion cost is obtained for getting the water right projects.
} 
ecosystems to name a few. Frederick et al. (1996) in their Economic Values of Freshwater discussion paper outlined water uses in terms of eight separate categories, split across the two themes of withdrawal and in-stream uses:

1) Withdrawal Uses

a. Domestic - water used for various household activities including drinking, bathing, washing, etc.

b. Irrigation - water artificially applied to agricultural crops

c. Industrial processing - water used as a factor of production

d. Thermoelectric power - water used in the generation of electric power with fossil fuel, nuclear, and geothermal energy

2) In-stream Uses

a. Hydroelectric power - water used to directly generate electricity

b. Recreation - water used for activities such as boating, swimming, fishing, etc.

c. Navigation - water used as part of the transportation system

d. Waste Disposal - water used as receptacle for human and industrial waste

The National Research Council's (NRC) Committee on Valuing Ground Water (1997) took a somewhat different approach in outlining the service flows provided by water, expanding on the ecological services and non-use values provided by water, and having little mention of the energy service flows as given in table 2.2 below. Understanding how changes in water quantity and water quality effected by a water management plan 
modification alter the above mentioned service flows is the foundation for the economic valuation of water as depicted in figure 2.4 .

Table 2.2: NRC Groundwater Uses

\begin{tabular}{|l|l|}
\hline \multicolumn{1}{|c|}{ Extractive Values } & \multicolumn{1}{c|}{ In Situ Values } \\
\hline Municipal Use & Ecological \\
Industrial Use & Buffer \\
Agricultural Use & Subsidence Avoidance \\
Other Extractive Use & Recreational \\
& Sea Water \\
& Existence \\
& Bequest \\
\hline
\end{tabular}

(Source: Adapted from NRC, 1997)

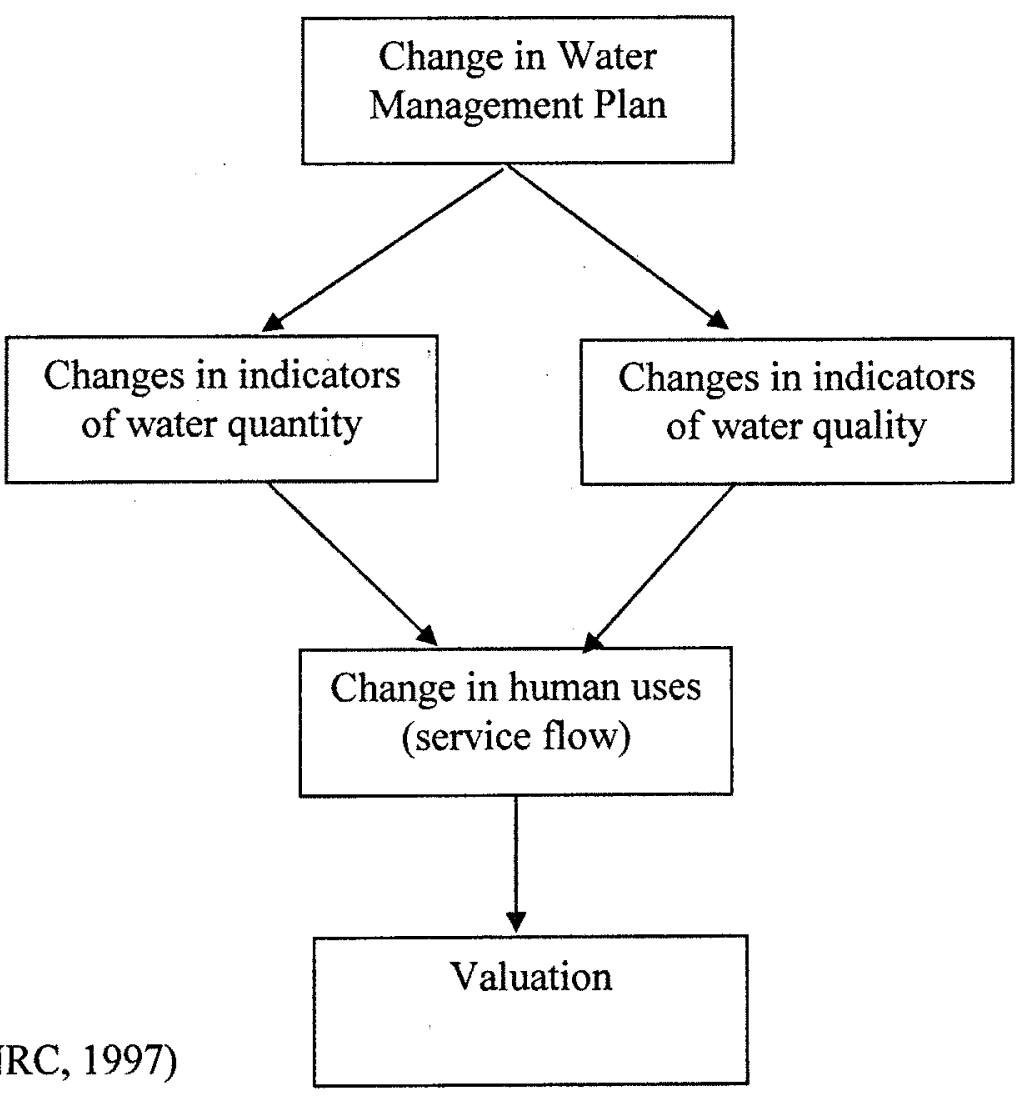

Figure 2.4: Conceptual Framework for Water Valuation 


\subsubsection{Water Quantity Benefit Estimation}

Changes to the quantity of water available for use can have a significant impact across both extractive and in-situ uses of water as summarized in the following water quantity impact consideration table:

Table 2.3: Water Quantity Impact Considerations

\begin{tabular}{|l|l|}
\hline \multicolumn{1}{|c|}{ Water Use } & \multicolumn{1}{c|}{ Quantity Consideration } \\
\hline Municipal \& Industrial & $\begin{array}{l}\text { Minimum supply to perform household activities } \\
\text { Minimum supply for production } \\
\text { Minimum supply for flood protection }\end{array}$ \\
\hline Agricultural & $\begin{array}{l}\text { Minimum irrigation supply for crop yields, drainage, flood } \\
\text { protection, erosion control, sediment control }\end{array}$ \\
\hline $\begin{array}{l}\text { Hydroelectric Power } \\
\text { Generation }\end{array}$ & Minimum head required for power generation \\
\hline Navigation & $\begin{array}{l}\text { Minimum depths required for navigation } \\
\text { Minimum flows required to maintain depths }\end{array}$ \\
\hline Recreation & $\begin{array}{l}\text { Required water depth for satisfactory swimming and } \\
\text { bathing opportunities } \\
\text { Minimum depth required for safe and aesthetic boating } \\
\text { Minimum flows required to maintain depth }\end{array}$ \\
\hline Fish \& Wildlife Habitat & $\begin{array}{l}\text { Effect of water depths and flow/level fluctuations on fish \& } \\
\text { wildlife species }\end{array}$ \\
\hline $\begin{array}{l}\text { Preservation of } \\
\text { Wetlands }\end{array}$ & $\begin{array}{l}\text { Minimum surface and groundwater flows required to } \\
\text { maintain wetland habitat } \\
\text { Effect of water level fluctuations on wetland species }\end{array}$ \\
\hline
\end{tabular}

(Source: Heathcote, 1998)

It is also probable that when water supplies reach too low or high of a level, that water quality impacts will ensue, hence compounding the impacts due to the changes in water quantity. This framework will keep these two impacts separate at this point, focusing on water quantity impacts only. The 1995 U.S. Geological Survey's water use statistics (Solley et al. 1998) indicate that the largest extractive uses of fresh water in the State of 
Florida are for agricultural irrigation and domestic uses respectively as reflected in the below figure:

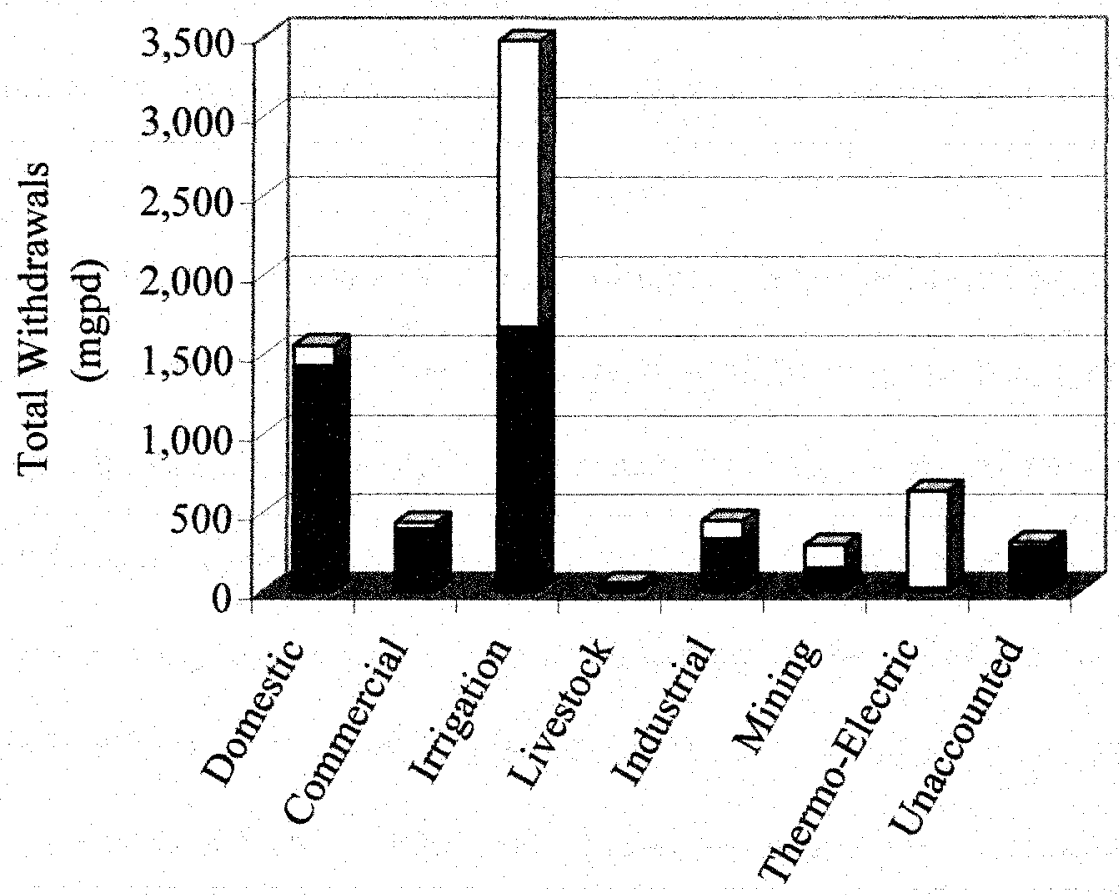

Extractive Use

Ground Water $\square$ Surface Water

(Source: Solley et al. 1998)

Figure 2.5: Florida Water Withdrawals in million gallons per day ${ }^{5}$

\subsubsection{Estimating Municipal Benefits}

As discussed in section 2.1.1 the area under a demand curve can be interpreted as the total WTP and therefore changes to the area under the demand curve can then be expressed as economic losses or benefits in monetary terms. Estimating the benefit

\footnotetext{
${ }^{5}$ Withdrawal estimates for domestic, commercial, industrial, thermo-electric, and unaccounted include water extracted from public supply sources as well as own supply sources
} 
through revealed preference techniques involves deriving the demand and then calculating the benefit from this demand information, again based on the economic consumer choice theory. For stated preference techniques the benefit estimation is more directly estimated, assuming the underlying economic theory of utility maximization.

There are three main components involved in estimating municipal benefits due to water quantity changes by revealed preference techniques - forecasting demand, incorporating elasticity into the forecast, and calculating the benefit. The literature has shown separate techniques for forecasting demand, ranging from a relatively simple per-capita measure (Heathcote, 1998) to a more complex econometric estimation involving a comprehensive array of relevant independent variables (Jenkins et al., 2003) and (Weber, 1989). The C\&SF CERP (USACE/SFWMD, 1999) used the following demand function to estimate the predicted water use in gallons per day, Q:

$$
\mathrm{Q}=\mathrm{a}+\mathrm{I}^{\mathrm{d} 1}+\mathrm{MP}^{\mathrm{d} 2}+\mathrm{e}^{(\mathrm{FC})(\mathrm{d} 3)}+\mathrm{H}^{\mathrm{d} 4}+\mathrm{HD}^{\mathrm{d} S}+\mathrm{T}^{\mathrm{d} 6}+\mathrm{R}^{\mathrm{d} 7}
$$

where:

$$
\begin{aligned}
& a=\text { intercept } \\
& I=\text { median household income } \\
& M P=\text { effective marginal price } \\
& e=\text { base of natural log } \\
& F C=\text { fixed charge } \\
& H=\text { mean household size } \\
& H D=\text { housing density } \\
& T=\text { maximum day temperature } \\
& R=\text { total seasonal rainfall } \\
& \text { d } 1 \ldots \text {... } 7 \text { = elasticity values for each independent variable }
\end{aligned}
$$

Jenkins et al. (2003) estimated municipal demand in California using observed water prices and quantities according to the following formula:

$$
\mathrm{P}=\exp [\{\ln (\mathrm{Q}) / \eta\}+\mathrm{C}]
$$


where: $\quad P$ is the price at which quantity $Q$ is demanded

$\eta$ is the price elasticity of demand $\Rightarrow(\Delta Q / Q) /(\Delta \mathrm{P} / \mathrm{P})$

$\mathrm{C}$ is the integration constant with observed prices $\left(\mathrm{P}_{\mathrm{obs}}\right)$, observed water uses $\left(Q_{\text {obs }}\right)$ and an estimated $\eta$, defined as:

$$
\mathrm{C}=\ln \left(\mathrm{P}_{\mathrm{obs}}\right)-\left\{\ln \left(\mathrm{Q}_{\mathrm{obs}}\right) / \eta\right\}
$$

As can be seen in the above equations, elasticity is an important factor in the demand forecast. Weber (1989) used his regression coefficients to estimate elasticity, whereas Thomas and Syme (1988) utilized a contingent valuation (CVM) survey, a stated preference technique, to estimate the price elasticity of demand for public water supplies. Once the demand curve (factoring in elasticity) has been estimated, the integration of the demand curve allows for the calculation of the benefit. Jenkins et al. (2003) calculate the WTP by converting their derived 2020 residential demand functions into economic loss functions, which was accomplished by integrating the demand curve from the 2020 maximum residential demand leftward to the delivery, performed down to a $50 \%$ residential water shortage. The loss function takes the following form:

$$
\operatorname{LOSS}\left(\mathrm{Q}_{\mathrm{ri}}\right)=\left[\exp \left(\mathrm{C}_{2020 \mathrm{i}}\right) /\left\{1+\left(1 / \eta_{\mathrm{i}}\right)\right\}\right] \times\left[\mathrm{Q}_{2020 \mathrm{i}}{ }^{\{1+(1 / \eta \mathrm{i})\}}-\mathrm{Q}_{\mathrm{ri}}{ }^{(1+(1 / \eta \mathrm{i})\}}\right]
$$

where: $\quad Q_{r i}=$ thousand acre foot of water delivered to residential sector in month $\mathrm{i}$ $\mathrm{Q}_{2020 \mathrm{i}}=$ forecasted maximum residential demand for the month

The C\&SF CERP (USACE/SFWMD, 1999) used a combined revealed and stated preference technique in their benefit estimation. The revealed preference demand forecast was generated as described above and compared to a forecasted supply. For an estimated shortage, a WTP value derived from a previous SFWMD CVM survey was multiplied by the shortage to generate the value of unmet demand, or the benefit of avoiding the shortage: 
An application of stated preference techniques to estimating municipal water quantity benefits is given by Griffin and Mjelde (2000). In their presented water supply reliability model, the social problem is to minimize the sum of investment costs and the expected welfare loss due to the water supply shortfall, that is:

$$
\min _{I}\left[I+\Sigma \int L_{t}\left(I, a_{t}\right) f_{t}\left(a_{t}\right) d a_{t}\right]
$$

where: $\quad L_{t}\left(I, a_{t}\right)$ is the overall loss function given investment $(I)$ and a short-term aridity index $\left(a_{t}\right)$ with a value of $1_{t}\left[D_{t}\left(a_{t}\right)-S_{t}\left(I, a_{t}\right)\right]$, when demand as a function of aridity $\left(D_{t}\left(a_{t}\right)\right)$ exceeds the supply as a function of investment and aridity $\left(\mathrm{S}_{\mathrm{t}}\left(\mathrm{I}, \mathrm{a}_{\mathrm{t}}\right)\right)$

Closed and open-ended CV techniques for hypothetical current and future shortfalls respectively are applied to value the losses of the form $1_{t}\left[D_{t}\left(a_{t}\right)-S_{t}\left(I, a_{t}\right)\right]$. Explanatory variables in the model include rain, summer, price, fee, shortfall, duration, income, activities, household size, severity, and several dummy variables. For the closed $\mathrm{CV}$, a logistic model of the following form is used to estimate the coefficients of the explanatory variables:

$$
F\left[\beta^{\prime} x\right]=e^{\beta^{\prime} x} / 1+e^{\beta^{\prime} x}
$$

where: $\quad F\left[\beta^{\prime} x\right]=$ cumulative density function associated with the logistic function $\mathrm{x}=$ matrix of explanatory variables

$\beta=$ vector of associated coefficients

For the open-ended CV, a tobit model of the of the following form is used to estimate the coefficients of the explanatory variables $\left(\mathrm{y}_{\mathrm{i}}\right)$ :

$$
Y_{i}=\beta^{\prime} x_{i}+\varepsilon_{i}
$$


Coefficients from these estimations are used to determine the WTP values.

\subsubsection{Estimating Commercial and Industrial Benefits}

Under economic production theory a producer chooses the quantities of inputs that minimize his costs subject to a production constraint. Solving this minimization problem gives the optimal quantities of inputs as functions of the input price and level of output, which can also be expressed as the conditional input demand for a particular input (Renzetti, 2002). The conditional input demand gives a producer's cost function, which when placed into a producer's profit function (total revenues minus total costs), any changes to the cost function will directly impact the level of profit and hence giving an estimate of benefits. Therefore, estimating the benefit for commercial and industrial uses through revealed preference techniques involves deriving the input demand, placing this into the profit function and then calculating the related benefit from this demand information. For stated preference techniques the benefit estimation is again more directly estimated, assuming the underlying economic producer theory of cost minimization and profit maximization.

The three main components involved in estimating municipal benefits by revealed preferences - forecasting demand, incorporating elasticity into the forecast, and calculating the benefit - are similarly identical in estimating commercial and industrial water quantity benefits. However, unlike municipal uses, there is a limited literature for commercial and industrial uses of water due to the lack of data on input and output prices and quantities (Renzetti, 2002). The relation between water use as an input, incorporated into a production function, and the production output, is the optimal way of deriving the 
benefit of water. This can be modeled either econometrically or via linear programming. Again, this approach may prove difficult as researchers feel that decisions on water use are often secondary to a firm's profit maximization decision (Renzetti, 2002). The C\&SF CERP (USACE/SFWMD, 1999) placed an economic value on industry water supply using the same overall unmet demand method as described earlier for municipal water, with the major difference being a distinct and much more simple demand equation used for the industry demand forecast -- gallons per employee per day multiplied by the number of employees. Lynne et al. (1978) estimated demand functions for various commercial sectors in Miami in order to analyze water price elasticity of demand. Following economic theory, profits for commercial firms are maximized according to the following:

$$
\text { Maximize } \Pi=p q-\Sigma r_{j} \mathbf{x}_{\mathbf{j}}
$$

where: $\quad p=$ product price

$q=$ quantity of the product and/or service produced

$\mathrm{x}_{\mathrm{j}}=$ quantity of inputs in the production process (factors of production) $r_{j}=$ the price of the factors of production $x_{j}$

The conditional input demand functions for the factors of production are determined by taking the derivative of (2.11) with respect to $\mathrm{x}_{\mathrm{j}}$. In order to derive these conditional input demand functions, Lynne et al. (1978) collected water consumption and price data, along with their model explanatory variable data, from various commercial establishments. The average monthly water purchase was then estimated econometrically from this data. The conditional input demand function for the natural log of the average monthly purchase of water $(\ln W)$ for department stores is presented:

$$
\ln W=\text { intercept }-\beta_{1} r+\beta_{2} \ln A+\beta_{3} R
$$


where: $\quad \mathrm{r}=$ water price

$$
\begin{aligned}
& A=\text { area of store } \\
& R=\text { area of restaurant }
\end{aligned}
$$

These demand equations were not used to estimate benefits but price elasticities.

Given the difficulty in estimating benefits for industrial and commercial uses via traditional derived demand techniques, an acceptable alternative is using the cost of recycling water within the production process as a proxy for the industrial water value, as it represents an upper bound on a firm's WTP for additional water usage (Calloway, et al. 1974).

\subsubsection{Estimating Agricultural Benefits}

The estimation of agricultural benefits is grounded in the same production theory as discussed for commercial and industrial uses. The literature primarily centers on the three revealed preference techniques of derived demand/production function, residual imputation, and hedonic pricing.

For the derived demand/production function estimation, the foundation in this approach is to model the role of water in the firm's (farm's) production function, i.e., how does the quantity of water effect crop yields. At the most basic level, this is a model between crop production and amount of water. In more complicated models it is a farm-level optimization model with respect to mix of crops, water and water-delivery capital and non-water inputs (Renzetti, 2002). The C\&SF CERP placed an economic value on 
agricultural water supply in their Socio-Economic appendix (USACE/SFWMD, 1999) based on this methodology where the value of unmet demand = (value of actual crop yields - value of maximum crop yields). The Agricultural Field Scale Irrigation Requirement System (AFSIRS) was used to forecast the irrigation water demand for maximum crop yields as a function of crop type, soil type, irrigation system, growing season, and climatic conditions. This demand figure was combined with projected supply, and where there is a supply shortage a regression equation is used to determine the change in yields per acre. The change in yields per acre is multiplied by the total number of acres to obtain a change to total crop output. The change to total crop output is then multiplied by crop prices to obtain the change to total revenues, or the economic value.

Residual imputation calculates the value of water by subtracting out all factors of production, excluding water, from the total value of the product, and then dividing by the quantity of water that is used during production. Both fixed and variable factors of production are subtracted including the cost of capital, land, and labor. The total value of the product should be considered from both a financial perspective and an economic perspective, whereas the economic perspective takes the effective rate of production into consideration. The time horizon for this valuation method is also important as the above description is more appropriate for the long-term but needs to be modified for short-term estimations. Schiffler used this method to economically value water for fruit tree and vegetable farms in Jordan (Schiffler, 1998). 
The hedonic property value methodology uses observed property transactions to estimate the value of a natural resource service. Faux and Perry (1999) show that the implicit price of irrigation water can be revealed by a hedonic analysis of farm property sales. This is accomplished by disaggregating the sale price of the bundled good, farm property, into its identified attributes, revealing their implicit prices. The attributes affecting land sale price identified in their model included irrigated and non-irrigated land classes, distance to town, month of the sale, number of residences permitted, and the assessed value of buildings on the property. The functional form of the hedonic model was determined by applying a box-cox heteroskedastic $(\mathrm{BCH})$ model of the following form to the data:

$$
y^{(\lambda)}=X \beta+u
$$

where: $\quad u=z_{i}^{\delta / 2} * e_{i}$

$$
\text { and if } \lambda=1 \text { and } \delta=0 \text { an ordinary least square model can be applied }
$$

Results of the $\mathrm{BCH}$ indicated a hedonic model with a linear functional form $(\lambda=1)$ incorporating heteroskedasticity $(\delta \neq 0)$. The implicit prices of irrigated and non-irrigated land classes derived from the hedonic analysis (i.e., coefficients returned from econometric estimation with the above mentioned form) allowed for the estimation of the value of irrigation water. This was accomplished by subtracting the value of nonirrigated land from the value of irrigated land as given by their implicit prices. Ultimately, the value of irrigation water was shown to be $\$ 9$ per acre-foot. Their case study was concerned with estimating the value of irrigated water, as consideration was being given to shifting the available supply of irrigated water to aid in salmon migration and survival and/or other uses with greater economic or social value. 


\subsubsection{Estimating Hydroelectric Power Benefits}

The most common method for valuing water used to generate electricity is through the avoided cost technique. In this way, the value of hydropower is estimated as the cost avoided from not having to use the next most expensive fuel, which essentially represents what electric utility providers are willing to pay for electricity on the open market. For Stewart in the Sierra Nevada ecosystem (Stewart, 1996), the next most expensive fuel is gas or oil at a range of 1.4 to 8 cents per $\mathrm{kWh}$.

\subsubsection{Estimating Recreation Benefits}

Water quantity changes, such as changes to lake levels, can have an impact on recreational activities and consequently recreational benefits. Eiswerth et al. (2000) use a combined revealed and stated preference approach to estimate recreation values for preventing a decline in a Nevada lake's water level. A survey was conducted that collected actual recreational trips taken (revealed preferences), and also estimated the number of trips that would be taken given a hypothetical $20 \%$ higher lake level (stated preferences) in an area that had been experiencing large declines in its lake levels over the years. The results of the survey were incorporated into pooled poisson revealed preference/contingent behavior count data model. The demand for trips to the recreation site (TRIPS) is given by:

$$
\text { TRIPS }=F(C, X, Z, D)
$$

where:

$$
\begin{aligned}
& C=\text { travel cost } \\
& X=\text { vector of respondent specific attributes } \\
& Z=\text { vector of site specific attributes } \\
& D=\text { dummy variable }-1 \text { for } C B \text { data, and } 0 \text { for } R P \text { data }
\end{aligned}
$$


This derived demand is then incorporated into the log likelihood function for the poisson:

$$
\log L(\beta)=\Sigma\left[-\lambda_{i}+\operatorname{TRIPS}^{\prime} \mathrm{X}_{\mathrm{i}}-\ln \operatorname{TRIPS}_{\mathrm{i}} !\right]
$$

where: $\quad \lambda_{\mathrm{i}}=\exp \left[\mathrm{F}\left(\mathrm{C}_{\mathrm{i}}, \mathrm{X}_{\mathrm{i}}, \mathrm{Z}, \mathrm{D}_{\mathrm{i}}\right)\right]$

Consumer surplus per trip from this estimation is given by:

$$
\text { CS per trip }=-1 / \beta_{\text {cost }}
$$

Results from the model indicated that a recreationist would take between 0.1 and 0.2 fewer trips per season with an associated loss of $\$ 12-\$ 18$ per person per season for a 1foot decline in the water level (1996 dollars). These results were aggregated for the hypothetical 20 -foot rise in the lake level to produce an estimated annual recreational value of $\$ 7-\$ 14$ million. In order to achieve a 20 -foot lake rise, an initial inflow of 700,000 acre-feet from upstream agricultural users would be required. Using an estimated value of water per acre-foot in agriculture (an example of a similar derivation is described in the hedonic agricultural study described in section 2.2.2.3), the recreational benefits were then compared to the agricultural costs.

Buchli et al. (2003) used a similar combined revealed and stated preference technique ${ }^{6}$ to estimate the benefits to increased flow levels for the Ticino River in Switzerland. They estimated the benefit for increased river flows through increased recreational fishing activities. Demand for recreational fishing, NV, was given by:

$$
\mathrm{NV}=\mathrm{f}\left(\mathrm{P}_{\mathrm{T}}, \mathrm{PS}_{\mathrm{T}}, \mathrm{Y}, \mathrm{D}, \mathrm{DHS}\right)
$$

\footnotetext{
${ }^{6}$ Different name was given to the approach - the hypothetical travel cost method (HTCM)
} 
where: $\quad P_{T}=$ implicit price of travel cost

$\mathrm{PS}_{\mathrm{T}}=$ implicit price of travel cost to substitute sites

$\mathrm{Y}=$ income

$\mathrm{D}=$ vector of socioeconomic variables

DHS $=$ dummy variable with $1=$ hypothetical, and $0=\mathrm{RP}$

The semi-logarithmic functional form was applied in order to estimate benefits:

$$
\operatorname{lnNV}=\alpha+\beta_{1} \mathrm{P}_{\mathrm{T}}+\beta_{2} \mathrm{PS}_{\mathrm{T}}+\beta_{3} \mathrm{DHS}+\beta_{4} \mathrm{Y}+\beta_{\mathrm{DUMMY}} \text { Dummy }
$$

\subsubsection{Estimating Ecological Function Benefits}

The quantity of water available is a key consideration for the proper functioning of an ecosystem such as a wetland. As Griffin and Mjelde (2000) point out, some water users must incur a water shortage during a drought situation, and that risk is most often transferred to the riparian and estuary habitat systems. However, these ecosystems provide important benefits such as flood protection, groundwater recharge and habitat for wildlife that can be estimated through both revealed and stated preference techniques.

Bell (1997) used a production function approach to estimate changes to recreational fishing benefits due to changes in wetland acres. A Cobb-Douglas production function for recreational fishing of the following form was used:

$$
C(t)=A D^{c}(t) M^{d}(t)
$$

where: $\quad D^{\mathfrak{c}}=$ the linear demand raised to the output elasticity of the fishing effort $\mathrm{M}^{\mathrm{d}}=$ marsh acreage raised to its output elasticity

A linear demand function for recreational fishing is also defined:

$$
D=B C^{h}(t)-v P
$$

where: $\quad C^{\text {h }}=$ output raised to the success elasticity $\mathrm{P}=$ WTP for recreational fishing days 
Assuming $\mathrm{P}=0$ and substituting (17) into (18) produces the recreational demand curve:

$$
D(t)=k M(t)^{d h /(1-c h)}
$$

The basic idea behind the analysis is that incremental changes in wetlands (M) will via the production function provide incremental changes in output $(\mathrm{C})$, which will therefore shift the demand curve and increase consumer surplus. Bell estimated the dollar value of the marginal consumer surplus per acre of wetlands and obtained a value of $\$ 6,471$ per acre for the East Coast of Florida and $\$ 981$ per acre for the West Coast of Florida.

Shultz and Leitch (2003) use benefit-cost ratios to determine whether the costs of restoring previously drained wetlands in North Dakota's Red River Valley is economically feasible given the benefits of reducing flood damage due to the restored wetlands. The benefit-cost analysis is accomplished through the integration of hydrologic and economic data over a 20 -year time period. Avoided flood damage was the technique used to estimate the benefits of restoring the drained wetlands. In order to estimate avoided flood damage, historical flood damage data from 1989 to 1998 was collected, such as insurance claims, loans, public assistance, and charity for nonagricultural flood damage. Agricultural flood damage was extrapolated from previous agricultural flood damage estimates. The equation for expected annual reduction in flood damage, $\Delta \mathrm{E}(\mathrm{D})$ over a 20 -year time period and $5 \%$ discount rate was given as:

$$
\Delta \mathrm{E}(\mathrm{D})=\Sigma \mathrm{P}(\mathrm{X}) \mathrm{R}(\mathrm{X}) \mathrm{d}(\mathrm{X})
$$

where: $\quad X=1$ to 4 represent the four flood event classes

$\mathrm{P}(\mathrm{X})$ is the probability of a particular flood event class recurring in any given year 


$$
\begin{aligned}
2 \mathrm{yr} & \Rightarrow 50 \% \text { probability of recurring } \\
10 \mathrm{yr} & =>10 \% \\
25 \mathrm{yr} & =>4 \% \\
50 \mathrm{yr} & \Rightarrow 2 \%
\end{aligned}
$$

$\mathrm{R}(\mathrm{X})$ is the expected reduction in peak flood stage (and flood damage) specific to a particular flood event class and a pre-determined level of storage bounce. Bounce is a function of wetland volume and depth as well as antecedent soil moisture and precipitation, and reflects a wetland's storage potential and hence ability to reduce flood flow $\mathrm{d}(\mathrm{x})$ is the annual observed flood damage

Englehardt (1998) presents a model to measure the net present value of a construction effort aimed at restoring a more natural pattern of water levels to the Everglades. He builds ecological factors into his model, including hydroperiod changes and cattail expansion, to estimate the benefits.

$$
\begin{aligned}
& \mathrm{NPV}=\left[-(\mathrm{f} 1)(\mathrm{V})(\mathrm{Ho}) / \mathrm{i} \times\left(\mathrm{e}^{-\mathrm{iT}}-1\right)\right]-\left[(\mathrm{f} 1)(\mathrm{V})(\mathrm{Co}) /(\mathrm{r}-\mathrm{i}) \times\left(\mathrm{e}^{(\mathrm{r}-\mathrm{i}) \mathrm{T}}-1\right)\right] \\
& +\left[(\mathrm{f} 2)(\mathrm{V})(\mathrm{Cor}) / \mathrm{i} \times(\mathrm{r}-\mathrm{i}) \times\left(\mathrm{e}^{(\mathrm{r}-\mathrm{i}) \mathrm{T}}-1\right)\right]
\end{aligned}
$$

where: $\quad f 1=$ fractional benefit of phase I hydroperiod changes - calculated from hydroperiods estimated by the SFWMD $\mathrm{V}=$ Annual value of an acre of natural marsh - estimate modified from a Louisiana freshwater marsh study Ho $=$ Probabilistic acreage affected in terms of hydroperiod $\mathrm{i}=$ real interest rate

$\mathrm{T}=$ length of Phase I period $\mathrm{Co}=$ Probabilistic acreage of cattail at the beginning of Phase I $\mathrm{r}=$ probabilistic annual rate of cattail expansion $\mathrm{f} 2=$ change in the value of sawgrass acres to be converted to $100 \%$ cattails [Note: The whole equation can be read as the benefit obtained from interim hydropattern changes to the acres affected, minus any such benefits attributed to cattail expansion (first term) plus losses due to cattail expansion (second term)]. 
Acharya and Barbier (2002) estimate the value of groundwater recharge in their study modeling demand via a household production function approach, while Loomis et al. (2000) use CV survey to estimate five ecosystem services; natural purification of water, erosion control, habitat for fish and wildlife, dilution of wastewater, and recreation use.

\subsubsection{Water Quality Benefit Estimation}

Water quality directly affects nearly all users of water (Heathcote, 1998). For municipal uses, the level of water quality is directly related to a source of potable supply. Agricultural and industrial uses need a satisfactory water quality level for the proper production of their goods. Furthermore, unsatisfactory levels of water quality in these two areas may pose health risks. Water quality will also have an effect on recreational activities and the health of water-based ecosystems and the services they provide.

\subsubsection{Estimating Municipal Benefits}

There are several techniques available for measuring the municipal benefits for water quality. Bergstrom et al. (2001) cite the revealed preference techniques of averting expenditures, damages avoided, production function, and hedonic pricing, as well as the stated preference techniques of contingent valuation and conjoint analysis.

Abdalla (1990) used the averting expenditure methodology (avoided costs) to estimate economic costs resulting from groundwater contamination that occurred in a central Pennsylvania community. The costs estimates were generated from a survey, aimed at identifying expenditures on durable goods, expenditures on non-durable goods, and the 
changes to daily routines all to avoid the adverse impacts of the contaminants. The averting expenditures method estimates WTP for changes in environmental quality from individual's preferences as revealed by choices of health and health-related goods and services. This methodology has its foundation in the household production model of consumer behavior in which consumers do not derive utility directly from purchased goods, but rather use these goods as inputs to produce outputs of value to the household. As individuals are viewed as being endowed with a stock of the health commodity that depreciates with age and can be increased with investment, observed behavior (choices of health and health-related goods and services) is determined by individual preferences and a household production technology. Utility is maximized by equating the present value of the marginal costs with the present value of the marginal benefits of health. Therefore, if environmental quality declines, households adjust their consumption of health-related goods and services in order to minimize utility loss. Compensating variation (CV) and equivalent variation (EV) are the measures used to estimate the economic costs. Households choose their personal environmental quality level by adjusting averting expenditures given an externally determined pollution level. It is the demand estimate of the personal quality level that allows for the $\mathrm{CV}$ and $\mathrm{EV}$ calculations.

Responses to the survey were used to estimate costs associated with purchasing bottled water, hauling water, boiling water, and water treatment. Market price data was multiplied by the additional bottled water purchased to determine the costs associated with purchasing bottled water. For hauling water, hauling mileage was determined and 32.6 cents per mile was applied to generate the cost figure. For boiling water, energy 
costs (per kw-hour electricity costs) were applied to the number of gallons boiled in order to determine the cost. In addition, for both hauling and boiling of water, lost leisure time was calculated. The number of hours spent doing each activity was determined from the survey and the average manufacturing wage was applied as an opportunity cost. Water treatment costs were determined from market price data for the water treatment devices purchased. Results estimated an annual averting cost of $\$ 252$ per household. This equates to approximately $\$ 21$ per month, or three times the average water bill of $\$ 7.50$, showing a significant cost per household. The averting expenditures do not estimate the full economic losses associated with the contamination as this methodology does not address losses related to human health effects, increased fear and anxiety, ecological damages, and reduced nonuser benefits.

Raucher (1983) lays out a conceptual framework for estimating the benefits of protecting groundwater from contamination caused by waste disposal sites (although applicable to other contamination causes). The foundation of his framework is that the value of the benefits derived from the protection effort is as least as great as the costs of the contamination that would occur with no action taken to alleviate it. Importantly though, his benefit estimation must be interpreted as a lower bound estimate as no intrinsic benefits, such as option and existence values, are estimated within the framework. The cost estimates used within the framework are primarily determined by local conditions, namely, the uses made of water drawn from the aquifer, the types and concentrations of contaminants, and the hydrogeological conditions of the aquifer in combination with the location of the source of contamination relative to the placement of user wells. 
Therefore, the benefits of protecting groundwater will vary significantly from aquifer to aquifer based upon these local conditions. Also, the benefit estimations will vary depending upon the time horizon and social rate of discount used within the framework as presented below:

$$
\mathrm{E}\left(\mathrm{Nb}_{\mathrm{i}}\right)=\mathrm{E}(\mathrm{Bi})-\mathrm{X}_{\mathrm{i}}
$$

where: $\quad E\left(\mathrm{Nb}_{\mathbf{i}}\right)=$ expected net benefits

$E(B i)=$ expected social benefits of protection strategy $i$

$\mathrm{X}_{\mathrm{i}}=$ social costs associated with implementation of that protection strategy

The benefits of groundwater protection are defined by the change in the expected damage, $\mathrm{E}(\mathrm{D})$, associated with contamination

$$
E(D)=p\left[q C_{r}+(1-q) C_{u}\right]
$$

where: $\quad p=$ probability, in the absence of policy $i$, that contamination will occur $(0 \leq \mathrm{p} \leq 1)$

$q=$ probability that contamination would be detected before tainted water was used $(0 \leq \mathrm{q} \leq 1)$

$\mathrm{C}_{\mathrm{r}}=$ expense of the most economically efficient response to the contamination incident $\left(\mathrm{C}_{\mathrm{r}} \geq 0\right)$

$\mathrm{C}_{\mathrm{u}}=$ cost incurred if contaminated water were used in the same manner as prior to the incident $\left(\mathrm{C}_{\mathrm{u}} \geq \mathrm{C}_{\mathrm{r}}\right)$

This equation can be interpreted as the expected damage associated with contaminated groundwater equals the probability that aquifer indeed will be tainted (p) times the expected costs of contamination - where the expected costs of contamination are a weighted average of the expense imposed if the contamination is known and an economically appropriate response is implemented, $\mathrm{qC}_{\mathrm{r}}$, and the costs imposed if the tainting is undetected and the impure water is used as if it were still pure, $(1-q) C_{u}$ 
As policies designed to protect groundwater actually change the probability that contamination will occur, for a policy that reduces the likelihood of contamination (dp(i) $<0)$ the expected benefits become

$$
E\left(B_{i}\right)=-d E(D) / d p(i)=-d p(i)\left[q C_{r}+(1-q) C_{u}\right]
$$

where: $\quad d p(i)=$ the change in probability induced by policy $i$

$$
E\left(B_{i}\right) \geq 0 \text { for any } d p(i)<0
$$

For policies that increase the likelihood of detection $(\mathrm{dq}>0)$ while leaving the probability of contamination, $p$, unchanged, benefits can be expressed as

$$
E\left(B_{j}\right)=-d E(D) / d q(j)=-d q(j)\left[p\left(C_{r}-C_{u}\right)\right]=d q(j)\left[p\left(C_{u}-C_{r}\right)\right]
$$

where: $\quad E\left(B_{j}\right) \geq 0$ for any $d q(j) \geq 0$

Shultz and Lindsay (1990) undertook a contingent valuation (CV) study in order to estimate households' WTP for a groundwater protection plan and also to determine the socioeconomic factors that most influence this WTP estimate. Their study was unique to the literature in that their WTP estimate provided an aggregation of use, option, and bequest values, and also that the influencing socioeconomic factors were to be identified. A dichotomous choice bidding (yes or no format) CV survey was sent to 600 property owners in Dover, New Hampshire in order to gauge WTP for future groundwater protection laws/ordinances. Previous literature has shown that when the results of this type of survey are modeled in a log linear format, the estimations are consistent with utility maximization, Hicksian demand curves, and consumer demand theory. This allows for a mean WTP calculation via integration of the demand curve. A logit model (nonlinear, maximum likelihood estimation) was used to analyze the relationship between 
the dichotomous and independent variables collected from the survey, where the predicted logit probabilities of a yes/no response were expressed by the following logistic equation:

$$
Z=b_{0}+b_{1} x_{1}+b_{2} x_{2}+\ldots+b_{k} x_{k}+u_{i}
$$

where: $\quad Z=\log$ (probability of yes) / (probability of no)

$\mathrm{X}_{1}=$ dollar amount of the WTP bid

$\mathrm{X}_{2} \ldots \mathrm{X}_{\mathrm{k}}=$ significant independent variables

$\mathrm{U}_{\mathrm{i}}=$ random error

The logistic value, $Z$, was then converted into a predicted probability, $P$

$$
\mathrm{P}=1 / 1+\exp ^{-\mathrm{Z}}
$$

where: $\quad P$ is the probability of a yes response to the WTP

The mean WTP of a sample of respondents is represented by the area under the cumulative distribution curve (i.e., the probability distribution of yes/no responses at alternative dollar amounts), and can be obtained through the integration of the inverse cumulative distribution function as follows:

$$
\text { WTP }=\text { indefinite integral of }\left[1-F_{e}(\$ x)\right] d(\$ x)
$$

where: $\quad \mathrm{F}_{e}(\$ \mathrm{X})=$ the cumulative distribution function for $\mathrm{e}$ $\mathrm{e}=$ error term in utility difference

The results of their study indicated a median WTP (median WTP was used as opposed to mean to give more statistical robustness) of $\$ 40$ per household. This was aggregated for the community by assigning a $\$ 0$ WTP for all non-respondents and multiplying the $\$ 40$ by the number of households that did respond. 


\subsubsection{Estimating Recreational Benefits}

Recreational benefits due to water quality and quantity improvements can be estimated through revealed preference techniques, stated preference techniques, and a combination of revealed and stated preference techniques. An introduction to the various methodologies employed for each preference category is depicted below:

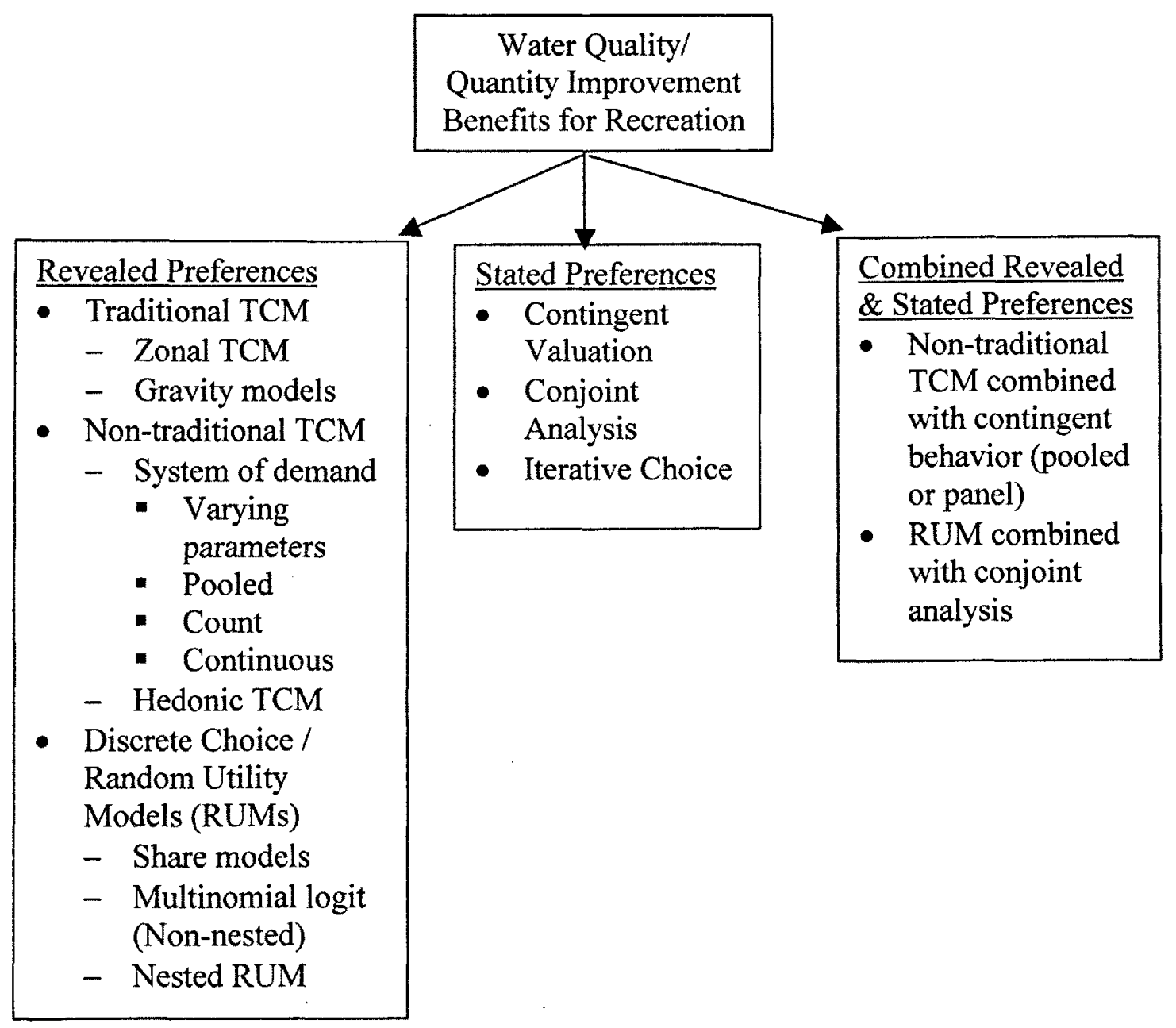

Figure 2.6: Techniques for Measuring Recreational Benefits

The literature review suggests that application of traditional TCM approaches is the least favorable due to the difficulty in identifying the change in recreation demands from the 
quality change (Whitehead et al., 2000) as well as the difficulty in incorporating quality differences across sites and hence the measurement of trade-offs between costs and quality (Bockstael et al., 1987). The other revealed preference techniques may have issues concerning the historical range of the water quality variables in relation to the policy being proposed, experience collinearity, or have difficulty in relating the objective measure of water quality to the recreational use (Whitehead et al., 2000); (Adamowicz et al., 1994); and (Englin et al., 1997). However, studies have addressed these issues and proposed workarounds (Englin et al., 1997); (Bockstael et al., 1987). The choice between using a nested vs. non-nested RUM has to do with the independence from irrelevant alternatives issues (Kaoru, 1995); (Tay \& McCarthy, 1994), as well as the application of "conventional wisdom" (Apogee Research, 1996). Von Haefen and Phaneuf (2003) discuss the attractiveness of the pooled system of demand models as compared to the RUMs, which currently are a large share of the literature on recreational water quality improvement benefits. Stated preference methodologies have their normal issues related to its hypothetical nature and lack of observed data (Adamowicz et al., 1994), but also offer alternatives to some of the revealed preference issues discussed above such as the historical data range (Whitehead et al., 2000). Combined approaches offer alternatives to the issues for both revealed and stated preferences and also are able to incorporate the estimation of non-participants (Whitehead et al., 2000); (Bhat, 2003); and (Adamowicz et al., 1994). The choice of the RUM combined approach or the "contingent behavior" approach may depend on whether the focus of the analysis is on the value of the improvements as opposed to the value of site attributes, and/or whether the focus is on the change in the total number of visits in the region as opposed to the reallocation of 
visits across sites (Hanley et al., 2003). Outside of the traditional TCM, robust benefit values may be attained from the application of any of the methodologies above as long as the relevant issues are addressed and incorporated into the model.

\section{Revealed Preferences:}

Bockstael et al. (1989) estimate the benefits to beach use, boating, and fishing from a $20 \%$ reduction in the product of total nitrogen and total phosphorus for Chesapeake Bay. The benefits for beach use and boating are estimated using a varying parameter travel cost model, while the benefits for fishing are estimated using a pooled travel cost model. In the model, an individual maximizes his utility as a function of the number of trips taken to the $n$ quality-differentiated sites (x), the quality characteristics of each site (q), and a Hicksian good (z), with his utility constrained by the sum of the costs of accessing each site multiplied by the number of trips taken (px) plus the Hicksian good ( $\mathrm{z}$ ) equal to his income (y). Formally, this is represented by:

$$
\operatorname{Max} u(x, q, z) \quad \text { s.t. } p x+z=y
$$

The solution to this maximization problem gives the demand functions for an individual as a function of prices, water quality, and income: $x_{i}=g_{i}(p, q, y)$, from which the benefits can be determined. However, while the demand for each site is expected to be a function of price and quality, no variation in site quality will be observed as the quality characteristic at site $\mathrm{i}\left(\mathrm{q}_{\mathrm{i}}\right)$ is constant across individuals. By introducing water quality characteristics via a varying parameter approach this issue can be overcome. For example, take a linear demand function for the ith site:

$$
\mathrm{x}_{\mathrm{i}}=\beta_{0 \mathrm{i}}+\beta_{1 \mathrm{i}} \mathrm{p}_{\mathrm{i}}+\beta_{\mathrm{si}} \mathrm{p}_{\mathrm{s}}+\beta_{\mathrm{yi}} \mathrm{y}+\varepsilon
$$


where: $\quad i=1, \ldots, n ; p_{i}=$ own price; $p_{s}=$ substitute price

Then let the demand parameters, the $\beta \mathrm{s}$, be deterministic functions of the quality characteristics:

$$
\begin{aligned}
& \beta_{0 \mathrm{i}}=\alpha_{0}+\alpha_{1} q_{\mathrm{i}} \\
& \beta_{1 \mathrm{i}}=\alpha_{2}+\alpha_{3} \mathrm{q}_{\mathrm{i}} \\
& \beta_{\mathrm{si}}=\alpha_{4}+\alpha_{5} q_{\mathrm{i}} \\
& \beta_{\mathrm{yi}}=\alpha_{6}+\alpha_{7} \mathrm{q}_{\mathrm{i}}
\end{aligned}
$$

Therefore, this implies that the variations in the demand parameters across sites $\left(\beta_{0 i} \mathbf{S}\right.$, $\beta_{1 \mathrm{i}} \mathrm{S}$, etc.) correspond to variations in own-site quality characteristics $\left(\mathrm{q}_{\mathrm{i}} \mathrm{s}\right)$. It can be seen from the above that the estimation requires two steps -1 ) estimate the number of trips to each site regressed on prices and income, and 2) regress the coefficients from these $n$ regressions on the quality characteristics of the $\mathrm{n}$ sites. Step 1, estimating the demand functions, is accomplished using a tobit estimation:

$$
x_{i}=\left\{\begin{array}{l}
\beta_{0}+\beta_{1} p+\beta_{s} p+\beta_{y} y+\varepsilon \\
\beta_{0 i}+\beta_{1 i} p_{i}+\beta_{s i} p_{s}+\beta_{y i} y+\varepsilon>0 \\
0
\end{array}\right.
$$

A second-stage model for boating is given as:

$$
\hat{\beta_{\mathrm{kj}}}=\alpha_{0 \mathrm{k}}+\alpha_{\mathrm{ik}} \operatorname{TNP}_{\mathrm{j}}+\mathrm{v}_{\mathrm{j}}
$$

where:

$$
\begin{aligned}
& k=\# \text { of parameters } \\
& j=\text { \#of sites }
\end{aligned}
$$

For fishing, a pooled model of the following form was used in place of the varying parameters model:

$$
x_{i}=f\left(p_{i}, q_{i}, y_{i}, I B_{i}, O B_{i}\right)
$$


where: $\quad p_{i}$ is the cost of fishing

$\mathrm{q}_{\mathrm{i}}$ is the catch rate associated with a $20 \%$ reduction in TNP

$\mathrm{y}_{\mathrm{i}}$ is the recreational budget

IB and OB are dummy variables for inboard or outboard boats

Benefit values are estimated from the following:

$$
\mathrm{CS}=\Sigma\left[\left(\mathrm{x}_{\mathrm{ij}}\left(\mathrm{q}_{\mathrm{j}}^{\mathrm{l}}\right)\right)^{2} /\left(-2 \beta_{\mathrm{ji}}\left(\mathrm{q}_{\mathrm{j}}^{1}\right)\right)-\left(\mathrm{x}_{\mathrm{ij}}\left(\mathrm{q}_{\mathrm{j}}^{0}\right)\right)^{2} /\left(-2 \beta_{\mathrm{ji}}\left(\mathrm{q}_{\mathrm{j}}^{0}\right)\right)\right]^{*} \mathrm{k}_{\mathrm{i}} / \mathrm{N}
$$

Average aggregate benefits determined from the above analysis were $\$ 34, \$ 5$, and $\$ 1.3$ million for beach use, boating, and fishing respectively. Clearly, beach use is the largest beneficiary of an improvement in water quality in the Chesapeake Bay.

A random utility model (RUM) has the ability to model the decision process of choosing a recreation site to visit from a finite set of quality differentiated sites and therefore importantly incorporating the availability of substitute sites. Kaoru (1995) uses a nested RUM to obtain benefit values from water quality improvements for marine recreational fishing in the Albemarle-Pamlico estuary of North Carolina. Three issues are concentrated on in the study - 1) the importance of party composition for explaining recreational choice decisions, 2) the implications of estimating a nested RUM on the functional structure of the underlying indirect utility function, and 3) the implementation of benefit measurement for multiple, simultaneous quality improvements in the context of a nested RUM. A nested RUM is estimated in order to overcome the independence from irrelevant alternatives, i.e., the probability of choosing any two sites is not affected by an addition or deletion of a site to or from the existing choice set, that may be exhibited in a non-nested RUM estimation. Kaoru estimates a three-level nested RUM where first the 
recreationist decides how many days to go fishing, then which of the five regions of estuary to visit, and finally which specific site within the selected region to visit. The conditional indirect utility function for this nested RUM estimation is explicitly given as:

$$
U_{h}=V_{h}\left(y, p_{h}, Q_{h}, S\right)+\varepsilon_{h}=V_{i j k}\left(X_{i j k}, W_{i j}, Z_{i}\right)+\varepsilon_{i j k}=\alpha X_{i j k}+\beta W_{i j} \gamma Z_{i}+\varepsilon_{i j k}
$$

where: $\quad P_{h}$ is the travel cost of visiting site $h$

$Q_{h}$ is a vector of quality variables describing site characteristics

$\mathrm{S}$ is a vector of socioeconomic variables including party composition $\mathrm{X}_{\mathrm{ijk}}, W_{\mathrm{ij}}$, and $Z_{\mathrm{i}}$ are vectors of explanatory variables for the lowest, middle, and highest decision levels respectively

Adopting the generalized extreme value distribution for the error terms, the probabilities of selecting site $\mathrm{k}$, region $\mathrm{j}$, and trip length $\mathrm{i}$ are given as:

$$
\begin{aligned}
& \operatorname{Prob}(\mathrm{k} \mid \mathrm{ij})=\exp \left\{[\alpha /(1-\sigma)] \mathrm{X}_{\mathrm{ijk}}\right\} / \exp \mathrm{J}_{\mathrm{ij}} \\
& \operatorname{Prob}(\mathrm{j} \mid \mathrm{i})=\exp \left\{[\beta /(1-\delta)] \mathrm{W}_{\mathrm{ij}}+\left[(1-\sigma) /(1-\delta) \mathrm{J}_{\mathrm{ij}}\right\} / \operatorname{exp~\mathrm {I}_{\mathrm {i}}}\right. \\
& \operatorname{Prob}(\mathrm{i})=\exp \left[\gamma \mathrm{Z}_{\mathrm{i}}+(1-\delta) \mathrm{I}_{\mathrm{i}}\right] / \Sigma \exp \left[\gamma \mathrm{Z}_{\mathrm{i}}+(1-\delta) \mathrm{I}_{\mathrm{r}}\right]
\end{aligned}
$$

where

$$
\begin{aligned}
& \mathrm{J}_{\mathrm{ij}}=\ln \left[\Sigma \exp \left(\alpha /(1-\sigma) \mathrm{X}_{\mathrm{ijk}}\right)\right] \\
& \mathrm{I}_{\mathrm{i}}=\ln \left[\Sigma \exp \left(\beta /(1-\delta) \mathrm{W}_{\mathrm{ij}}+(1-\sigma) /(1-\delta) \mathrm{J}_{\mathrm{ij}}\right)\right]
\end{aligned}
$$

Parameters of the conditional indirect utility function are estimated by a sequential maximum likelihood estimation technique.

For a particular water quality improvement from $\mathrm{Q}^{0}$ to $\mathrm{Q}^{1}$, the corresponding recreational benefits are measured by the compensating variation in the unconditional indirect utility function:

$$
\mathrm{U}\left(\mathrm{y}-\mathrm{CV}, \mathrm{P}, \mathrm{Q}^{1}, \mathrm{~S}, \mathrm{R}\right)=\mathrm{U}\left(\mathrm{y}, \mathrm{P}, \mathrm{Q}^{0}, \mathrm{~S}, \mathrm{R}\right)
$$


The expected value of this unconditional indirect utility function is taken in order to eliminate the random error term $\mathrm{R}$. Due to the linearity of the indirect utility function, the CV can be solved for according to:

$$
\mathrm{CV}=1 / \alpha_{1}\left[\ln \mathrm{G}\left(\mathrm{e}^{\mathrm{V}}\right)-\ln \mathrm{G}\left(\mathrm{e}^{\mathrm{v}_{0}}\right)\right]
$$

where $\quad G()$ is the distribution of the error term, $\alpha_{1}$ is the marginal utility of income $V_{1}$ and $V_{0}$ represent the deterministic part of the indirect utility function before and after the quality improvement.

Data were obtained from a 1982 intercept survey at 35 boat ramps in the region. 547 observations were used for the analysis. Explanatory variables for the highest trip length decision level, $Z_{i}$, include inclusive value, lodging costs, and 3 party composition dummys. Explanatory variables for the middle regional decision level, $\mathrm{W}_{\mathrm{ij}}$, include inclusive value, ratio of surface water area to horsepower of fishing boat, nitrogen discharge, phosphorus discharge, and a boat ownership dummy. Explanatory variables for the lowest site decision level, $\mathrm{X}_{\mathrm{ijk}}$, include travel cost, catch rate, type of boat ramp, biochemical oxygen demanding materials discharged, and suspended solids discharged. Benefit measures from improvements in pollution variables at different locations with and without an associated $25 \%$ improvement in catch rates were estimated. For overall quality measures benefit estimates ranged from $\$ .09$ to $\$ 5.16$

\section{Stated Preferences:}

Magat et al. (2000) developed a survey approach methodology they termed the "iterative choice approach", in order to estimate benefit values due to water quality improvements according to the EPA's attainment of use scoring categorization. As mandated by the 
federal Clean Water Act, all waters must be classified by their designated use and scored according to the percent of water meeting each level of water quality. Designated uses include aquatic life use support, primary contact and recreation, fish and shellfish consumption, and drinking water use. Levels of water quality by use include the percent of water that is good fully supporting, good threatened, fair partially supporting, poor not supporting, and poor not attainable. An example of the scoring framework is given in the following table.

Table 2.4: EPA Designated Use Scoring Categorization

\begin{tabular}{|c|c|c|c|c|c|c|}
\hline \multirow[b]{2}{*}{$\begin{array}{l}\text { Designated } \\
\text { Use }\end{array}$} & \multirow[b]{2}{*}{$\begin{array}{c}\text { Total } \\
\text { Assessed }\end{array}$} & \multicolumn{5}{|c|}{$\%$ of Water Meeting Each Level of Water Quality } \\
\hline & & $\begin{array}{c}\text { Good } \\
\text { Fully } \\
\text { Supporting }\end{array}$ & $\begin{array}{c}\text { Good } \\
\text { Threatened }\end{array}$ & $\begin{array}{c}\text { Fair } \\
\text { Partially } \\
\text { Supporting }\end{array}$ & $\begin{array}{l}\text { Poor Not } \\
\text { Supporting }\end{array}$ & $\begin{array}{l}\text { Poor Not } \\
\text { Attainable }\end{array}$ \\
\hline $\begin{array}{l}\text { Aquatic Life } \\
\text { Support }\end{array}$ & & & (r) & & & \\
\hline $\begin{array}{l}\text { Primary } \\
\text { Contact and } \\
\text { Recreation }\end{array}$ & & & & & & \\
\hline $\begin{array}{l}\text { Fish \& } \\
\text { Shellfish } \\
\text { Consumption }\end{array}$ & & & & & & \\
\hline $\begin{array}{l}\text { Drinking } \\
\text { Water }\end{array}$ & & & & & & \\
\hline
\end{tabular}

(Source: Magat et al., 2000)

For purposes of their study, Magat et al. (2000) did not include drinking water use as a part of their survey, and also evaluated changes between "good" and "not good" where good includes the levels of good fully supporting and good threatened, while not good includes the levels of fair partially supporting, poor not supporting, and poor not attainable. The contingent valuation methodology (CVM) is often applied when using stated preference techniques to value environmental goods. The CVM is used to elicit 
people's preferences in the form of WTP monetary amounts by describing a hypothetical market in which respondents are asked how much of their income in dollars they would be willing to give up for an associated improvement in the level of the environmental good. In this way, a direct evaluation of compensating surplus (i.e., the benefit gained from the improvement) is obtained and can be represented by: (Carson and Mitchell, 1993):

$$
C S=\left[e\left(p_{0}, q^{*}, q_{0}, U_{0}\right)\right]-\left[e\left(p_{0}, q_{*}, q_{1}, U_{o}\right)\right]
$$

where: $\quad \mathrm{e}$ is the expenditure function

$\mathrm{p}_{0}$ is the vector of prices for marketed goods

$\mathrm{q}_{*}$ is the vector of nonmarketed good which remains fixed

$\mathrm{q}_{\mathrm{o}}$ initial level of the nonmarketed good being valued

$\mathrm{q}_{1}$ subsequent level of the nonmarketed good being valued

$\mathrm{U}_{\mathrm{o}}$ is the initial level of utility

The iterative choice methodology is similar to the CVM in that hypothetical scenarios are presented to respondents and ultimately used to estimate WTP, but differs in three significant ways. First, while the CVM is concerned with eliciting WTP to improve the quality of an environmental good after being presented with a detailed description of the good, the iterative choice approach is concerned with "determining individual preferences based on the valuation of underlying attributes." That is, "the survey structure establishes a valuation of each of the component attributes of water quality, determines these tradeoff values, and also assesses the overall conversion of the water quality component improvements into a dollar valuation of water quality more generally." The second difference is that respondents not only consider hypothetical scenarios related to an environmental good they are familiar with, but also moves to a hypothetical location. This allows for benefits estimations that can be applied more 
generally on a location basis for policy analysis. Finally, by conducting the survey via computer based interviewing, as opposed to paper and pencil, face-to-face interviews typically employed with the CVM, the iterative approach allows respondents to make a choices until they reach a point of indifference.

The main purpose of the survey was to obtain an estimate of an individual's tradeoff value between money and improvements to water quality from a general perspective. This objective was accomplished via a cost of living vs. water quality scenario, where the value of water quality improvement is determined in terms of the dollar increase in cost of living a respondent is willing to incur for a percent improvement in water quality. An example of this type of iterative choice scenario is given in figure 2.7 below. In addition to the general cost of living vs. water quality tradeoff, nine other tradeoffs were estimated in a similar iterative fashion - lake/river usage, question format explanation, lake quality vs. river quality, water uses tradeoff, source of pollution, non-use value and probabilistic use, aesthetic properties/smelliness/cloudiness, cost of living vs. water quality referendum, and demographics. Table 2.5 contains the relevant WTP estimates derived:

Table 2.5 : Iterative Choice WTP Results

\begin{tabular}{|l|l|}
\hline WTP per Household & As Per \\
\hline$\$ 22.40(\$ 1998)$ & $1 \%$ improvement in total \% of good water (general) \\
\hline $35.3 \%$ of $\$ 22.40$ & Swimmable water quality \\
\hline $31.8 \%$ of $\$ 22.40$ & Aquatic Support \\
\hline $28.4 \%$ of $\$ 22.40$ & Fishable water quality \\
\hline $50 \%$ of $\$ 22.40$ & $\begin{array}{l}1 \% \text { improvement in total } \% \text { of good water for a region } \\
\text { respondent will never visit } \text { Non-use Value) }\end{array}$ \\
\hline $67 \%$ of $\$ 22.40$ & $1 \%$ improvement to Lakes only \\
\hline $33 \%$ of $\$ 22.40$ & $1 \%$ improvement to Rivers only \\
\hline
\end{tabular}

(Source: Magat el al., 2000) 


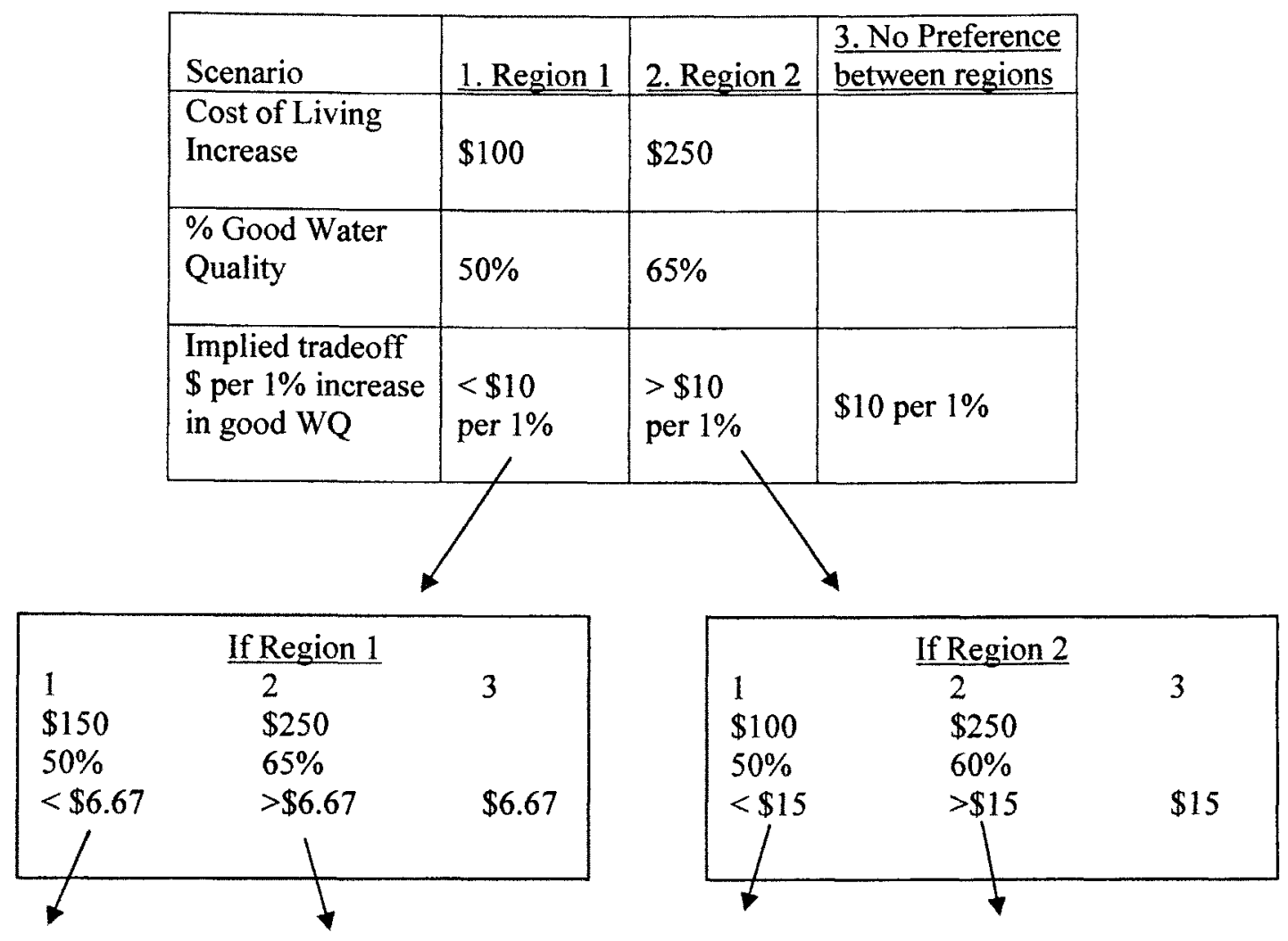

Etc.

(Source: Magat el al., 2000)

Figure 2.7: Iterative Choice Scenario - Cost of Living vs. Water Quality

Regression analysis of the table 2.5 estimates indicated that age (although decreasing over time), female gender, full-time employment, household family income, visit to a lake or river in the past 12 months, and living in the country all had a positive relationship to WTP, while minorities, household size, member of an environmental organization, and living in the suburbs all had a negative relationship to WTP. Whether a respondent had visited a lake or river in the past 12 months, or if they were a non-black minority had the largest positive and negative impacts respectively. 
Carson and Mitchell (1993) estimated WTP for boatable, fishable, and swimmable water quality, as defined by Resources For the Future's water quality ladder, through a CVM conducted at the national level. 564 usable WTP amounts were derived from the survey of 813 national respondents. Various survey procedures were put into place in order to neutralize biases. The payment vehicle used in the survey was annual taxes and higher product prices. In order to determine a baseline value, respondents were asked how much they would be willing to pay in order to "keep the nation's freshwater bodies from falling below the boatable (minimum) level where they are now". A total value bid curve for the WTP as a function of the base water quality level $\left(\mathrm{q}_{\mathrm{o}}\right)$, level of water quality being valued $\left(\mathrm{q}_{\mathrm{i}}\right)$, disposable household income $\left(\mathrm{Y}_{\mathrm{o}}\right)$, the tastes variables of water-based recreational use $\left(\mathrm{W}_{\mathrm{r}}\right)$, and environmental attitudes $\left(\mathrm{A}_{\mathrm{e}}\right)$ :

$$
\operatorname{TOTWTP}_{\mathrm{i}}=f\left(\mathrm{q}_{\mathrm{i}}, \mathrm{Y}_{\mathrm{o}}, \mathrm{W}_{\mathrm{r}}, \mathrm{A}_{\mathrm{e}} \mid \mathrm{q}_{\mathrm{o}}\right)
$$

Differentiating this bid curve with respect to $q_{i}$ yields the inverse Hicksian compensated demand curve, and from here they obtain the following results:

TOTWTP $_{\mathrm{i}}=\exp \left[0.413+0.819 * \log \left(\mathrm{q}_{\mathrm{i}}\right)+0.959 * \log \left(\mathrm{Y}_{\mathrm{o}}\right)+0.207 * \mathrm{~W}_{\mathrm{r}}+0.460 * \mathrm{~A}_{\mathrm{e}}\right]$

Table 2.6 : Boatable, Fishable, Swimmable WTP

\begin{tabular}{|lll|}
\hline Mean WTP values were given as: & Original & Adjusted \\
\hline Nonboatable to boatable & $\$ 106$ & $\$ 93$ \\
Boatable to fishable & $\$ 80$ & $\$ 70$ \\
Fishable to swimmable & $\$ 89$ & $\$ 78$ \\
Total WTP & $\$ 275$ & $\$ 242$ \\
\hline
\end{tabular}

(Source: Carson and Mitchell, 1993) 
Combined Revealed and Stated Preferences:

Whitehead et al. (2000) combine revealed and stated preference techniques to estimate the recreation benefits gained (change in consumer surplus) due to a fixed quality improvement that is measured by increased fish catch rates and opened shellfish beds in Albemarle and Pamlico Sounds in North Carolina. Importantly, they attempt to incorporate initial non-participants that become participants due to the quality improvement.

A telephone survey was conducted to elicit respondent's recreation participation for the previous 12 months (revealed preferences, $t=1$ ) and expected participation (stated preferences, $t=2$ ) for the next 12 months given the current quality levels. Furthermore, a hypothetical scenario (stated preferences, $t=3$ ) of the enactment of pollution laws that would restore quality levels to those of 1981 and hence improve fish catch rates by $60 \%$ as well as open $25 \%$ more shellfish beds was described, and respondents were asked their anticipated participation rates for the next 12 months given this improved quality level scenario. 765 survey observations were pooled into a panel data set for estimation.

A random effects Poisson model with dummy variables is used to estimate the joint recreation demand model from the panel data. The number of trips taken by individual $i$ in a particular trip scenario $t$ is given by:

$$
\operatorname{Prob}\left(X_{i t}=x_{i t}\right)=e^{-\mu}{ }_{i t} \mu_{i t}{ }_{i t}^{x} / x_{i t} !
$$

where: $\quad \mathrm{x}_{\mathrm{it}}=0,1,2, \ldots$ 
$\mu_{\mathrm{it}}=\alpha_{1}+\beta_{1} \mathrm{TCP}_{\mathrm{it}}+\delta_{1} \mathrm{TCF}_{\mathrm{it}}+\phi_{1} \mathrm{INCOME}_{\mathrm{it}}+\varphi_{1} \mathrm{PAMLICO}_{\mathrm{it}}+\mathrm{a}_{2} \mathrm{D}_{2} 2+$ $\mathrm{b}_{2} \mathrm{D}_{2} 2 \mathrm{TCP}_{\mathrm{it}}+\mathrm{c}_{2} \mathrm{D} \_2 \mathrm{TCF}_{\mathrm{it}}+\mathrm{d}_{2} \mathrm{D} \_2 \mathrm{INCOME}_{\mathrm{it}}+\mathrm{a}_{3} \mathrm{D} \_3+\mathrm{b}_{3} \mathrm{D} \_3 \mathrm{TCP}_{\mathrm{it}}+\mathrm{c}_{3}$ D_3TCF ${ }_{i t}+d_{3} D_{-} 3 \overline{I N C O M E}_{i t}+u_{i}$

where: $\quad$ TCP $=$ travel cost Pamlico

$\mathrm{TCF}=$ travel cost to Cape Fear

D $2=1$ if $t=2,0$ otherwise

D_3 $=1$ if $t=3,0$ otherwise

An individual's seasonal recreational value of a quality improvement is given by:

$$
\Delta \mathrm{CS}=\left(\mathrm{x}^{\prime} / \beta^{\prime}\right)-(\mathrm{x} / \beta)
$$

where: $\quad \mathrm{x}^{\prime}=$ the number of trips taken under higher quality

$\beta^{\prime}$ is the coefficient of price in the new demand function at a the higher quality level.

After running the proper statistical tests to ensure that revealed and stated behavior data can be combined and jointly estimated, the model gives the following results:

Table 2.7: Combined Revealed \& Stated Preference Study Results

\begin{tabular}{|ll|}
\hline Estimate & $\underline{\text { Value }}$ \\
Predicted trips for current quality: & 1.88 \\
Predicted trips for improved quality: & 2.49 \\
& $\$ 64.14$ \\
CS per trip for current quality & $\$ 84.99$ \\
CS per trip for improved quality & $1.88 \times \$ 64.14=\$ 120.53$ \\
& $2.49 \times 84.99=\$ 154.54$ \\
CS per season for current quality & \\
CS per season for improved quality & \\
\hline
\end{tabular}

(Source: Whitehead et al., 2000) 


\subsubsection{Estimating Agricultural Benefits}

Agricultural benefits due to proposed water quality improvement were estimated as part of the IRLS feasibility study (USACE/SFWMD, 2002). Specifically, the relationship between citrus yields and the concentration of total dissolved solids in irrigation waters was used to estimate benefits due to water quality improvements. Traditionally, citrus producers in the IRLS utilize surface waters for their agricultural irrigation. However, in instances of drought water may be used from the Floridan aquifer, which has total dissolved solid concentrations ranging from 700 to $2,500 \mathrm{mg} / \mathrm{l}$. "Citrus trees, especially young trees, begin to show damage when irrigated with water containing dissolved solids concentrations as low as $600 \mathrm{mg} / \mathrm{l}$ ". As the IRLS restoration is proposed, reservoirs to be created will eliminate the need for citrus producers to withdraw irrigation water from the Floridan aquifer during drought conditions, as the reservoirs will become the source of irrigation water. The relationship between citrus yields and the concentration of total dissolved solids was combined with annual withdrawal data from the Floridan aquifer to estimate the increased citrus yields due to irrigation water being supplied by the created reservoirs as opposed to the aquifer. It was estimated that without the creation of the reservoirs through the IRLS restoration citrus yields would be 263 boxes per acre vs. 271 boxes per acre with the restoration and created reservoirs. The 8 boxes per acre difference was multiplied by the price per box of $\$ 4.90$ and the number of available acres of approximately 157,000 in order to generate an annual agricultural benefit of $\$ 6.1$ million due to water quality improvements. 


\subsubsection{An Overall Approach}

Pretty et al. (2003) presented a framework for costing out environmental and health costs associated with freshwater eutrophication. The methodologies used were based on a wide range of valuation studies and varied across the specific cost categories. Costs were separated between two categories, damage costs and policy costs, with damage costs defined as those costs that "represent a loss of existing value rather than an increase in costs". There is difficulty in concretely defining when nutrient enrichment (eutrophication) causes adverse effects to freshwater, and is the primary hurdle in developing relevant cost measures. In order to deal with this issue a frequency of closure (fc) estimate that is used throughout many of the other cost calculations was developed. Using 1990-99 national data on blue-green algal blooms, fc was defined as the following:

$$
\mathrm{fc}=(\operatorname{Ibg} * \mathrm{~N}) /(\mathrm{C}[\mathrm{S}(.5) \text { or } \mathrm{S}(1)])
$$

where: $\quad$ Ibg - \# of incidents of blue-green algal bloom

$\mathrm{N}$ - \# of days water body closed for each incident

$\mathrm{C}$ - \# of water bodies affected

$\mathrm{S}(.5)$ - season length, days in half year

$\mathrm{S}(1)$ - season length, days in full year

Ten separate use damage costs were estimated:

1) Reduced value of waterside dwellings - The hypothesis is that waterfront properties lose value if the quality of water falls due to adverse effects to water from eutrophication. Collecting data on waterfront properties the following value loss function was defined

$$
\operatorname{VL}(1)=\left(P_{n} * f_{c}\right) * V L_{p}
$$


where: $\quad P_{n}$ - \# of waterside properties

$F_{c}$ - frequency of loss of value due to some eutrophication

$\mathrm{VL}_{\mathrm{p}}$ - value loss per average of 10 meters of frontage

2) Reduced value of water bodies for abstraction, livestock watering, navigation, irrigation, and industrial uses

$$
\mathrm{VL}(2)=\mathrm{V}_{\mathrm{w}} * \mathrm{f}_{\mathrm{c}}
$$

where: $\quad V_{w}$ - value of water for industrial, farming, and navigation - a proxy for this was derived by the charges made for licenses.

3) Drinking water treatment costs (For algal toxins and algal decomposition products) -

Suppliers of water and sewerage treatment plants need to spend money to for nutrient compliance or maintenance of operations/water quality levels

$$
\operatorname{VL}(3)=\left[\left(C_{o} * A_{p}\right) * A S P_{o}\right]+\left[\left(C_{c} * A_{p}\right) * A S P_{c}\right]+C_{r}
$$

where: $\quad \mathrm{C}_{0}-$ annual operating expenditure by water companies

$A_{p}$ - proportion of production liable to suffer from algal proliferation $\mathrm{ASP}_{\mathrm{o}}$ - proportion of algal sensitive production(ASP) operating costs for eutrophication

$\mathrm{C}_{\mathrm{c}}$ - annual capital expenditure by water companies

$\mathrm{ASP}_{\mathrm{c}}$ - proportion of ASP capital costs for eutrophication

$\mathrm{C}_{\mathrm{r}}-$ annual cost of reservoir management

4) Drinking water treatment costs (Nitrogen) - Costs to comply with drinking water standards (analogous to above)

$$
\mathrm{VL}(4)=\mathrm{NC}_{\mathrm{o}}+\mathrm{NC}_{\mathrm{c}}
$$

where: $\quad \mathrm{NC}_{\mathrm{o}}-$ annual operating costs of removal of nitrates

$\mathrm{NC}_{\mathrm{c}}$ - annual capital costs of removal of nitrate

5) Cleanup costs of waterways

$$
\mathrm{VL}(5)=\left(\Sigma \mathrm{W}_{\mathrm{c}}\right) * \mathrm{P}
$$


where: $\quad \mathrm{W}_{\mathrm{c}}-$ cost of weed cutting for organizations

$\mathrm{P}$ - \% of weed cutting attributable to eutrophication

6) Reduced value of nonpolluted atmosphere - Greenhouse gases impose costs on the environment by contributing to climate change and acidification

$$
\mathrm{VL}(6)=\left(\mathrm{E}_{\mathrm{CH} 4} * \mathrm{P}_{\mathrm{w}} * \mathrm{C}_{\mathrm{ch} 4}\right)+\left(\mathrm{E}_{\mathrm{N} 2 \mathrm{O}} * \mathrm{P}_{\mathrm{w}} * \mathrm{C}_{\mathrm{N} 2 \mathrm{O}}\right)+\left(\mathrm{E}_{\mathrm{NH} 3} * \mathrm{P}_{\mathrm{w}} * \mathrm{C}_{\mathrm{NH} 3}\right)
$$

where: $\quad E$ is the annual emissions of $\mathrm{N}_{2} \mathrm{O}, \mathrm{CH}_{4}$ and $\mathrm{NH}_{3}$

$\mathrm{P}_{\mathrm{w}}-\%$ of emission arising from water bodies

$\mathrm{C}$ is the environmental costs per metric ton of each gas - used from another study

7) Reduced recreational and amenity value of water bodies for water sports - Closures of water bodies due to eutrophication cause loss of revenue for recreational related activities

$$
\operatorname{VL}(7)=\mathrm{N}_{\mathrm{v}} * \mathrm{f}_{\mathrm{c}} * \mathrm{C}_{\mathrm{s}}
$$

where: $\quad \mathrm{N}_{\mathrm{v}}$ - \# of visits made to water bodies each year

$\mathrm{F}_{\mathrm{c}}$ - frequency of closure

$\mathrm{C}_{\mathrm{s}}$ - consumer surplus for use of water-body

8) Net Economic Losses for Formal Tourist Industry - Reflect net losses associated with reduced recreational activities, but the loss here is to peripheral industries such as lodging, food services, etc

$$
\operatorname{VL}(8)=\mathrm{N}_{\mathrm{v}}{ }^{*} \mathrm{f}_{\mathrm{c}} * \mathrm{E}_{\mathrm{day}}
$$

where: $\quad \mathrm{N}_{\mathrm{v}}$ and $\mathrm{f}_{\mathrm{c}}$ same as above

$$
E_{\text {day }} \text { - total expenditure per day }
$$

9) Net economic losses for commercial aquaculture and fisheries 


$$
\operatorname{VL}(9)=V_{f}^{*} f_{c}
$$

where: $\quad V_{f}-$ value of commercial fisheries

$F_{c}-$ closure

10) Health costs to humans, livestock and pets - Incidents are rare and therefore cost assumed 0

\subsubsection{Non-Use Values of Water}

Services provided by water can be tangible, functional, and also intangible (Freeman, 2003). Most of the discussion up to this point has centered upon the tangible (municipal, agriculture, recreation, etc.) uses and the functional (ecological) uses of water, and how changes to these uses serve as the basis for benefit estimation. However, total value estimates also include the intangible or non-use (passive use) values as well: Total Environmental Economic Valuation $=$ Use Values + Non-Use Values

Non-use values, or the preferences that individuals may have for natural resources beyond current direct uses of the resource such as the desire to use the resource in the future or know that it exists for others to use in the future, have no market value and can only be measured through stated preference techniques such as contingent valuation (Apogee Research, 1996). Kramer and Eisen-Hecht (2002) conducted a contingent valuation study in order to determine the economic value of protecting water quality in the Catawba River basin, for both use and non-use values, including recreation, drinking water, and wastewater assimilation. In addition to the 10 use value loss functions 
described above, Pretty et al. (2003) also estimated a non-use value loss arising from ecological damage costs.

\subsubsection{Other Factors To Consider}

Johnston et al. (2002) utilize a multi-attribute contingent choice framework to assess whether WTP for distinct elements of a watershed management policy program is affected by other elements of the program. More specifically, where policy elements of a program interact as substitutes, independent cost-benefit estimates may either overstate or understate true values. Their research aim is to develop a model of preferences (which is equivalent to a model of social valuation) through the contingent choice framework that aids policy analysts in evaluation of a potentially large set of possible combinations of watershed policy components. The analysis goes on to show that the reported changes in WTP are consistent with their hypothesis that groundwater and surface water are substitutes, i.e., the value of surface water quality improvements increases as groundwater quality decreases, if all other factors remain unaltered. These finding indicate the danger of evaluating watersheds that have interacting components on an independent basis, e.g., conducting a cost-benefit analysis based on WTP estimations of surface water quality improvements or groundwater quality improvements in isolation. These results also highlight additional complications for benefit transfer analysis, i.e., must not only consider differences between resident populations in different watersheds but also effects of substitution amongst the physical components of the watershed. 
For every restoration effort, the effort itself will bring direct, indirect, and induced impacts to the area in addition to the costs and benefits that ensue from the proposed changes. These are most typically measured via an input-output model. Weisskoff (2000), Hamilton et al. (2002), and Hazen and Sawyer P.C. (2002) use input-output models in their benefit-cost estimations.

\subsection{Cost-Benefit Analysis}

The concept of pareto optimality (defined in section 2.1.3) is itself often times impractical in a given "real world" situation. Therefore, another less stringent efficiency measure has been defined - that policies or projects have net benefits if gainers are able to compensate losers. More succinctly, if benefits are able to exceed costs then the project or policy may be deemed worthwhile assuming availability of funds. (Letson, 2002) However, it is not sufficient to simply compare total benefits vs. total costs, as many projects have benefits and costs that accrue over various time periods. Therefore, an intertemporal analysis is necessary to properly account for the varying time periods by discounting future costs and benefits into a common measurement value - the present value (Boardman et al., 2001). There are two main economic justifications for discounting: 1) consumers prefer consumption today and therefore must be compensated for waiting which is evidenced by a benefit occurring in the future being larger than a benefit occurring today, and 2) alternative investment opportunities and the productivity of capital (Letson, 2002). More formally the intertemporal analysis is summarized by, "an investment proposal can either be accepted if it is expected to yield a positive discounted net cash flow above the breakeven point of net present value equal to zero, or 
rejected if it does not" (Russell et al., 2001), where net present value (NPV) is the difference between the present value of the stream of benefits minus the present value of the stream of costs.

$$
\mathrm{NPV}=\sum_{\mathrm{t}=0}^{T}\left[1 /(1+\mathrm{r})^{t}\right] \times[\operatorname{Benefits}(\mathrm{t})-\operatorname{Costs}(\mathrm{t})]
$$

where: $\quad t=$ time periods

$$
r=\text { interest rate }
$$

As can be readily seen from equation (2.59) the rate of interest, time period, and accuracy of benefit and cost estimates all have important direct effects on the NPV result. For example, Lupi and Hoehn (1998) graphically depict how a higher interest rate will decay the PV of a dollar as compared to a lower interest rate; as the higher the interest that can be earned on alternative investments the less weight is given to future benefit and costs.

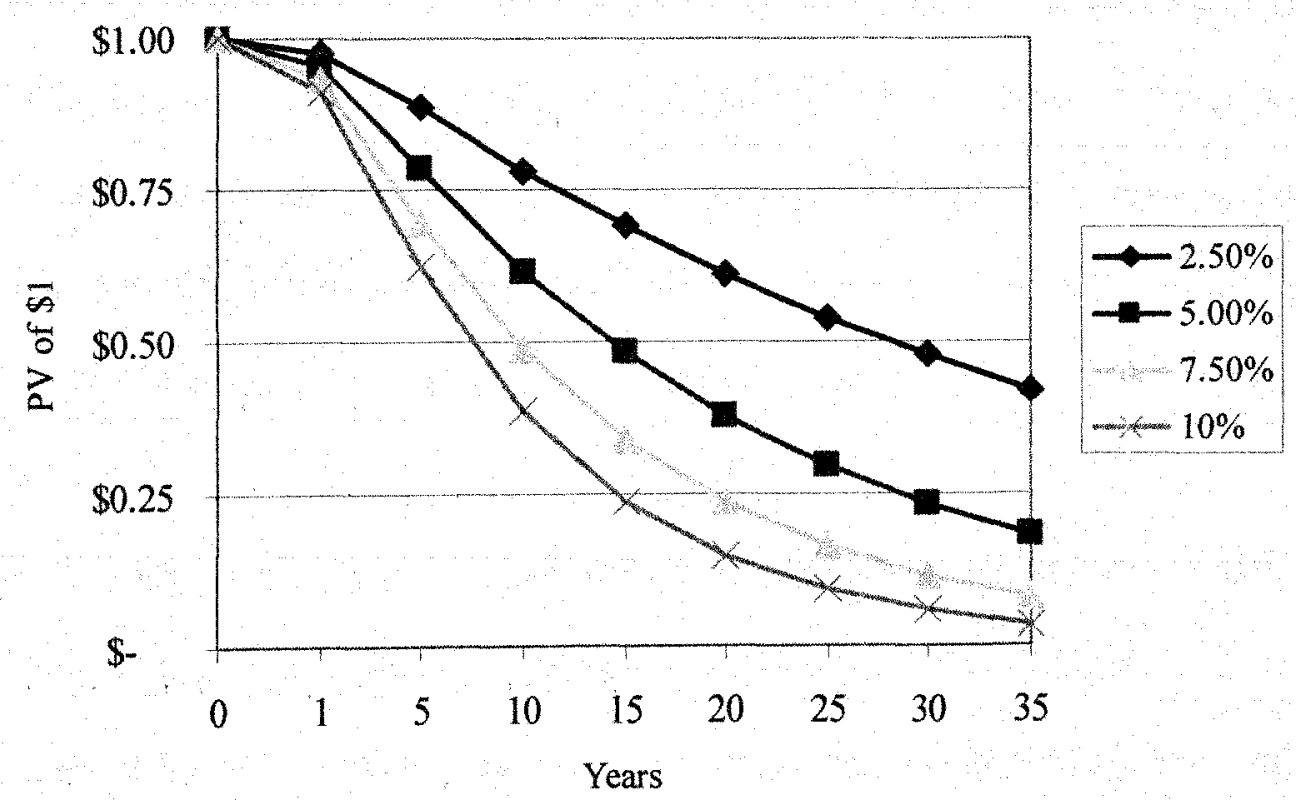

(Source: Lupi and Hoehn, 1998)

Figure 2.8: Interest Rate Decay for PV of $\$ 1$ 
From this simple interest rate example it is shown that a level of uncertainty, in terms of which is the most appropriate rate of interest to use over a thirty-year time period as interest rates will most certainly fluctuate over this period, has entered into the NPV estimation. Uncertainty also surrounds the time period of project implementation as well as the accuracy of the benefit and cost estimations. There are three major techniques that can be used to account for the inherent uncertainty in the NPV estimation: 1) Expected Value Analysis, 2) Sensitivity analysis, and 3) Monte Carlo Probabilistic Risk Analysis (Boardman et al., 2001) \& (Russell et al., 2001)

Expected value analysis involves specifying a set of exhaustive and mutually exclusive contingencies, i.e., outcomes/events, surrounding a project and assigning appropriate probabilities of their occurrence $\left(\mathrm{p}_{\mathrm{i}}\right)$ where $\Sigma \mathrm{p}_{\mathrm{i}}=1$. For example, there is a $90 \%$ probability that a project will succeed, and a $10 \%$ chance that the project will fail with the probabilities determined by an uncertain event, nature, that is outside of the project's control. Once the contingencies and their associated probabilities have been assigned, expected net benefits, E[NB], can be determined:

$$
E[N B]=p_{1}\left(\text { benefits }_{1}-\operatorname{costs}_{1}\right)+\ldots+p_{n}\left(\text { benefits }_{n}-\operatorname{costs}_{n}\right)
$$

Sensitivity analysis acknowledges the uncertainty in the cost-benefit analysis, and as the name implies conveys how sensitive estimated net benefits are to changes in the most crucial inputs of the net benefit estimation. Often times this is done through standard but arbitrary percentage increases and decreases (e.g., $\pm 10 \%, \pm 25 \%$, etc.) of the key factors. There are two main limitations to this type of analysis -1) it might not take account of all 
available information about assumed values of parameters, and 2) no information is provided concerning the variance/standard distribution of the net benefits. Monte Carlo probabilistic risk analysis is able to overcome these limitations by assigning a probability distribution (either subjectively or objectively) to each input variable that has a relevant influence on the net benefits, and then "through repeated simulation, an empirical approximation to the probability distribution of the outcome of interest is obtained" (Russell et al., 2001).

\subsection{Indian River Lagoon South Project Overview}

The Indian River Lagoon (IRL) is listed as an estuary of national significance and included in the EPA's National Estuary Program. The southern portion of the IRL (IRLS), which includes that portion of the IRL from the St. Lucie-Indian River County line south to the Martin-Palm Beach County Line, is an area rich in habitat and species and considered one of the most bio-diverse estuaries in North America. In August, 2002 the U.S. Army Corp of Engineers in conjunction with the South Florida Water Management District issued the Central and Southern Florida Project Indian River Lagoon - South (IRLS) Feasibility Study, Final Integrated Feasibility Report and Supplemental Environmental Impact Statement (USACE/SFWMD, 2002) in order to investigate water resource opportunities in the Martin and St. Lucie Counties in relation to the C\&SF canal system, including canals C-23, C-24, C-25, and C-44. The IRLS study area is shown in Figure 2.9 below. Human activities over the past 100 years have altered the IRLS. In the late 1800 's the St. Lucie Inlet was constructed, connecting the IRLS to the Atlantic Ocean and changing the St. Lucie river (SLR) from a freshwater 
river to a riverine estuary. Beginning in the 1920 's, a network of canals, including C-23, C-24, C-25, and C-44, were constructed in order to facilitate urban and agricultural development. A number of detrimental environmental consequences occurred from the construction of these canals and the subsequent development. Rainfall, which used to slowly flow over the land to the SLR, quickly flows into the canals without the water

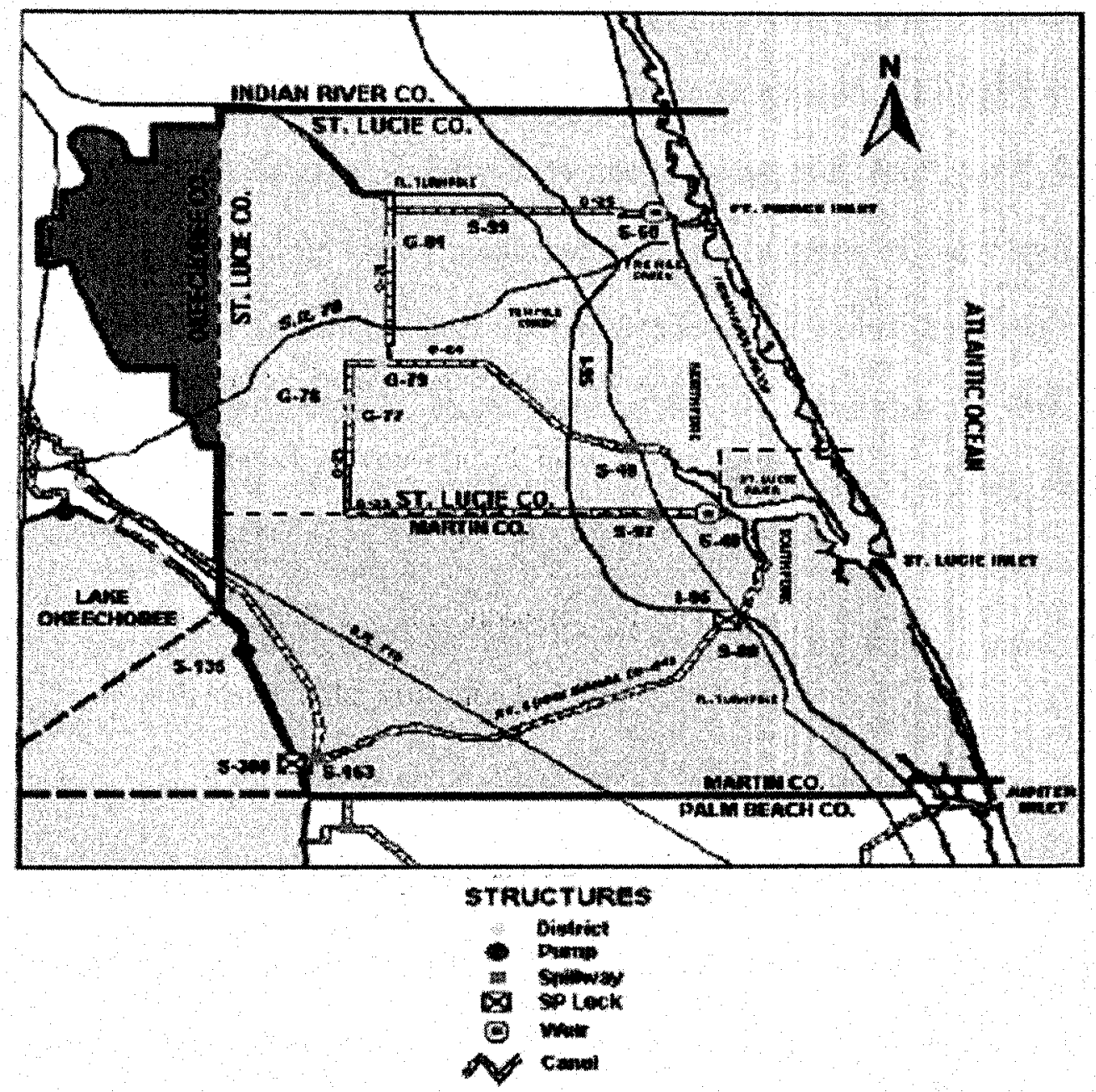

(Source: USACE/SFWMD, 2002)

Figure 2.9: Indian River Lagoon South 
quality treatment and flow quantity buffering that was originally provided by the natural systems. Also, the runoff contains heightened levels of contaminants due to the agricultural and urban development.

Therefore, the water quality flowing to the SLR and estuaries has become degraded, and the quantity and timing of flows has become highly variable. Both of which have negative consequences on the health of the estuarine community. In addition to the increased volume of discharges to the estuary due to the quicker runoff, the C-44 canal also handles discharges from Lake Okeechobee in order to regulate its water levels. The increased volumes of freshwater discharges results in salinity changes to the estuary balance, again causing negative health consequences to the estuarine community. Increased development of the estuarine shoreline has replaced natural shoreline vegetation, which helps to stabilize substrate, filter runoff, and provide habitat, causing the rapid accumulation of sediment and muck that leads to further water quality degradation.

The primary goal of the IRLS restoration study is to "recommend a plan to reduce negative water quality impacts to the IRL caused by freshwater discharges from upstream areas of the St. Lucie estuary basin". In order to achieve this goal, the plan came up with five recommended features:

1) Reservoirs - Construction and operation of four above ground freshwater storage reservoirs and their corresponding canals, control structures, pumps, and levees. The construction would require the acquisition of 12,000 acres of 
land. The reservoirs will provide 135,000 acre-feet of storage, capturing water from the $\mathrm{C}-23, \mathrm{C}-24, \mathrm{C}-25$, and C-44 canals. The water stored would allow for the reduction of freshwater discharges, reduction of nitrogen and phosphorus loads, and additional water supply for agriculture.

2) Stormwater Treatment Areas - Construction and operation of five stormwater treatment areas (STAs) and their corresponding canals, control structures, pumps, and levees. The construction would require the acquisition of 9,000 acres of agricultural and pastureland. The STAs will provide 35,000 acre-feet of storage and reduce nitrogen, phosphorus and sediment loads.

3) Natural Storage and Water Quality Treatment Areas - Acquisition of 90,000 acres of upland/wetland mosaic and plugging of the existing drainage system of the 90,000 acres. These areas would provide an additional 30,000 acre-feet of storage, reduction in nitrogen and phosphorus loads, groundwater recharge, re-hydration of historic wetlands, and restoration of existing impacted wetlands

4) Diversion of existing watershed flows - Operational constraint placed on the recommended reservoirs, STAs, and restored wetlands that would divert 105,000 acre-feet per year of canal flows from the middle estuary.

5) Muck Removal and Artificial Habitat - Removal of 5.5 million cubic yards of muck from four degraded areas, creating 2,650 acres of clean substrate. In addition, another 90 acres of habitat will be created. 
Total initial costs for the above plan discounted at a rate of $6.125 \%$ are $\$ 996$ million $^{7}$, with $\$ 4.2$ million in ongoing operations and maintenance ${ }^{8}$. Construction has been estimated to last nearly 10 years, beginning in 2002 through 2010 . The $\$ 996$ million is roughly split evenly between construction and real estate acquisition costs as shown in the table below:

Table 2.8: Estimated Initial Costs for IRLS Construction Features (Oct 2001 Price Levels in millions of dollars)

\begin{tabular}{|c|c|c|c|c|c|c|}
\hline \multirow[b]{2}{*}{ Construction Feature } & \multicolumn{6}{|c|}{ Costs } \\
\hline & & truction & & 1 Estate & & $\begin{array}{l}\text { tal Initia } \\
\text { Cost }\end{array}$ \\
\hline C-44 West Reservoir and STA & $\$$ & 86.2 & $\$$ & 49.4 & $\$$ & 135.6 \\
\hline C-44 East STA & $\$$ & 21.5 & $\$$ & 20.2 & $\$$ & 41.7 \\
\hline $\begin{array}{l}\text { C-44 Palmar Complex - Natural Storage } \\
\text { and Treatment Areas }\end{array}$ & $\$$ & 15.0 & $\$$ & 76.8 & $\$$ & 91.8 \\
\hline C-23 North Reservoir & $\$$ & 57.6 & $\$$ & 39.5 & $\$$ & 97.1 \\
\hline C-23 South Reservoir & $\$$ & 57.8 & $\$$ & 37.3 & $\$$ & 95.1 \\
\hline C-23/C-24 STA & $\$$ & 30.3 & $\$$ & 23.2 & $\$$ & 53.5 \\
\hline C-23/C-44 STA and Diversion Canal & $\$$ & 30.7 & $\$$ & 1.0 & $\$$ & 31.7 \\
\hline $\begin{array}{l}\text { Allapattah Complex - Natural Storage and } \\
\text { Treatment Areas }\end{array}$ & $\$$ & 26.8 & $\$$ & 139.5 & $\$$ & 166.3 \\
\hline $\begin{array}{l}\text { Cypress Creek Complex - Natural Storage } \\
\text { and Treatment Areas }\end{array}$ & $\$$ & 20.6 & $\$$ & 111.5 & $\$$ & 132.1 \\
\hline C-25 Reservoir and STA & $\$$ & 27.7 & $\$$ & 8.3 & $\$$ & 36.0 \\
\hline Muck Remediation and Habitat & $\$$ & 105.6 & $\$$ & - & $\$$ & 105.6 \\
\hline North Fork Floodplain Restoration & $\$$ & - & $\$$ & 9.3 & $\$$ & 9.3 \\
\hline PMP Development & $\$$ & 0.3 & $\$$ & - & $\$$ & 0.3 \\
\hline Total & $\$$ & 480.1 & $\$$ & 516.0 & $\$$ & 996.1 \\
\hline
\end{tabular}

(Source: USACE/SFWMD, 2002)

\footnotetext{
${ }^{7}$ The costs are given in real terms as given in the IRLS feasibility report - "in accordance with Federal water resource-planning regulations does not include future price escalation". Although, does not explicitly state whether the $6.125 \%$ interest rate is real or nominal, given that the costs are real, assuming the interest rate used is real as well.

${ }^{8}$ Assuming the O\&M costs have been discounted as well at the real interest rate of $6.125 \%$ as the IRLS feasibility report states "the cost stream for the recommended plan was mathematically translated into an equivalent time basis value". Although the way its has been presented in the report is not clear.
} 
Project benefits were identified across environmental quality (EQ), national economic development (NED), and regional economic development (RED) accounts according to federal guidelines. EQ accounts have not been monetized, NED accounts were partially monetized, and the RED accounts were monetized via an input-output analysis. EQ, NED, and RED benefits are listed in tables $2.9,2.10$, and 2.11 respectively.

Table 2.9: Identified IRLS Environmental Quality Benefits

\section{Estimated EQ Benefit}

- 122 metric tons of phosphorus load reductions, $41 \%$ of 2050 base load

- 475 metric tons of nitrogen load reduction, $26 \%$ of 2050 base load

- 53,665 acres of wetlands restored

- 2,650 acres of benthic habitat created in St. Lucie River and Estuary

- 889 acres of oyster habitat restored

- 922 acres of submerged aquatic vegetation restored

(Source: USACE/SFWMD, 2002)

Table 2.10: Identified IRLS National Economic Development Benefits

\begin{tabular}{|l|l|}
\hline \multicolumn{1}{|c|}{ NED Account } & \multicolumn{1}{c|}{ Net Change for With Project Conditions } \\
\hline $\begin{array}{l}\text { Water Supply Benefits } \\
\text { for Citrus Irrigation - } \\
\text { Annual Output }\end{array}$ & $\$ 6.1$ million annually (see section 2.2.3.3) \\
\hline Flood Control & $\begin{array}{l}\text { Limited evaluation of impacts; Removal of peaks from } \\
\text { high flow events is expected to provide some } \\
\text { improvement over existing flood control }\end{array}$ \\
\hline $\begin{array}{l}\text { Commercial } \\
\text { Navigation }\end{array}$ & $\begin{array}{l}\text { No difference expected between with and without } \\
\text { project conditions }\end{array}$ \\
\hline
\end{tabular}




\begin{tabular}{|l|l|}
\hline NED Account & \multicolumn{1}{|c|}{ Net Change for With Project Conditions } \\
\hline Recreation & $\begin{array}{l}\text { Improvement to health of St. Lucie River \& Estuary and } \\
\text { the IRL will substantially support and sustain local } \\
\text { recreational-based businesses }\end{array}$ \\
\hline $\begin{array}{l}\text { Commercial / } \\
\text { Recreational Fishing }\end{array}$ & $\begin{array}{l}\text { Improvement to health of St. Lucie River \& Estuary and } \\
\text { the IRL will substantially support and sustain local } \\
\text { commercial and recreational fishing }\end{array}$ \\
\hline
\end{tabular}

(Source: USACE/SFWMD, 2002)

Table 2.11: Identified IRLS Regional Economic Development Benefits

\begin{tabular}{|c|c|}
\hline RED Account & Net Change with Project Conditions \\
\hline $\begin{array}{l}\text { Construction } \\
\text { - } \quad \text { Employment (FTE) } \\
\text { - } \quad \text { Earnings } \$(000) \\
\text { - } \quad \text { Output } \$(000)\end{array}$ & $\begin{array}{l}\text { - } 10,945 \\
\text { - } 308,123 \\
\text { - } 760,557\end{array}$ \\
\hline $\begin{array}{l}\text { Real Estate } \\
\text { - Employment (FTE) } \\
\text { - } \quad \text { Earnings } \$(000) \\
\text { - Output } \$(000) \\
\end{array}$ & $\begin{array}{ll}- & 2,198 \\
- & 41,656 \\
- & 397,713 \\
\end{array}$ \\
\hline $\begin{array}{l}\text { Annual O\&M } \\
\text { - Employment (FTE) } \\
\text { - } \quad \text { Earnings } \$(000) \\
\text { - } \text { Output } \$(000)\end{array}$ & $\begin{array}{ll}\text { - } & 115 \\
\text { - } & 3,325 \\
\text { - } & 7,317\end{array}$ \\
\hline $\begin{array}{l}\text { Water Supply Benefits for Citrus Irrigation } \\
\text { - Employment (FTE) } \\
\text { - } \quad \text { Earnings } \$(000) \\
\text { - } \quad \text { Output } \$(000)\end{array}$ & $\begin{array}{ll}\text { - } & 96 \\
\text { - } & 2,664 \\
\text { - } & 10,001 \\
\end{array}$ \\
\hline $\begin{array}{l}\text { Impacts of Loss of Citrus \& Sugar Cane } \\
\text { - } \\
\text { - Emnual Output } \$(000) \\
\text { - } \\
\text { Earnings } \$(000) \\
\text { Output } \$(000)\end{array}$ & $\begin{array}{ll}- & (23,457) \\
- & (363) \\
- & (10,427) \\
& (42,454) \\
\end{array}$ \\
\hline
\end{tabular}

Note: Construction, real estate, and O\&M impacts will occur for six years beginning in 2004, while citrus related impacts will occur annually indefinitely.

(Source: USACE/SFWMD, 2002) 


\subsection{Nutrient Over-Enrichment and Its Effects}

As identified in section 2.4, improved water quality, primarily accomplished through nitrogen and phosphorus reductions, is the focus of the IRLS restoration effort. Therefore, it is important to have an understanding of how nutrient over-enrichment affects a waterbody. More often than not, nutrient over-enrichment leads to detrimental effects on a waterbody ${ }^{9}$. It is generally agreed that the primary nutrients that cause adverse impacts to waterbodies are nitrogen and phosphorus (Bricker et al., 1999); (NRC, 2000); and (U.S. EPA, 2001). Excessive inputs of nitrogen and phosphorus lead to several significant direct effects on a waterbody such as decreased light availability, algal dominance changes, and increased organic matter decomposition, which in turn lead to other significant indirect effects ${ }^{10}$ such as loss of submerged aquatic vegetation, harmful algae blooms, low dissolved oxygen (Bricker et al., 1999). These direct and indirect effects from nutrient over-enrichment will therefore lead to economic impacts related to the uses of the waterbody such as fishing, swimming, boating, etc. However, it is important to understand that elevated concentrations of nitrogen and phosphorus do not solely cause adverse impacts on a waterbody, as other biological and physical processes, human influences (e.g., engineered water flow), and some other nutrients play an important role in determining a waterbody's susceptibility to nutrients (Bricker et al., 1999). In their study of national estuaries, Bricker et al. (1999) devised a scoring mechanism to incorporate not only the direct and indirect effects from high nitrogen and

${ }^{9}$ Given a waterbody's physical and biological processes that are occurring, it is possible that increased levels of nutrients can have a positive impact on the waterbody, however this is generally not the case.

${ }^{10}$ It is possible that indirect effects can exist without originating from direct effects (Bricker et al., 1999). 
phosphorus concentrations, but also how these direct and indirect effects are influenced

by spatial coverage and the frequency of high nutrient events, measures of nutrient export potential and susceptibility that incorporated flushing and dilution potentials, as well as a score for human influence factors. The following figure graphically depicts the potential economic impacts caused from increased concentrations of nitrogen and phosphorus.

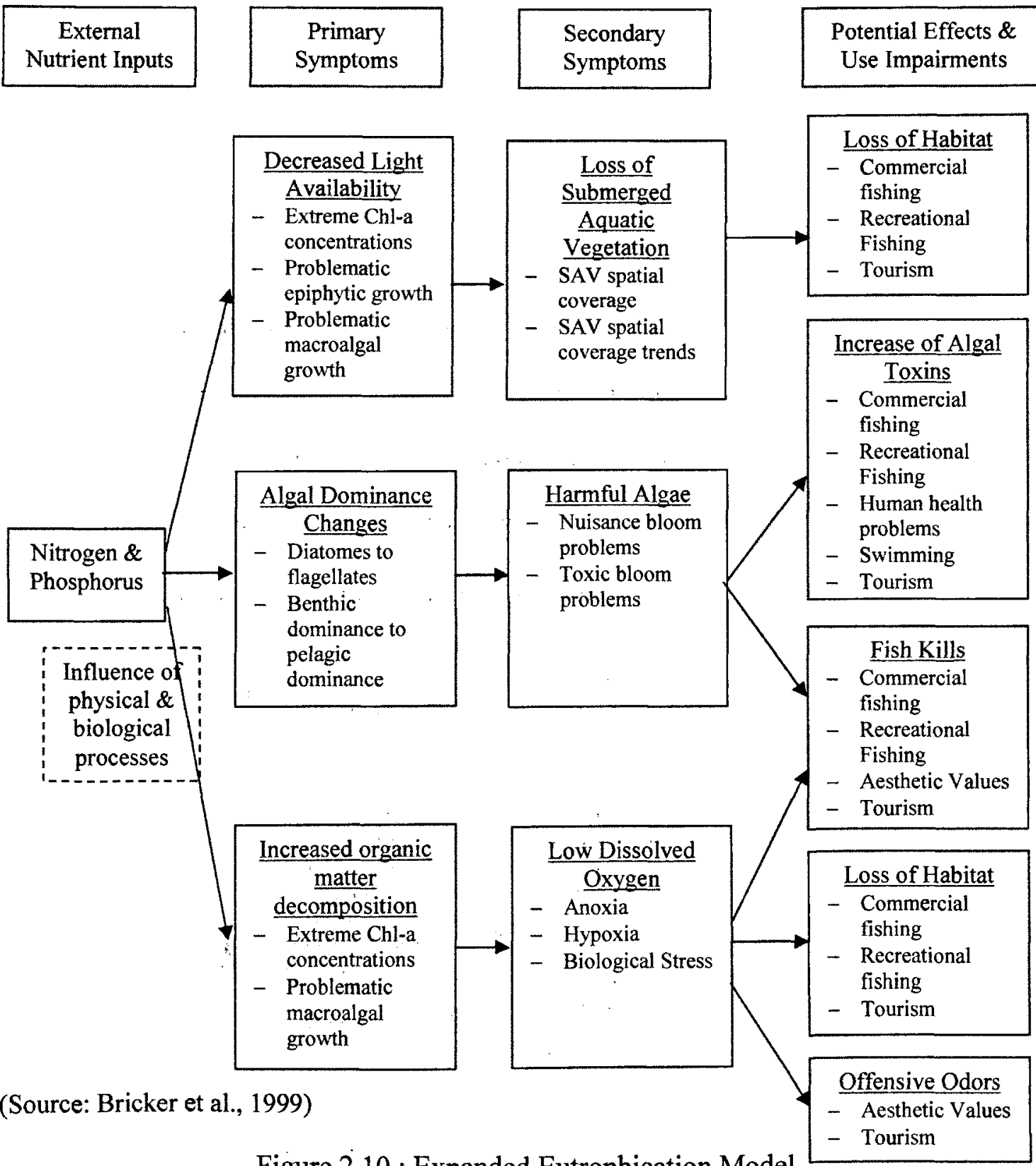

Figure 2.10: Expanded Eutrophication Model 
To understand what would be considered nutrient over-enrichment for nitrogen and phosphorus, one should look at available water quality standards in regard to concentrations of these nutrients. For nitrogen and phosphorus, national water quality standards have not yet been adopted as part of the Clean Water Act ${ }^{11}$. Therefore, best available information has been reviewed here in terms of water quality numeric concentration standards for nitrogen and phosphorus.

Bricker et al. (1999) classified total nitrogen concentrations above $1.0 \mathrm{mg} / \mathrm{l}$ as low quality $^{12}$, between 0.1 and $1.0 \mathrm{mg} / 1$ as medium quality, and $<0.1$ as high quality ${ }^{13}$. Aggregate total nitrogen reference conditions for ecoregions XII, Southern Coastal Plain, and XIII, Southern Florida Coastal Plain based on the $25^{\text {th }}$ percentile are $0.52 \mathrm{mg} / 1$ and $1.27 \mathrm{mg} / 1$ respectively (U.S. EPA, $2000 \mathrm{~A}, \mathrm{~B}$ ) are shown in figure 2.11 below. Jain et al. (1993) classified total phosphorus concentrations above $0.2 \mathrm{mg} / \mathrm{l}$ as bad, $<0.2$ and $>0.1$ $\mathrm{mg} / \mathrm{l}$ as doubtful, $<0.1$ and $>0.05$ as fairly clean, $<0.05$ and $>0.02$ as clean, and $<0.02$ as very clean. Aggregate total phosphorus reference conditions for ecoregions XII, Southern Coastal Plain, and XIII, Southern Florida Coastal Plain based on the $25^{\text {th }}$ percentile are $0.01 \mathrm{mg} / \mathrm{l}$ and $0.017 \mathrm{mg} / \mathrm{l}$ respectively (U.S. EPA, $2000 \mathrm{~A}, \mathrm{~B}$ ) are shown in figure 2.12 below.

\footnotetext{
${ }^{11}$ Under section 304(a) of the Clean Water Act the EPA has provided technical guidance to States and Tribes in developing numeric nutrient criteria. The State of Florida at the time of this writing is in the process of developing these criteria.

${ }^{12}$ The actual classification used was $>1.0 \mathrm{mg} / \mathrm{l}$ equates to a high concentration which is translated here to low quality

${ }^{13}$ The actual classification used was $<0.1 \mathrm{mg} / \mathrm{l}$ equates to a low concentration which is translated here to high quality
} 


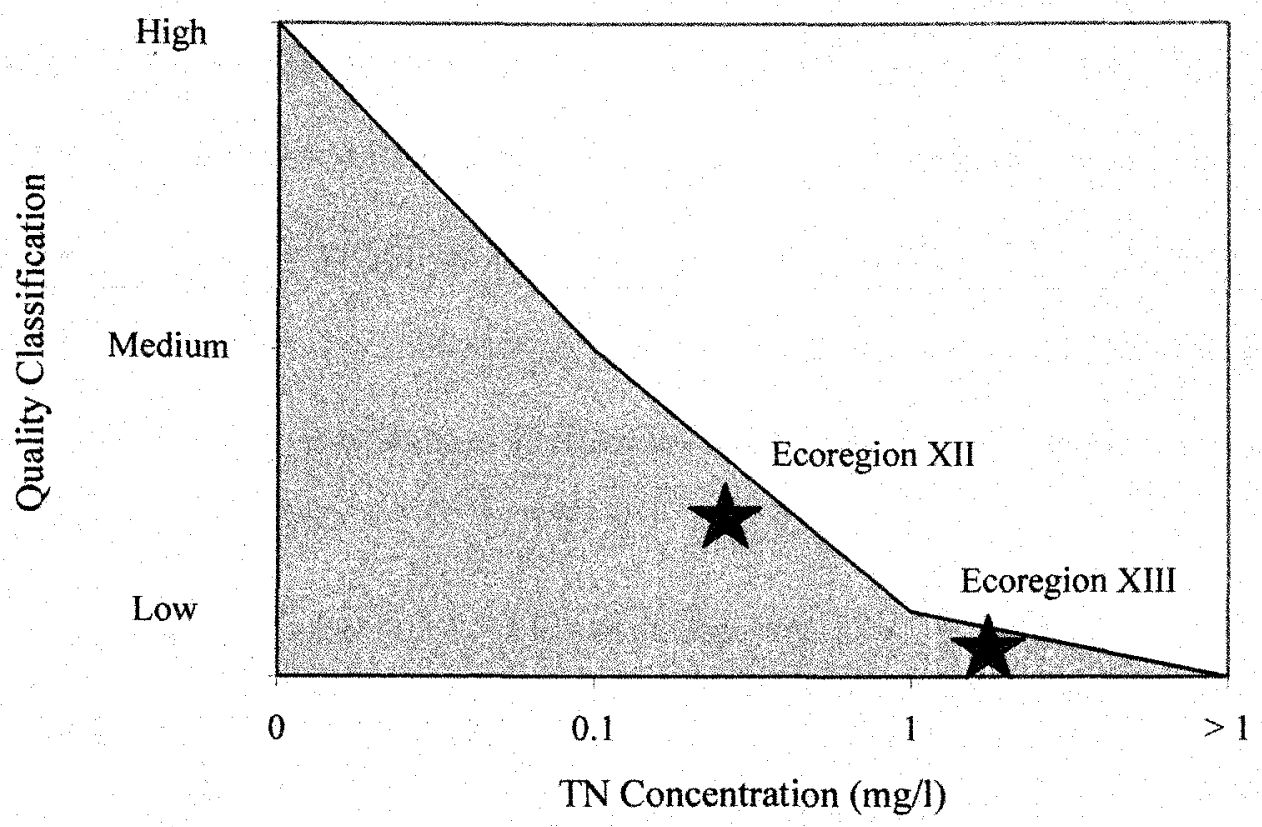

Figure 2.11: Total Nitrogen Concentration Classification

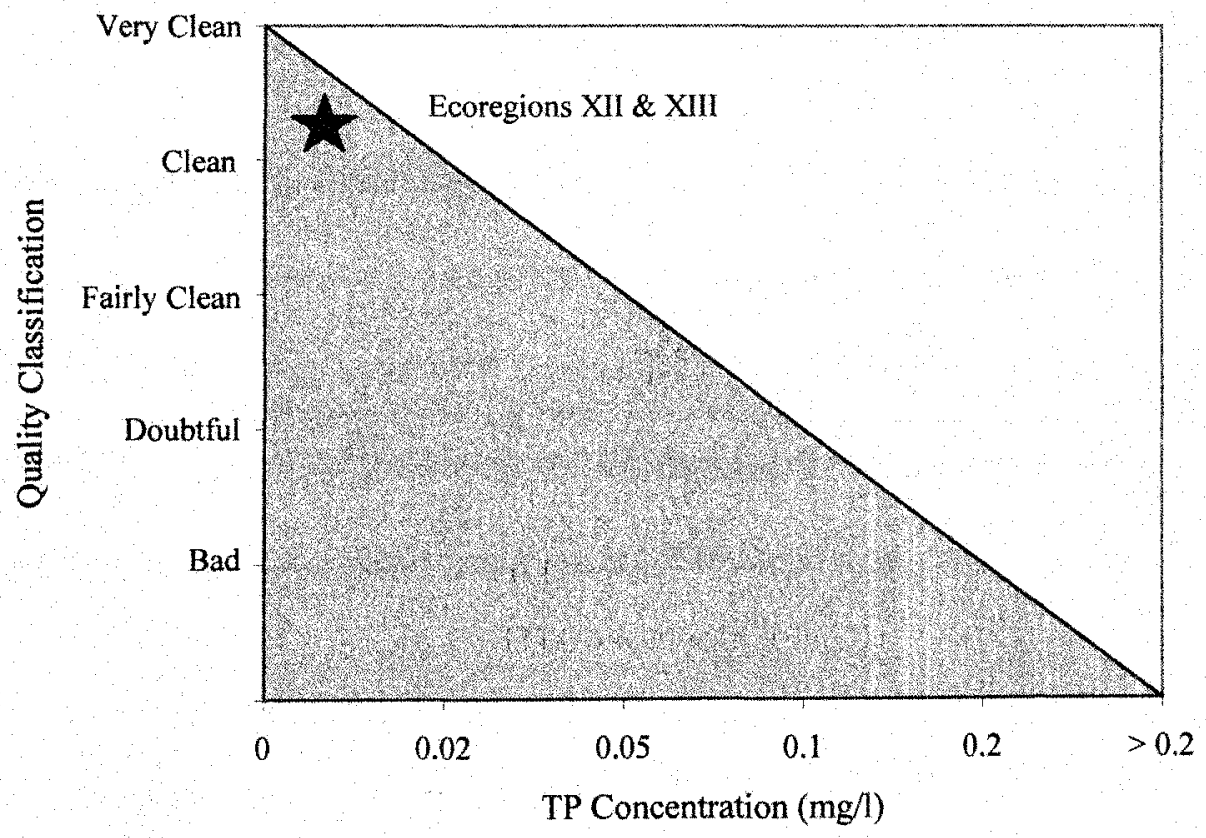

Figure 2.12: Total Phosphorus Concentration Classification 
In addition to classification of overall concentration levels, it is also useful to examine concentrations by designated uses. EPA guidance under the Clean Water Act has outlined four designated uses of water - aquatic life use, primary contact and recreation, fish and shellfish consumption, and drinking water. Section 303(c) of the Clean Water Act requires all states and authorized Tribes to establish designated uses for their waters (U.S. EPA, 2001). The State of Florida has established five classes for their designated uses of water:

Table 2.12: Florida Designated Uses of Water

\begin{tabular}{|c|l|}
\hline Class & Designated Use \\
\hline I & Potable water supplies \\
\hline II & Shellfish propagation for harvesting \\
\hline III & $\begin{array}{l}\text { Recreation, propagation and maintenance of a healthy, } \\
\text { well-balanced population of fish and wildlife }\end{array}$ \\
\hline IV & Agricultural water supplies \\
\hline V & Navigation utility and industrial use \\
\hline
\end{tabular}

(Source: FDEP, 2002)

As overall concentration classifications standards have not been established, it is logical that concentration standards by designated use would not be established as well. Again, one could look to best available information for guidance in this regard. The International Center for the Environmental Management of Enclosed Coastal Seas (2003) has established nutrient standards based on its designated uses. 
Table 2.13: Nutrient Standards by Designated Use

\begin{tabular}{|c|l|c|c|}
\hline Class & Water Use & $\begin{array}{c}\text { Total } \\
\text { Nitrogen } \\
(\mathbf{m g} / \mathbf{l})\end{array}$ & $\begin{array}{c}\text { Total } \\
\text { Phosphorus } \\
(\mathbf{m g} / \mathbf{l})\end{array}$ \\
\hline I & Conservation of the natural environment & 0.2 & 0.02 \\
\hline II & Fishery Class 1, bathing & 0.3 & 0.03 \\
\hline III & Fishery Class 2 & 0.6 & 0.05 \\
\hline IV & Fishery Class 3, Industrial Water & 1 & 0.09 \\
\hline
\end{tabular}

(Source: ICEMECS, 2003)

\section{METHODOLOGY}

\subsection{Overall Methodology Approach}

The methodological approach defined in this section has the ultimate goal of allowing for a cost-benefit analysis to be conducted on the IRLS restoration effort for reasons and objectives stated in section 1 of this study. Following Milon (2002), with a baseline economic value for the IRLS's resources, the difference between an upper value of benefits given the completion of the restoration effort and the lower value of benefits given the absence of the restoration effort, can be estimated ${ }^{14}$. This net benefit of the IRLS restoration effort (graphically depicted in figure 3.1 below) can then be compared with the costs of the restoration effort in a cost-benefit analysis. Applying the high-level methodology described below in conjunction with the economic theory, valuation framework, and valuation techniques discussed in the background section allows for a proper economic analysis of the IRLS restoration effort.

\footnotetext{
${ }^{14}$ The linear growth and/or decrease in benefits over time is illustrative only
} 


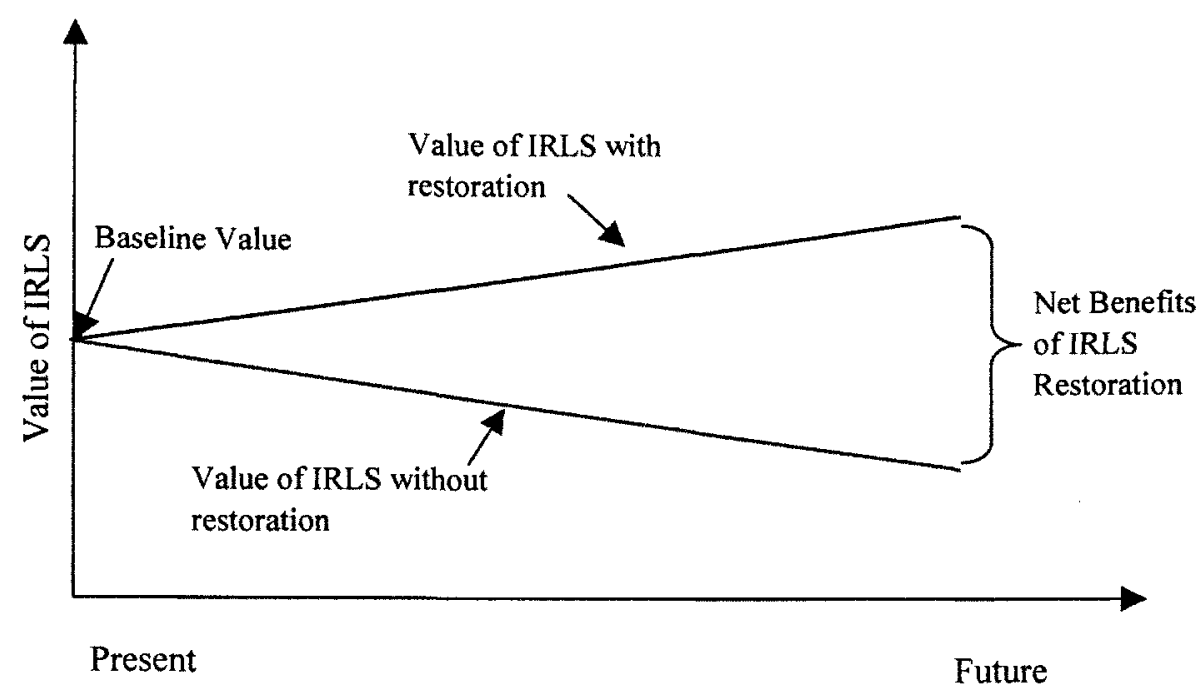

(Source: Milon, 2002)

Figure 3.1: Measuring the Benefit of the IRLS Restoration

Methodology: (i.e., the major steps in monetizing the benefits of the IRLS restoration project)

1) Identify the service flows (uses) of the natural resource;

2) Estimate the baseline economic value of these service flows;

3) Identify appropriate water quality and/or water quantity baseline and relate to standards;

4) Understand how, with and without the restoration effort, the identified service flows will be changed and economically measure the impact of the change(s) to the baseline value;

5) Assess the net benefit of the restoration effort vs. the costs in a economic analysis. 


\subsection{Identifying the Service Flows}

Possible service flows of water, as identified in section 2.2.1, deemed relevant to the IRLS restoration are as indicated by Table 2.10: Identified IRLS National Economic Development Benefits, in section 2.4.

\subsection{Estimating the Baseline}

In January, 1996 Apogee Research, Inc. (1996) in association with Resource Economics Consultants, Inc. submitted a study estimating the total economic value of the Indian River Lagoon, where:

Total Economic Value $=$ Market Value + Nonmarket Value

Market value is comprised of direct use values and nonmarket values are comprised of direct use and passive use values. Indirect market and nonmarket values were not estimated. See Figure 2.1: Total Marshallian WTP - Market and Nonmarket, of section 2.1.1 for a graphical depiction of these values. This study was conducted as part of a larger finance and implementation study initiated by the Indian River Lagoon National Estuary Program (IRLNEP), in their development of a Comprehensive Conservation and Management Plan (CCMP) for the lagoon. The total economic value estimate derived from the study was viewed as a baseline value associated with the different activities and services the lagoon supports. The Indian River Lagoon (IRL) was defined to be the Florida five county region of Volusia, Brevard, Indian River, St. Lucie, and Martin Counties. 
The Apogee study was used as an initial baseline estimate for the purposes of this study. The economic values were split out for the IRLS (St. Lucie and Martin counties), updated for current demographics and adjusted to reflect October 2001 price levels ${ }^{15}$. This section documents the valuation techniques used to estimate the Apogee 1996 baseline and can be considered a methodology that could be employed to estimate a market/nonmarket direct use and passive use baseline for any estuarine related restoration effort. Section 3.4 documents the methodology employed in this research to update the 1996 Apogee baseline to reflect the IRLS and its current demographics, and adjust it to reflect October 2001 price levels.

\subsubsection{Market Direct Use Valuation}

A resident telephone survey and a non-resident intercept survey, were used to elicit the WTP for market direct use values of recreational goods and services. In the surveys, respondents were asked to explicitly state the expenses such as food, supplies and transportation they incurred to undertake a recreational activity in the IRL. Since the respondent had incurred these expenses to participate in the recreational activity, they had revealed their WTP the market price for the recreational goods and services. The surveys were conducted due to a lack of data on participation rates and economic values for IRL related recreational activities among residents and non-residents. 1,000 adult IRL country residents (200 surveys in each of the five IRL counties of Volusia, Brevard,

\footnotetext{
${ }^{15}$ October 2001 is the price level used in the IRLS feasibility study
} 
Indian River, St. Lucie, and Martin) were surveyed via a random digit dialing telephone survey. 500 adult Florida non-residents were surveyed via an intercept survey at five separate popular visitor destinations in the IRL. In both surveys, participation rates, expenditures, and socioeconomic characteristics were collected for purposes of deriving market direct use values for the recreational activities of fishing, shellfishing, swimming, boating, watersports, nature observation, and hunting. A comparison of resident socioeconomic characteristics to the 1990 census data indicated little difference between the survey sample population and the IRL general regional population. In addition, resident sampling error rates of $+/-3 \%$ for the IRL region and $+/-8 \%$ for each country were identified. Therefore, sample results for residents were determined to be able to be directly extrapolated to the regional population segmented by county. Although, socioeconomic characteristics of the non-residents were shown to be very similar to the resident socioeconomic characteristics and sampling error rates were $+/-4.5 \%$, nonresident survey results were evaluated only for the IRL region as a whole, not segmented by county.

In order to obtain resident participation rates and expenditures for the above-mentioned IRL recreational activities, the following set of questions was asked for each activity. Boating questions are given as an example below:

Have you gone boating, other than for fishing, in Florida during the past year?

Can you estimate how many days you went boating, other than for fishing, in Florida last year?

Can you estimate how many of those days were spent boating, other than for fishing, in the IRL? 
On the average day that you were boating, other than for fishing, in the IRL, can you estimate how much money you spent on the following items?

a. Food, drink, refreshments

b. Transportation expenses such as fuels and tolls

c. Boating expenses such as launching fees and small equipment

The results from the above questions allowed for the computation of a participation rate and total average annual expenditures of respondents, which were than multiplied by the county populations in order to generate total IRL annual expenditures by activity.

In order to obtain non-resident participation rates and expenditures for the abovementioned IRL recreational activities, the following set of questions was asked for each activity. The questions were similar to the resident questions, but the staging of the questions was different, as well as the use of a map. Swimming questions are given as an example below:

You indicated that you have been or will be swimming in a river, lake, or ocean on this trip. Have you been or will you be swimming in the IRL?

On this trip, in which county or counties in the IRL did you or do you plan to go swimming?

On this trip, on how many days was swimming or will swimming be your primary recreational activity in the IRL?

On an average swimming day in the IRL how much did you or do you expect to spend on each of the following items:

a. Food, drink, and refreshments

b. Transportation

c. Lodging

d. Other 
The results from the above questions allowed for the computation of a participation rate and total average tourist expenditures per party per trip, which were than multiplied by the estimated number of tourist parties in order to generate total IRL annual expenditures by activity. The estimated number of tourist parties was generated from the total number of visitors to the IRL, $5,982,517$, which is $15 \%$ of the total 39.9 million visitors to Florida in 1994. The 5.9 million visitors to the IRL was further split out by allocating $55 \%$, approximately 3.2 million, to visiting Volusia county, and the other $45 \%$, approximately 2.6 million, to the rest of the region. These two numbers were then divided by the average number of people per party of 2.75 to obtain the estimated number of tourist parties.

\subsubsection{Nonmarket Passive Use Valuation}

A contingent valuation methodology (CVM), via the same resident telephone survey and the same non-resident intercept survey as described above, was also used to elicit the WTP for nonmarket passive use values of IRL recreational goods and services. This was accomplished through additional questions aimed at eliciting respondents' perceptions of the environmental quality of the IRL, opinions of the relative effectiveness of three environmental programs intended to improve the quality of the IRL (wetlands protection, land acquisition, and stormwater management), and their WTP for such programs. Passive use values, or the preferences that individuals may have for natural resources beyond current direct uses of the resource such as the desire to use the resource in the future or know that it exists for others to use in the future, have no market value and can only be measured through nonmarket techniques such as the CVM. 
A double bounded referendum valuation approach was used in both the resident and nonresident surveys. The referendum valuation approach poses questions such as suppose this plan would increase your taxes by $\$$ _ each year, would you vote for or against it? It is double bounded because a follow up vote question is asked with a prespecified higher or lower amount, depending upon whether the initial vote was for or against, respectively. The votes for or against are indirect statements of preferences and imply a value. The value is derived through the investigation of the frequency of the distribution of for responses, which can be used to estimate sample statistics such as the mean and/or median value. The frequency distribution was formally analyzed via a bivariate probit regression analysis for both the resident and non-resident survey responses in this study. The details of this formal analysis were not presented in the report.

For residents, payment for three possible environment improvement programs would occur through an increase in household taxes levied by local governments. A split sample approach was used, with 500 respondents in each sample, in order to investigate the aggregation of individual plan valuations. The first group of 500 respondents was surveyed concerning individual action plans, while the second group was surveyed concerning a composite plan. The predicted mean and median WTP values were multiplied by the number of households by county to generate the aggregate resident passive use values. 
For non-residents, payment for three possible environment improvement programs would occur through a tax on lodging and restaurant bills. A split sample approach was not used, and respondents were only surveyed concerning a composite plan. The predicted mean and median WTP values were multiplied by the estimated number of tourist parties to the IRL, to generate the aggregate resident passive use values. The number of tourist parties estimated is the same process as that described in the non-resident market direct use value of section 3.2 .1 above, however only $25 \%$ of the estimated 3.2 million Volusia county non-residents are used for this estimate. Dividing this value by 2.75 , the average number of people per party, yields a Volusia non-resident tourist party amount of $299,126$.

\subsubsection{Nonmarket Direct Use Valuation}

While the expenditure survey and the CVM, both via the resident telephone survey and the non-resident intercept survey, were used to elicit the WTP for market direct use values as well as nonmarket passive use values of IRL recreational goods and services, the information collected in the survey was not sufficient to estimate the nonmarket direct use values associated with these recreational goods and services. Nonmarket direct use values for recreational goods and services are the values representing access to the goods and services, i.e., consumer surplus, and are separate from the market costs of these goods and services,. For example, due to the public nature of a recreational good such as fishing in a lagoon, an angler derives value from going fishing in the lagoon but is not required to make an explicit payment for the right to fish in the lagoon, while he would incur market costs for items such as fishing equipment, 
bait, etc. The amount an angler would be willing to pay to have access to fish in the lagoon would be considered the nonmarket direct use value of recreational fishing. Using data from a previous and separate study, Apogee research applies a nested random utility model (RUM) in order to estimate the resident nonmarket direct use values of recreational fishing in the IRL.

RUMs attempt to identify the reasons a person chooses a specific recreational site to visit from amongst a set of other available and differentiated recreational sites, i.e., substitute sites. The selection of the chosen recreational site is based on the maximization of utility of the following general function:

$$
P V_{i j}=P V_{i j}\left(P_{i j}, P_{i k}, Q_{i j}, Q_{i k}, X_{i}\right)
$$

where: $\quad P_{\mathrm{ij}}=$ probability of individual $i$ choosing site $j$

$P_{i j}=$ travel costs incurred from using the $j$ th site by the $i$ th person

$Q_{i j}=$ vector of quality attributes site $j$

$\mathrm{P}_{\mathrm{ik}}$ and $\mathrm{Q}_{\mathrm{ik}}$ are the travel costs and qualities at competing sites

$\mathrm{X}_{\mathrm{i}}=$ vector of socio-economic variables for the ith individual

A nested structure was chosen in order to model the decision process in an iterative fashion, as opposed to a non-nested structure that models the decision process simultaneously. The nested indirect utility function applied in the study is of the following general form:

$$
\mathrm{V}_{\mathrm{ims}}=\beta \mathrm{Z}_{\mathrm{ims}}+\beta \mathrm{W}_{\mathrm{ms}}+\varepsilon_{\mathrm{ims}}
$$

where: $\quad V_{\mathrm{ims}}=$ indirect utility associated with choosing site $\mathrm{i}$, area $\mathrm{m}$, and targeting species $\mathbf{S}$

$Z_{\text {ims }}=$ a set of attributes at site $\mathrm{i}$ based on area $\mathrm{m}$ and species $\mathrm{s}$

$\mathrm{W}_{\mathrm{ms}}=$ set of variables that vary only with mode and species 
The model applied in the study has 75 separate elemental choices, with each choice representing a specific county, mode and target species. Brevard, Indian River, Volusia, St. Lucie, and Martin counties represent the 5 counties an angler can choose from. Shore, nearshore, and offshore are the 3 modes. Redfish, snook, trout, nearshore, and offshore are the 5 targeted species. The seven variables affecting these choices include, expected catch rates, travel costs, modal costs, a binary boat specific constant and the three dummy variables of winter months, boat ownership and income. The data used for the analysis came from a previous survey that identified 422 anglers that live and fish in the specified lagoon counties accounting for 2,143 shore trips, 912 nearshore trips, and 753 offshore trips.

From an iterative perspective, the initial decision is whether to use a boat or not (b), which is based on boat ownership (BOAT), income (INC), the season of the year (WIN), and the binary boat constant (BT).

$$
\begin{gathered}
\operatorname{Prob}(\mathrm{b})=\left[\exp \left(\beta_{\mathrm{i}} \mathrm{BT}+\beta_{\mathrm{i}} \mathrm{INC}+\beta_{\mathrm{i}} \mathrm{WIN}+\beta_{\mathrm{i}} \mathrm{BOAT}+(1-\sigma) \mathrm{IV}_{\mathrm{cms}}\right] /\right. \\
{\left[\Sigma \exp \left(\beta_{\mathrm{j}} \mathrm{BT}+\beta_{\mathrm{j}} \mathrm{INC}+\beta_{\mathrm{j}} \mathrm{WIN}+\beta_{\mathrm{j}} \mathrm{BOAT}+(1-\sigma) \mathrm{IV} \mathrm{V}_{\mathrm{cms}}\right]\right.}
\end{gathered}
$$

The choice of county/mode/species conditional on which boat choice is made ( $\mathrm{cms} \mid \mathrm{b})$ is based on distance to the counties (DIST), modal costs (COST), and the catch rates (CR). Catch rates were estimated themselves through an ordinary least squares regression analysis.

$$
\begin{aligned}
\operatorname{Prob}(\mathrm{cms} \mid \mathrm{b})=\quad & {\left[\exp \left(\left(\beta_{\mathrm{i}} \mathrm{CR}+\beta_{\mathrm{i}} \mathrm{DIST}+\beta_{\mathrm{i}} \mathrm{COST}\right) /(1-\sigma)\right)\right] / } \\
& {\left[\exp \left(\left(\beta_{\mathrm{j}} \mathrm{CR}+\beta_{\mathrm{j}} \mathrm{DIST}+\beta_{\mathrm{j}} \mathrm{COST}\right) /(1-\sigma)\right)\right] }
\end{aligned}
$$

A graphical depiction of the iterative process is given below: 


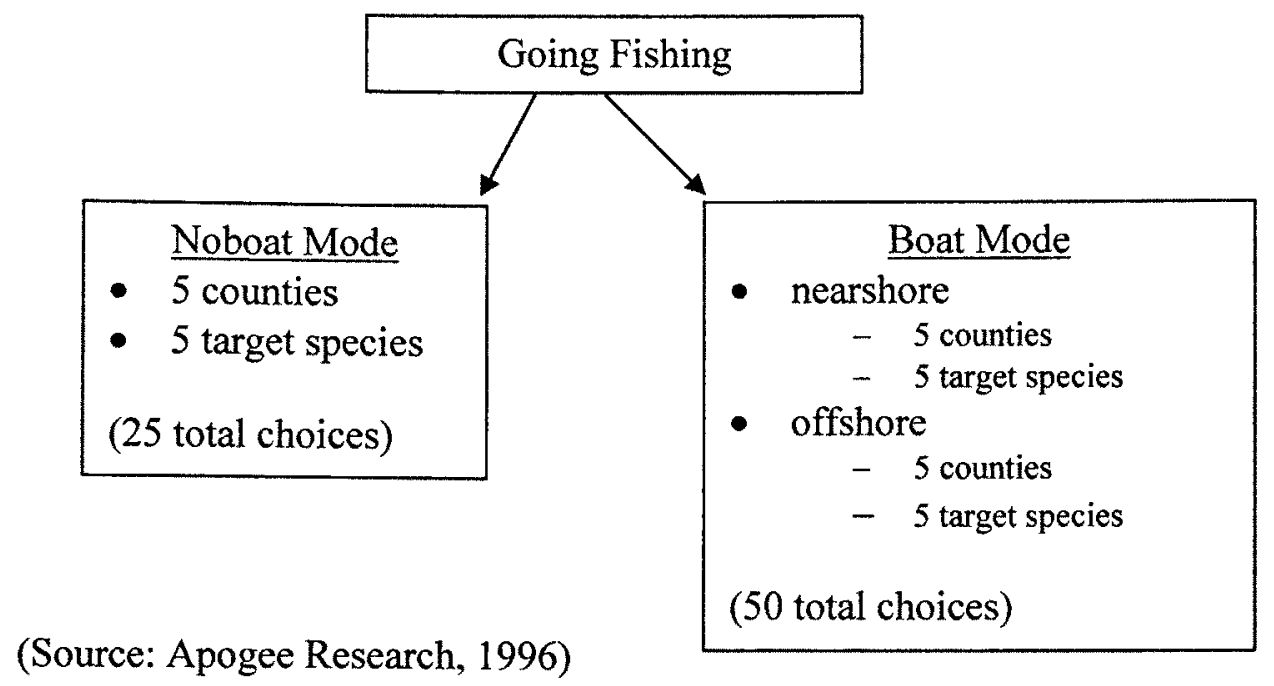

Figure 3.2: Apogee Research RUM Iterative Process

$\mathrm{Q}$, the expected maximum utility, i.e., the economic value of access to the lagoon, can be determined from the above boat and county/mode/species choices in the following equation:

$$
\begin{aligned}
\mathrm{Q}= & {\left[\sum \exp \left(\beta_{\mathrm{b}} \mathrm{BT}+\beta_{\mathrm{b}} \mathrm{INC}+\beta_{\mathrm{b}} \mathrm{WIN}+\beta_{\mathrm{b}} \mathrm{BOAT}\right)+\left(\Sigma \operatorname { e x p } \left(\beta_{\mathrm{cms}} \mathrm{CR}+\beta_{\mathrm{cms}} \mathrm{DIST}\right.\right.\right.} \\
& \left.\left.\left.+\beta_{\mathrm{cms}} \mathrm{COST}\right) /(1-\sigma)\right)^{1-\sigma}\right]
\end{aligned}
$$

Average annual access values per angler in county of residence and for the IRL as a whole were determined. Lack of data and project scope issues dictated that similar analyses for non-residents as well as the other recreational activities of the lagoon; swimming, boating, nature observation, water sports, and hunting, were not conducted as part of this study. Therefore, the nonmarket direct use values for these activities are not included and the values for recreational fishing can be considered a lower bound for the total nonmarket direct use values of the IRL. 


\subsubsection{Riverfront Residential Land Value}

The premise for this economic value is that the value people have for a waterbody, such as the IRL, is partially capitalized (the present value of the stream of benefits obtained from the land over the anticipated ownership period) in the price of the land in relation to the proximity to the waterbody. That is, the closer the land is to the waterbody, the higher the price of land is expected to be. For this study, the difference between the aggregate value of IRL riverfront land and the aggregate value of parcels disconnected from the riverfront represents the capitalized value that residents have for the IRL, which is a component of the total value of the IRL.

The just value of land and the just value of structures/improvements to the land were collected by parcel from each of the five counties appraisers' office. The derivation of the capitalized value of the IRL came from the just value of the land only and therefore did not include the appraised value of parcels identified as condominiums. Land parcels were further delineated between riverfront and non-riverfront properties. Riverfront property was defined as being a location on the waterfront of the IRL and its estuarial tributaries, and actually having direct riverbank footage.

In the absence of acreage per parcel data, the value of riverfront and non-riverfront parcels were aggregated and the average value per parcel was derived. The difference between riverfront parcels and non-riverfront parcels was then multiplied by the number

of riverfront parcels, to generate the value of land attributed to river-frontage. As appraised values represent $85 \%$ of market value, the value of land attributed to river- 
frontage was divided by 0.85 in order to estimate the total market value. Only half of the value of land attributable to river-frontage was included for Volusia County, as half of the county land lies outside the IRL region. Also, values for Martin and Volusia Counties were extrapolated from the data from the other three counties.

The capitalized values were than converted into annual values for analytical purposes. This was accomplished by multiplying the capitalized values by a discount rate of $4 \%$, the risk-free interest rate from 30-year U.S. government bonds, $6.6 \%$, minus the 1994 rate of inflation, $2.6 \%$.

\subsubsection{Commercial Fishing Value}

Annual dockside values of landings of both shellfish and finfish were collected for the IRL region. These values were used directly as the commercial fishing value.

\subsection{Updating the Initial Baseline}

The IRLS feasibility study (USACE/SFWMD, 2002) proposes restoration projects associated with the southern portion of the IRL, specifically St. Lucie and Martin Counties, with costs given at October 2001, price levels. Therefore, in order to properly update the Apogee Research initial baseline estimate to use as a baseline estimate for a cost-benefit analysis of the IRLS feasibility study, the Apogee Research baseline values need to be split out for St. Lucie and Martin counties (the IRLS), updated for current demographics and adjusted to reflect October 2001 price levels. This section documents the methodology and assumptions used to accomplish this. 


\subsubsection{Socioeconomic Comparison}

In order to verify that their survey sample was representative of the IRL region and therefore to be able to directly extrapolate the results from the resident telephone and non-resident intercept surveys to the IRL region general population, Apogee research conducted a socioeconomic characteristic comparison of their survey sample to the IRL region by county, with the county socioeconomic characteristics obtained from 1990 census data. Socioeconomic characteristics compared included age, gender, ethnicity, education, income, and household related data. To be able to again extrapolate the survey data to the current IRLS population, the same socioeconomic comparison needs to be made using the more recent 2000 census data. Apogee research also analyzed the socioeconomic characteristics of non-residents surveyed, comparing them to the resident survey results, and concluded that the socioeconomic characteristics of non-residents were similar to the resident sample. For this study, non-resident socioeconomic information was collected where available and compared to the non-resident results from the Apogee Research study. After confirming that the socioeconomic characteristics from the survey are applicable to the current resident and non-resident socioeconomic characteristics, it is possible to update the values from the surveys.

\subsubsection{Updating Market Direct Use Values}

Apogee Research resident market direct use values were split out by county, so the necessary steps for updating resident values is rather straightforward, i.e., obtain recent population statistics and adjust expenditures for inflation. However, a number of assumptions concerning the data still need to be made, namely: 
- Average daily expenditures have remained constant over time, excluding adjustments for inflation

- Survey IRL participation rates and number of days participating annually have remained constant over time ${ }^{16}$

- Indicated IRL survey participation rates coincide to participation in the respondent's county of residence (Participation rates from the survey were collected for the IRL region as a whole as shown in section 3.3.1)

Given these assumptions, the formula for the derivation of the updated market direct use values by county for residents $\left(M D_{R}\right)$ is explicitly given as:

$$
M D_{R}=\left(P_{i}\right) \times\left(\% P_{P A R T}\right) \times\left(E X P_{R}\right)
$$

where: $\quad$ POP $_{\mathrm{i}}=$ adult population of county $\mathrm{i}^{17}$

$\% \mathrm{PART}=\%$ of the resident adult population participating in the IRL ${ }^{18}$ $\mathrm{EXP}_{\mathrm{R}}=$ total average annual expenditures of resident ${ }^{19}$

The original non-resident market direct use values were not split out by county as it was reasoned that non-residents may visit more than one county within the region and therefore the results should only be evaluated for the IRL region, not by county. However, as participation rates by county were collected in the intercept survey and the purpose of this effort is to estimate a benefit estimate specifically for the IRLS, the

\footnotetext{
${ }^{16}$ Participation rates and number of days participating does not factor in any increases or decreases to the water quality or quantity of the IRL since the time of the Apogee Research study, factors that may have affected participation since the 1996 study and today as indicated in the background section

${ }_{17}$ Adult population estimates are as of January 1, 2003 and obtained from the Florida Office of Economic and Demographic Research.

${ }^{18}$ Participation rates are as given from the Apogee Research (1996) resident telephone survey

${ }^{19}$ Total average annual expenditure are as given from the Apogee Research (1996) resident telephone survey and adjusted for inflation according to $\left(1995 \mathrm{EXP}_{\mathrm{R}}\right) \times($ Oct $2001 \mathrm{CPI} / 1995$ average CPI)
} 
participation rates collected will be used under the assumption that the county indicated in the survey was the primary county where the recreational activities occurred. Other assumptions need to be made for the non-resident benefit estimate, namely:

- $15 \%$ of total non-resident visitors to Florida, traveled to visit the IRL ${ }^{20}$

- $55 \%$ of the total IRL visitors were allocated to Volusia County with the remaining $45 \%$ split amongst the other four counties ${ }^{21}$

- Average daily expenditures have remained constant over time, excluding adjustments for inflation

- Survey IRL participation rates and number of days participating in an activity have remained constant over time $\mathrm{e}^{22}$

- Average number of people per party (2.75) has remained constant over time

Given these assumptions, the formula for the derivation of the updated market direct use values by county for non-residents $\left(\mathrm{MD}_{\mathrm{NR}}\right)$ is explicitly given as:

$$
\mathrm{MD}_{\mathrm{NR}}=(\mathrm{TP}) \times\left(\% \mathrm{PART}_{\mathrm{NR}}\right) \times\left(\mathrm{EXP}_{\mathrm{NR}}\right)
$$

where: $\quad T P=$ estimated \# of tourist parties to IRL net of Volusia County

$$
=[(76.2 \text { million }) \times(45 \%) / 2.75]
$$

as the total number of non-resident visitors to Florida for all of 2002 was 76.2 million $^{23}, 45 \%$ is the amount of visitors allocated to

\footnotetext{
${ }^{20}$ This assumption was held from the original Apogee Study

${ }^{21}$ This assumption was held from the original Apogee Study

${ }^{22}$ Participation rates and number of days participating does not factor in any increases or decreases to the water quality or quantity of the IRL since the time of the Apogee Research study, factors that may have affected participation since the 1996 study and today as indicated in the background section

${ }^{23}$ Provided by Visit Florida, the official tourism marketing corporation for the State of Florida. However, it should be noted that Visit Florida did not begin to track visitor data with its current system until July of 1999 , and when this occurred there was a significant increase in the number of visits assumed due to the
} 
non-Volusia counties as given in the assumptions above, and 2.75 is the average number of people per party as given in the assumptions above

$\% \mathrm{PART}_{\mathrm{NR}}=\%$ of the non-resident adult population participating in the IRL by county ${ }^{24}$

$\mathrm{EXP}_{\mathrm{NR}}=$ total average tourist expenditures per party per trip ${ }^{25}$

\subsubsection{Updating Nonmarket Passive Use Values}

The original resident nonmarket passive use values were split out by county, so the necessary steps for updating resident values is rather straightforward, i.e., obtain recent number of household statistics and adjust WTP estimations for inflation. However, a number of assumptions concerning the data still need to be made, namely:

- The three composite action plans used to determine WTP for the plans, and hence passive use values, are still relevant ${ }^{26}$

- WTP estimates reflected through increased tax payments have remained constant over time, excluding adjustments for inflation

- Updated values do not affect statistical results achieved from the original bivariate probit regression analysis

improved quality of the tracking system. The original study had obtained its estimate from the FL Dept of Commerce, which became privatized to Visit Florida in 1996.

${ }^{24}$ Participation rates are as given from the Apogee Research (1996) non-resident intercept survey

${ }^{25}$ Total average tourist expenditures per party per trip are as given from the Apogee Research (1996) nonresident intercept survey and adjusted for inflation according to (1995 $\left.\mathrm{EXP}_{\mathrm{NR}}\right) \times($ Oct $2001 \mathrm{CPI} / 1995$ average $\mathrm{CPI}$ )

${ }^{26}$ IRLS Feasibility study objectives as stated in section 2.4 reflects this as valid, as does personal investigation of the area 
Given these assumptions, the formula for the derivation of the updated nonmarket passive use values by county for residents $\left(\mathrm{NMP}_{\mathrm{R}}\right)$ is explicitly given as:

$$
\mathrm{NMP}_{\mathrm{R}}=\left(\mathrm{HH}_{\mathrm{i}}\right) \times\left(\mathrm{WTP}_{\mathrm{R}}\right)
$$

where: $\quad \mathrm{HH}_{\mathrm{i}}=\#$ of households per county $\mathrm{i}^{27}$

$$
\mathrm{WTP}_{\mathrm{R}}=\text { resident median } \mathrm{WTP}^{28}
$$

Similar to the non-resident market direct use values, the original non-resident nonmarket passive use values were not split out by county. However, as participation rates by county were collected in the intercept survey, and the purpose of this effort is to estimate a benefit estimate specifically for the IRLS, the participation rates collected will be used to assign passive use values by county. Other assumptions need to be made for the nonresident benefit estimate, namely:

- $15 \%$ of total non-resident visitors to Florida, traveled to visit the IRL ${ }^{29}$

- $55 \%$ of the total IRL visitors are allocated to Volusia County with the remaining $45 \%$ split amongst the other four counties ${ }^{30}$

- Average number of people per party (2.75) has remained constant over time

- The three composite action plans used to determine WTP for the plans, and hence passive use values, are still relevant ${ }^{31}$

\footnotetext{
${ }^{27}$ Estimates are as of April 1, 2002 and were obtained from the Florida Bureau of Economic and Business Research, Florida Population Studies, Volume 36, Number 2, Bulletin 135

${ }^{28}$ Resident median WTP is as given from the Apogee Research (1996) resident telephone survey and adjusted for inflation according to $\left(1995 \mathrm{WTP}_{\mathrm{R}}\right) \times$ (Oct $2001 \mathrm{CPI} / 1995$ average CPI)

29 This assumption was held from the original Apogee Study

${ }^{30}$ This assumption was held from the original Apogee Study

31 IRLS Feasibility study objectives as stated in section 2.4 reflects this as valid, as does personal investigation of the area
} 
- WTP estimates reflected through increased lodging and dining tax payments have remained constant over time, excluding adjustments for inflation

- Updated values do not affect statistical results achieved from the original bivariate probit regression analysis

- An average of the participation rates collected in the survey is a relevant proxy for splitting out the 1995 WTP passive use values by county

Given these assumptions, the formula for the derivation of the updated nonmarket passive use values by county for non-residents $\left(\mathrm{NMP}_{\mathrm{NR}}\right)$ is explicitly given as:

$$
\mathrm{NMP}_{\mathrm{NR}}=(\mathrm{TP}) \times\left(\mathrm{WTP} \mathrm{NR}_{\mathrm{N}}\right)
$$

where: $\quad \mathrm{TP}=$ estimated \# of tourist parties to IRL net of Volusia County

$$
=[(76.2 \text { million }) \times(45 \%) / 2.75]
$$

as the total number of non-resident visitors to Florida for all of 2002 was 76.2 million ${ }^{32}, 45 \%$ is the amount of visitors allocated to non-Volusia counties as given in the assumptions above, and 2.75 is the average number of people per party as given in the assumptions above

$\mathrm{WTP}_{\mathrm{NR}}=$ non-resident median $\mathrm{WTP}^{33}$

\footnotetext{
${ }^{32}$ Provided by Visit Florida, the official tourism marketing corporation for the State of Florida. However, it should be noted that Visit Florida did not begin to track visitor data with its current system until July of 1999 , and when this occurred there was a significant increase in the number of visits assumed due to the improved quality of the tracking system. The original study had obtained its estimate from the FL Dept of Commerce, which became privatized to Visit Florida in 1996.

${ }^{33}$ Non-resident median WTP is as given from the Apogee Research (1996) non-resident intercept survey and adjusted for inflation according to (1995 WTP $\left.\mathrm{WR}^{\mathrm{i}}\right) \times$ (Oct $2001 \mathrm{CPI} / 1995$ average CPI)
} 


\subsubsection{Updating Nonmarket Direct Use Values}

Although the original study estimated resident nonmarket direct use values at a county level, the estimates were meant to reflect the entire IRL as opposed to individual counties. Again, as the purpose of this update is to estimate a benefit estimate specifically for the IRLS, a methodology was developed in order to accomplish this, i.e., to estimate nonmarket direct use values by county. The assumptions made for the updated nonmarket direct use benefit estimation are the following:

- Access values derived by the RUM are not affected by updated population figures and therefore can be adjusted for inflation to make current

- Participation rates have remained constant over time $\mathrm{e}^{34}$

- Allocating $25 \%$ of the net access value for the IRL system value that was identified for each county is a reasonable allocation method

Given these above assumptions, the formula for the derivation of the updated nonmarket direct use values by county for residents $\left(N M D_{R}\right)$ is explicitly given as:

$$
\begin{aligned}
& \mathrm{NMD}_{\mathrm{R}}=\left(\mathrm{POP}_{\mathrm{i}}\right) \times\left(\% \mathrm{PART}_{\mathrm{R}}\right) \times\left(\mathrm{AV}_{\mathrm{C}}\right)+\Sigma\left[\left(\mathrm{POP}_{\mathrm{i}}\right) \times\left(\% \mathrm{PART}_{\mathrm{R}}\right) \times\left(\mathrm{AV}_{\mathrm{IRL}}\right)\right]- \\
& {\left[\left(\mathrm{POP}_{\mathrm{j}}\right) \times\left(\% \mathrm{PART}_{\mathrm{R}}\right) \times\left(\mathrm{AV}_{\mathrm{C}}\right)\right] * 25 \% \text { for all other } 4 \text { counties }}
\end{aligned}
$$

where: $\quad$ POP $_{\mathrm{i}}=$ adult population of county $\mathrm{i}^{35}$

$\% \mathrm{PART}=\%$ of the resident adult population participating in the IRL ${ }^{36}$

$A V_{C}=$ Access value for IRL in county of residence ${ }^{37}$

\footnotetext{
${ }^{34}$ Participation rates do not factor in any increases or decreases to the water quality or quantity of the IRL since the time of the Apogee Research study, factors that may have affected participation since the 1996 study and today as indicated in the background section

${ }^{35}$ Adult population estimates are as of January 1, 2003 and obtained from the Florida Office of Economic and Demographic Research.

${ }^{36}$ Participation rates are as given from the Apogee Research (1996) resident telephone survey
} 


$$
\mathrm{AV}_{\mathrm{IRL}}=\text { Access value for IRL system }{ }^{38}
$$

\subsubsection{Updating Riverfront Residential Land Value}

In order to properly update the riverfront residential land value, i.e., to account for the growth in the population and the associated land use changes, the original methodology would need to be reapplied as a whole. At a minimum, the original values can be simply adjusted for inflation to attempt to account for the change in land value. Again, these values are meant to be minimum values and not necessarily representative. The formula for the derivation of the updated riverfront residential land values by county holding the discount rate constant at $4 \%$ is explicitly given as:

$\left(\mathrm{LV}_{\mathrm{i}}\right) \times($ Oct $2001 \mathrm{CPI} / 1995$ average $\mathrm{CPI})$

where: $\quad L V_{i}=1995$ Annualized Land Value by County

\subsubsection{Updating Commercial Fishing Values}

The formula for the derivation of the updated commercial fishing values is explicitly given as:

$\left(\mathrm{CF}_{\mathrm{i}}\right) \times($ Oct $2001 \mathrm{CPI} / 1995$ average $\mathrm{CPI})$

where: $\quad C F i=$ the 1995 estimated commercial fishing value is the per county 1992 $\%$ of the total landing values applied to the total 1994 landing value for the region, as landing value data by county was only given for 1992 .

${ }^{37}$ As given by RUM and adjusted for inflation according to (1995 $\left.\mathrm{AV}_{\mathrm{C}}\right) \times($ Oct $2001 \mathrm{CPI} / 1995$ average CPI)

${ }^{38}$ As given by RUM and adjusted for inflation according to (1995 $\left.\mathrm{AV}_{\mathrm{IRL}}\right) \times($ Oct $2001 \mathrm{CPI} / 1995$ average CPI) 


\subsection{Additional Baseline Values To Be Addressed}

Several gaps exist concerning the values that were addressed in the Apogee Research (1996) baseline estimate, including:

- Non-resident nonmarket direct use fishing value

- Resident and non-resident nonmarket direct use values for all other recreational activities except fishing

- All use and non-use value for residents of Florida that live outside the five-county IRL region (approximately 15 million people)

- Lack of a hedonic pricing analysis for residential land values

Furthermore, referencing the total economic valuation framework in section 2.1 .2 , the Apogee Research 1996 study did not include the valuation of any indirect use values. Therefore, the baseline (and updated baseline) can be considered a lower bound estimate. As this study will develop benefit values above the baseline estimate for a cost-benefit analysis, as described in section 3.1 , the nonmarket direct use values mentioned above will be estimated via a benefit transfer approach for comparative purposes.

As per section 3.4.2, updated resident market direct use values $\left(M D_{R}\right)$ are determined according to formula (3.7):

$$
\mathrm{MD}_{\mathrm{R}}=\left(\mathrm{POP}_{\mathrm{i}}\right) \times\left(\% \mathrm{PART}_{\mathrm{R}}\right) \times\left(\mathrm{EXP}_{\mathrm{R}}\right)
$$

where:

$\operatorname{EXP}_{\mathrm{R}}=$ (average annual \# of days participating in activity) $\mathrm{x}$ (total average daily expenditure). 
And updated non-resident market direct use values $\left(\mathrm{MD}_{\mathrm{NR}}\right)$ are determined according to formula (3.8):

$$
\mathrm{MD}_{\mathrm{NR}}=(\mathrm{TP}) \times\left(\% \mathrm{PART}_{\mathrm{NR}}\right) \times\left(\mathrm{EXP}_{\mathrm{NR}}\right)
$$

where: $\quad \mathrm{EXP}_{\mathrm{NR}}=($ Median $\#$ of days participating in activity) $\mathrm{x}$ (total average daily expenditure)

Net economic values, i.e., nonmarket values, per recreation day for the relevant IRLS recreation activities as given by Walsh et al. (1992) adjusted for inflation, replace total average daily expenditure given in the above formulas to generate the missing IRLS nonmarket updated baseline values.

\subsection{Water Quality Baseline Assessment}

Establishing the water quality baseline is essential to properly estimating the magnitude of change for a given water quality improvement. However, often times in the economic literature, even though a particular pollutant may be built into a demand analysis, little discussion will be devoted to the pollutant's baseline, especially in the context of its water quality standards. Frequently either water quality improvements will be taken as given according to a mandated policy, or hypothetical improvements will be modeled. Two water quality baselines for the IRLS were developed in order to form the basis for IRLS benefit estimation due to the proposed water quality improvements. These water quality baselines are described below.

As discussed in section 2.5 , the primary nutrients that cause adverse impacts to waterbodies are nitrogen and phosphorus, and as discussed in section $2.4,41 \%$ 
phosphorus and $26 \%$ nitrogen load reductions have been identified as main benefits of the IRLS restoration. Therefore, it is important to establish the nitrogen and phosphorus concentration water quality baseline for the IRLS. This is done by comparing IRLS water quality data (USACE/SFWMD, 2002) to the water quality standards for nitrogen and phosphorus as detailed in section 2.5. In addition, the eutrophication study conducted by Bricker et al. (1999) is referenced for further insight in regard to IRLS nutrient-overenrichment issues. Furthermore, a baseline assessment for a similar waterbody, the Albemarle and Pamlico Sound, will be presented in order to incorporate relevant data related to this waterbody into this analysis (to be described in section 3.7.1).

Under section 303(d) of the Federal Clean Water Act and the 1999 Florida Watershed Restoration Act, total maximum daily loads must be developed for all waters that do not meet their designated uses, and hence are defined as impaired (FDEP, 2003). Under section 305(b) of the Federal Clean Water Act, a biennial assessment of waterbodies occurs in order to officially designate waters as impaired, placing them on the 303(d) list of impaired waters (FDEP, 2003). Therefore, another aspect of the IRLS water quality baseline, $\%$ of waterbody that is impaired (or rated good or not good following the methodology described in Magat et al. (2000)), is developed through an analysis of the 2000305 (b) list and the FDEP Basin Report (2003). Total miles, square miles, and acres of rivers, estuaries, and lakes respectively for the IRLS are developed with their associated $\%$ good and $\%$ not good. 
These two baseline estimates play a significant role in the estimation of benefits from the proposed water quality improvements as described in the next section.

\subsection{Impact Assessment to Updated Baseline Estimate}

As per the economic theory described in section 2.1.1, an individual maximizes his utility according to a specified budget constraint. For example, given that an individual's utility is a function of the number of trips taken to a recreation site $\left(\mathrm{x}_{\mathrm{j}}\right)$, the quality of the site as measured by some indicative quality variable $\left(q_{j}\right)$, and a vector of all other goods (Z), this utility will be maximized according to the budget constraint that the vector of all other goods $(Z)$ plus the price per trip multiplied by the number of trips $\left(\mathrm{p}_{\mathrm{j}} \mathrm{x}_{\mathrm{j}}\right)$ is equal to his income (y). Explicitly, this is given as:

Maximize $U\left(x_{j}, q_{j}, Z\right)$ subject to $y=\dot{Z}+p_{j} x_{j}$

The solution to this maximization problem yields a system of Marshallian demand functions of the form $x_{j}\left(p_{j}, q_{j}, y\right)$, where the demand for trips is increasing with quality and income, and decreasing in price. Therefore, given an increase in quality from $\mathrm{q}^{0}$ to $\mathrm{q}^{1}$, the demand curve will shift to the right to reflect the increased demand for trips due to a higher quality level. The increased demand for trips translates into an increase in the market value by $(\mathrm{p} \Delta \mathrm{x})$. Also, as the area under the demand curve but above the price reflects the nonmarket value to a consumer, a shift to the right of a demand curve due to a quality improvement increases the nonmarket value as well (Whitehead et al., 2000). A graphical depiction of this value change is given in the below figure: 


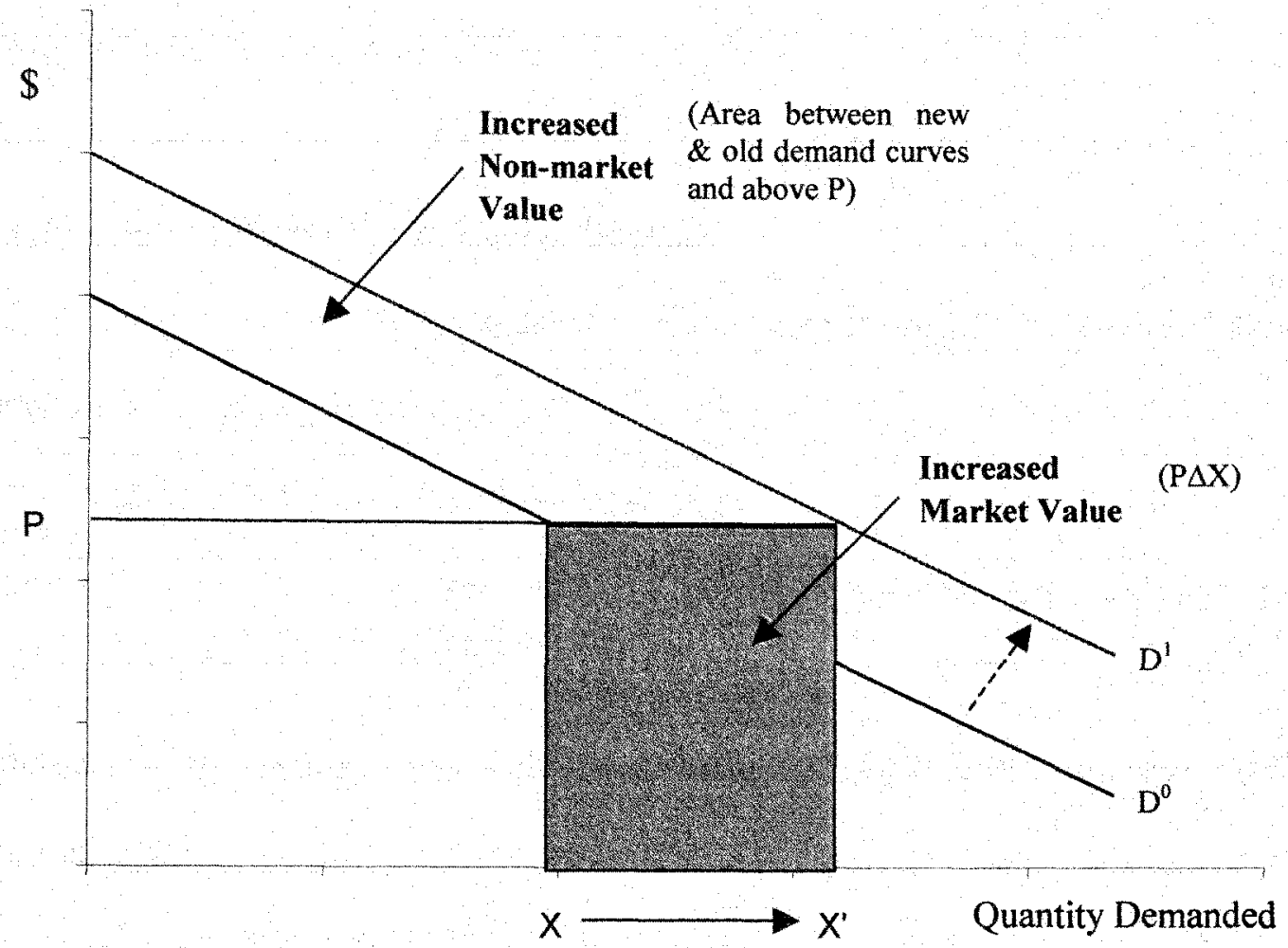

Figure 3.3: Recreational Value Change Due to Quality Improvement

The results of the water quality baseline assessment as described in section 3.6 are used as the basis in determining the changes in market and nonmarket values related to recreational activities ${ }^{39}$ for the IRLS as described above. Optimally, a formal demand model that explicitly derives these behavioral changes based on underlying consumer preferences would be used. However, as this type of demand model was not derived for this analysis, benefits are estimated using a combination of data available from previous studies, benefit transfers, and methodology transfers. Specifically, the following

\footnotetext{
${ }^{39}$ See section 4.1 concerning focus on recreational activities
} 
methodologies are used for the estimation of market direct use values and nonmarket direct and passive use values.

\subsubsection{Market Direct Use Impacted Benefits}

As per section 3.4.2, updated resident market direct use values $\left(M D_{R}\right)$ are determined according to formula (3.7):

$$
\mathrm{MD}_{\mathrm{R}}=\left(\mathrm{POP}_{\mathrm{i}}\right) \times\left(\% \mathrm{PART}_{\mathrm{R}}\right) \times\left(\mathrm{EXP}_{\mathrm{R}}\right)
$$

where: $\quad \mathrm{EXP}_{\mathrm{R}}=$ (average annual \# of days participating in activity) $\mathrm{x}$ (total average daily expenditure).

And updated non-resident market direct use values $\left(\mathrm{MD}_{\mathrm{NR}}\right)$ are determined according to formula (3.8):

$$
\mathrm{MD}_{\mathrm{NR}}=(\mathrm{TP}) \times\left(\% \mathrm{PART}_{\mathrm{NR}}\right) \times\left(\mathrm{EXP}_{\mathrm{NR}}\right)
$$

where: $\quad \operatorname{EXP}_{\mathrm{NR}}=($ Median \# of days participating in activity) $\mathrm{x}$ (total average daily expenditure)

As just presented above in section 3.7, a quality improvement is expected to lead to an increase in the demand for a recreational activity. This increase in demand is derived from two sources, current participants who now participate more due to the water quality improvement, and current non-participants who are enticed into beginning to participate with the increased water quality level. That is in terms of non-participants, if the quality improvement is sufficiently large, some of the initial recreation non-participants will 
become participants $^{40}$ (Whitehead et al., 2000). As discussed in section 2.4, the IRLS restoration effort is expected to achieve water quality improvements represented by $41 \%$ phosphorus and $26 \%$ nitrogen load reductions. Therefore, the market direct use benefits for the IRLS restoration are obtained by determining the increase in the average annual \# of days and median \# of days participating for residents and non-residents respectively, as well as the increase in the \% participating in the IRL given these nitrogen and phosphorus identified water quality improvements.

Again, as this analysis does not contain an economic behavioral model that will explicitly determine the \# of days and \% participating increases due to the identified water quality improvements, the following alternate sound methodology applying benefit transfers is employed. The following hypothesis is essential to the methodology employed in this study, i.e., the expected increase in the \# of days and \% participating is a direct function of the water quality baseline assessment discussed in section 3.6 - the baseline total nitrogen and total phosphorus concentrations as compared to their standards, as well as the eutrophic condition and impaired use IRL measurements given in Bricker et al. (1999). Specifically, poorer current water quality conditions lead to a larger expected increase in the \# of days and \% participating. In economic parlance, increases in water quality exhibit decreasing marginal returns. A depiction of this hypothesis using phosphorus water quality standards is given in the below figure:

\footnotetext{
${ }^{40}$ This inclusion of initial non-participants may not only increase the demand for trips, but may also change the shape of the original demand function (Whitehead et al., 2000)
} 


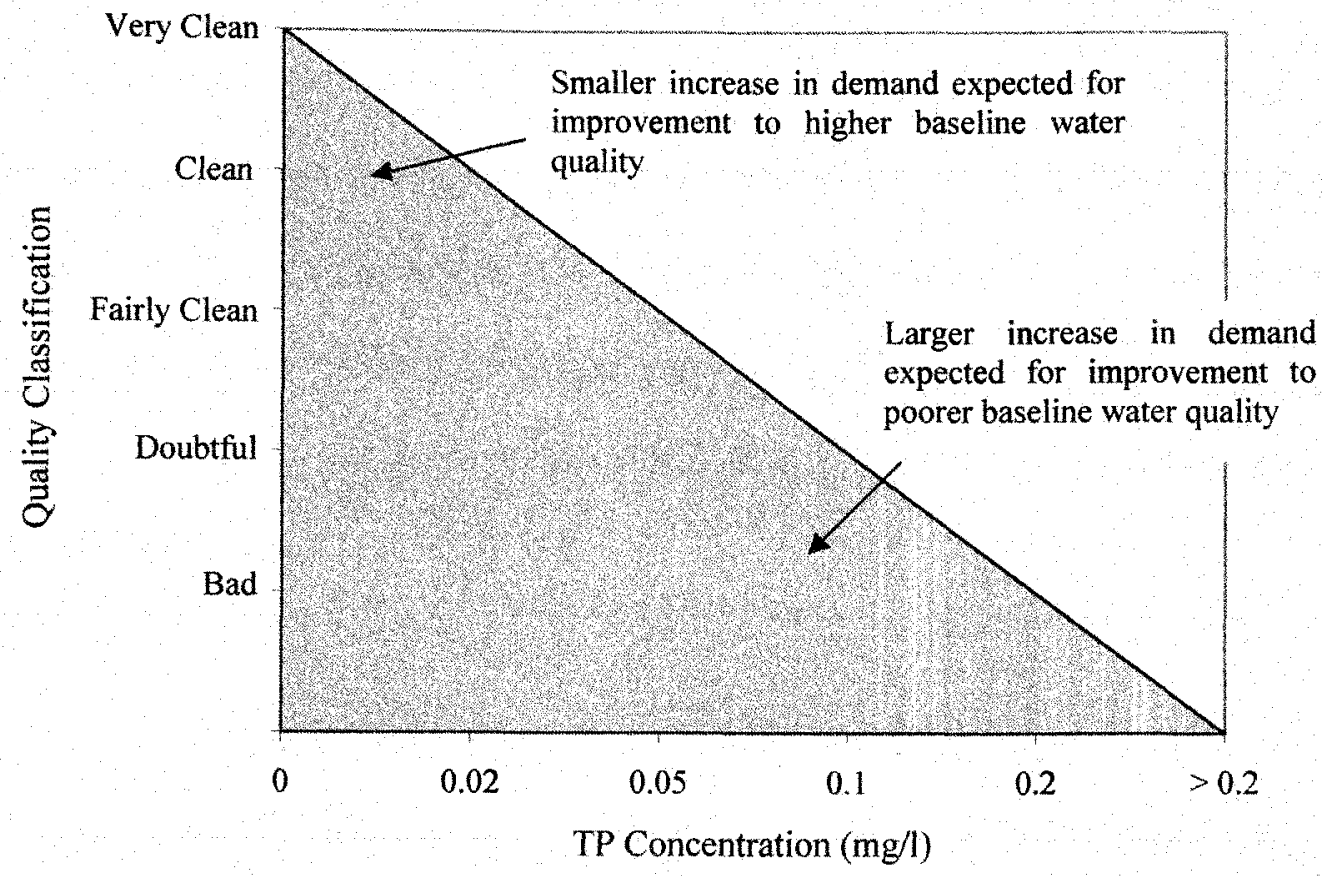

Figure 3.4: Diminishing Marginal Returns for WQ Improvement

As presented in section 2.2.3.2, Whitehead et al. (2000) developed a revealed and stated preference economic model that measured the increase in the \# of trips and \% participating in fishing, hunting, swimming, boating, skiing, windsurfing, birdwatching, and camping recreational activities for a proposed water quality improvement in the Albemarle and Pamlico Sound. Given that Albemarle and Pamlico Sound is an estuary in the same South Atlantic region as the IRLS, and that the baseline total nitrogen and total phosphorus concentrations are similar enough to the IRLS, a benefit transfer of their results is determined feasible. Although their results are generated from a resident survey, they are applied to both IRLS residents and non-residents. A conservative benefit transfer is applied to allow for possible inaccuracy of a single point estimate transfer. 
In summary, market direct use benefits due to the proposed IRLS total nitrogen and total phosphorus reductions are estimated by establishing the IRLS total nitrogen and total phosphorus baseline, transferring in increased \# of trips and \% participating results of a formal economic model derived for a relatively similar waterbody in terms of water quality, adjusting these transferred results to reflect the IRLS water quality baseline, and applying the transfer to the explicit formulas $(3.7 \& 3.8)$ used in the updated Apogee Research (1996) baseline.

\subsubsection{Nonmarket Direct and Passive Use Impacted Benefits}

Again, as this analysis does not contain an economic behavioral model that will estimate nonmarket values as well as determine explicitly the \# of days and \% participating increases due to the identified water quality improvements, an alternate sound methodology applying benefit transfers is employed. This methodology is based on Magat's et al. (2000) iterative choice stated preference technique as described in section 2.2.3.2. The relevant nonmarket WTP values for a $1 \%$ improvement in water quality derived from this study (as given in the figure 3.5 below) are combined with the $\%$ impaired water quality baseline discussed in section 3.6.

It is important to note that in the FDEP Basin Report (2003) a direct correlation between the IRLS restoration and the current impaired waters of St. Lucie and Martin counties is not explicitly stated. However, a definite significant correlation is implied as the FDEP Basin Report (2003) refers to the overall CERP restoration effort as having "the single largest impact in improving water quality, and timing and delivery of water to the South 
WTP per Household / Tourist Party

Per $1 \%$ Improvement in total $\%$ of of good water

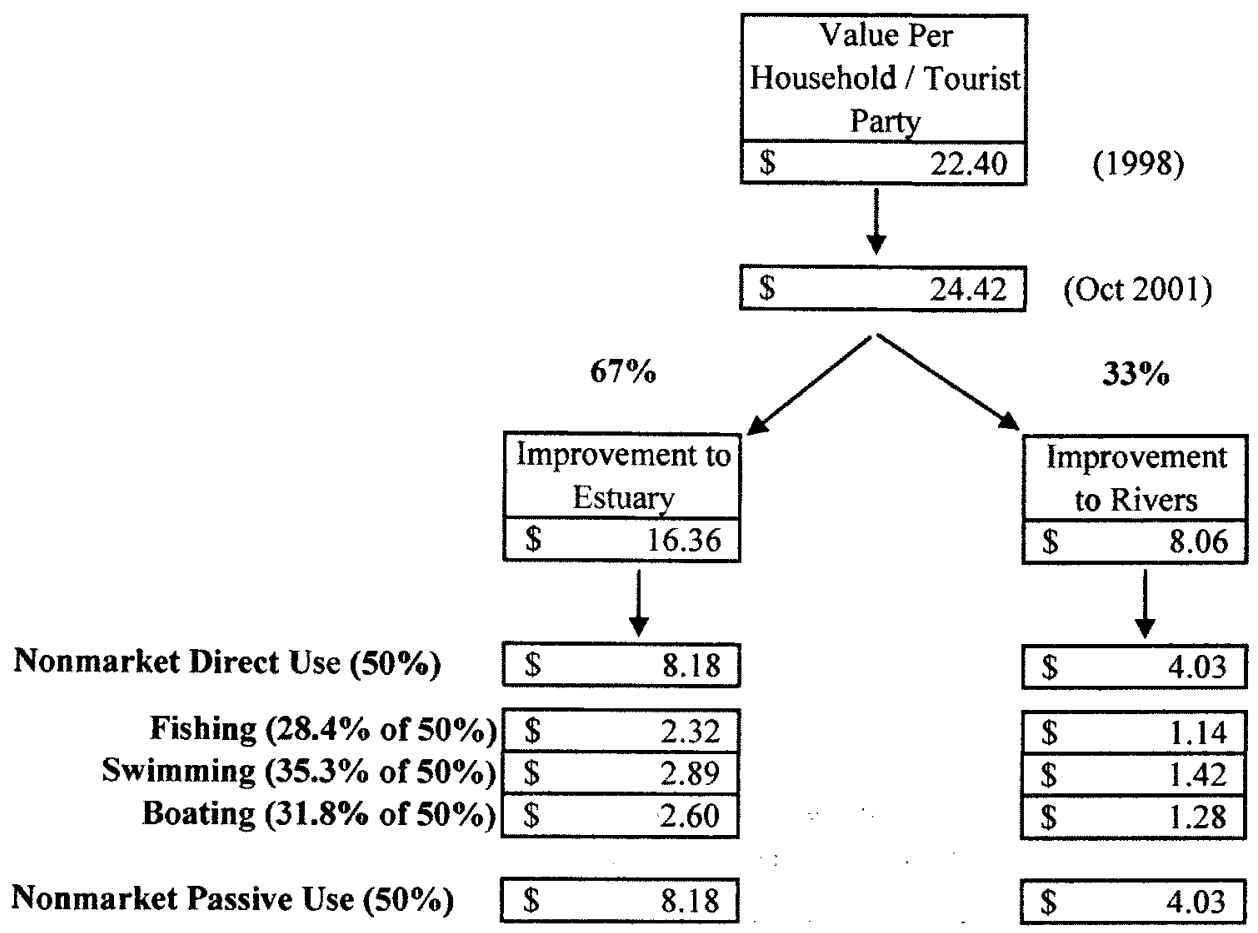

Figure 3.5: Nonmarket Direct \& Passive Use WTP Values

IRL and the SLE". Furthermore, a summary of the basin waterbodies receiving benefits from the IRLS restoration was provided (FDEP, 2003).

Table 3.1: IRLS Restoration Activities Affect On Water Quality

\begin{tabular}{|c|c|c|c|}
\hline $\begin{array}{l}\text { Project } \\
\text { Category }\end{array}$ & $\begin{array}{l}\text { CERP Project/ } \\
\text { Component }\end{array}$ & Location & $\begin{array}{c}\text { Major Group } 2 \\
\text { waterbodies receiving } \\
\text { benefits }\end{array}$ \\
\hline \multirow[t]{3}{*}{$\begin{array}{l}\text { Water Storage, } \\
\text { Treatment \& } \\
\text { Distribution }\end{array}$} & $\begin{array}{l}\text { IRLS/C-23/24/ } \\
\text { reservoirs and STAs }\end{array}$ & $\begin{array}{l}\mathrm{C}-23 \text { and } \mathrm{C}-24 \\
\text { Canal subbasins }\end{array}$ & $\begin{array}{l}\text { North fork St. Lucie } \\
\text { river, St. Lucie } \\
\text { estuary }\end{array}$ \\
\hline & $\begin{array}{l}\text { IRLS/C-25 reservoirs } \\
\text { and STAs }\end{array}$ & C-25 subbasin & IRL, C-25 canal \\
\hline & $\begin{array}{l}\text { IRLS/C-44 reservoirs } \\
\text { and STA }\end{array}$ & C-44 subbasin & $\begin{array}{l}\text { St. Lucie estuary, C- } \\
44 \text { canal }\end{array}$ \\
\hline
\end{tabular}




\begin{tabular}{|l|l|l|l|}
\hline \multicolumn{1}{|c|}{$\begin{array}{c}\text { Project } \\
\text { Category }\end{array}$} & \multicolumn{1}{|c|}{$\begin{array}{c}\text { CERP Project/ } \\
\text { Component }\end{array}$} & \multicolumn{1}{c|}{ Location } \\
\hline $\begin{array}{l}\text { Wetland } \\
\text { Restoration / } \\
\text { Reconnection }\end{array}$ & $\begin{array}{l}\text { IRLS/North Fork St. } \\
\text { Lucie natural flood } \\
\text { plain restoration }\end{array}$ & $\begin{array}{l}\text { North St. Lucie } \\
\text { Basin }\end{array}$ & $\begin{array}{l}\text { North fork } \text { St. Lucie } \\
\text { river, St. Lucie } \\
\text { estuary }\end{array}$ \\
\cline { 2 - 4 } & $\begin{array}{l}\text { IRLS/Cypress Creek } \\
\text { Complex natural storage } \\
\text { and water quality area }\end{array}$ & C-24 subbasin & $\begin{array}{l}\text { C-24 canal, St. Lucie } \\
\text { estuary }\end{array}$ \\
\cline { 2 - 4 } & $\begin{array}{l}\text { IRLS/Allapattah } \\
\text { complex natural storage } \\
\text { and water quality area }\end{array}$ & C-24 subbasin & $\begin{array}{l}\text { C-23 canal, C-24 } \\
\text { canal, North fork St. } \\
\text { Lucie river, St. Lucie } \\
\text { estuary }\end{array}$ \\
\cline { 2 - 4 } & $\begin{array}{l}\text { IRLS/Pal-Mar complex } \\
\text { natural storage and } \\
\text { water quality area }\end{array}$ & $\begin{array}{l}\text { South St. Lucie } \\
\text { subbasin }\end{array}$ & $\begin{array}{l}\text { South fork St. Lucie } \\
\text { river, St. Lucie } \\
\text { estuary, C-44 canal }\end{array}$ \\
\hline $\begin{array}{l}\text { Estuary } \\
\text { restoration }\end{array}$ & $\begin{array}{l}\text { IRLS/Muck remediation } \\
\text { and artificial habitat }\end{array}$ & $\begin{array}{l}\text { St. Lucie } \\
\text { estuary }\end{array}$ & St. Lucie estuary \\
\hline
\end{tabular}

(Source: FDEP 2003)

Specifically, results in this analysis are presented under the assumption that the IRLS restoration effort will ultimately improve $50 \%$ of the baseline identified impaired (not good) waters to not impaired (good).

Nonmarket Passive Use Values:

As per section 3.4.3, updated nonmarket resident passive use values $\left(\mathrm{NMP}_{\mathrm{R}}\right)$ are determined according to formula (3.9):

$$
\mathrm{NMP}_{\mathrm{R}}=\left(\mathrm{HH}_{\mathrm{i}}\right) \times\left(\mathrm{WTP}_{\mathrm{R}}\right)
$$

And updated nonmarket passive use values $\left(\mathrm{NMP}_{\mathrm{NR}}\right)$ for non-residents is given by formula (3.10):

$$
\mathrm{NMP}_{\mathrm{NR}}=(\mathrm{TP}) \times\left(\mathrm{WTP}_{\mathrm{NR}}\right)
$$


Substituting the appropriate nonmarket passive use values from Magat et al. (2000) ${ }^{41}$ as given above in figure 3.5 for $\mathrm{WTP}_{\mathrm{R}}$ and $\mathrm{WTP}_{\mathrm{NR}}$ in equations $(3.9 \& 3.10)^{42}$, and assuming a 50\% improvement to impaired waters from the IRLS restoration effort, the nonmarket passive use benefit for residents $\left(\mathrm{NMP}_{\mathrm{R}}\right)$ due to the restoration effort is calculated according to the following:

For rivers:

$\mathrm{NMP}_{\text {Rriver }}=\left(\mathrm{HH}_{\mathrm{i}}\right) \times(\$ 4.03) \times(\%$ IRLS rivers impaired $\times 50 \%)$

For estuaries ${ }^{43}$ :

$\mathrm{NMP}_{\text {Restuary }}=\left(\mathrm{HH}_{\mathrm{i}}\right) \times(\$ 8.18) \times(\%$ IRLS estuaries impaired $\times 50 \%)$

Similarly for non-residents, nonmarket passive use benefits $\left(\mathrm{NMP}_{\mathrm{NR}}\right)$ due to the restoration effort will be calculated according to the following:

For rivers:

$\mathrm{NMP}_{\mathrm{NR} \text { river }}=(\mathrm{TP}) \times(\$ 4.03) \times(\%$ IRLS rivers impaired $\times 50 \%)$

For estuaries $^{44}$ :

$\mathrm{NMP}_{\mathrm{NRestuary}}=(\mathrm{TP}) \times(\$ 8.18) \times(\%$ IRLS estuaries impaired $\times 50 \%)$

\section{Nonmarket Direct Use Values:}

As presented in section 3.3.3, residential fishing values were the only nonmarket direct use values estimated in the Apogee Research study (1996). As presented in section

\footnotetext{
${ }^{41}$ Magat et al. (2000) estimated non-use value, which for purposes of this study is the same as passive use

${ }^{42}$ Magat et al. (2000) WTP values are the same for residents and non-residents

${ }^{43}$ Improvement to lake acres are used as a proxy for estuaries as no estuary value was derived

${ }^{44}$ Improvement to lake acres are used as a proxy for estuaries as no estuary value was derived
} 
2.2.3.2, Magat et al. (2000) derived nonmarket WTP values for the direct uses of improved waters, specifically fishing, swimming, and boating. This analysis derives nonmarket direct use values via a two-step process. First, the nonmarket WTP direct use values derived by Magat et al. (2000) for fishing, swimming, and boating as given above in figure 3.5 are combined with the $50 \%$ improvement to impaired waters assumption cited above. Second, the increased \# of trips and \% participating data and methodology given in section 3.7.1 are incorporated into the updated nonmarket direct use values (due to a lack of nonmarket data from the Apogee Research original study). It should be noted that although this analysis only derives values for the activities of fishing, swimming, and boating, these activities account for over $80 \%$ of the total updated baseline values (see section 4.3.7).

For step one, the annual WTP per household/tourist party for an overall $50 \%$ improved fishable, swimmable, and boatable waters is calculated using the values from figure 3.5 and according to the following equations (where the river WTP is used as it is a more conservative estimate vs. lake/estuary value):

$$
\begin{array}{ll}
\mathrm{WTP}_{\text {Fishing }} & =(\$ 1.14) \times(\% \text { IRLS rivers impaired } \times 50 \%) \\
\mathrm{WTP}_{\text {Swimming }} & =(\$ 1.42) \times(\% \text { IRLS rivers impaired } \times 50 \%) \\
\mathrm{WTP}_{\text {Boating }} & =(\$ 1.28) \times(\% \text { IRLS rivers impaired } \times 50 \%)
\end{array}
$$

For step two, in order to incorporate the increased \# of trips and \% participating data and methodology given in section 3.7.1, the above derived annual WTP values from equations 3.19 to 3.21 must be converted into a daily WTP value appropriately. For 
residents, the annual WTP per household is converted first to an annual WTP per person by dividing by the average number of people per household from 2000 census data information -2.66 for St. Lucie county and 2.52 for Martin county (see table 4.8 ). This annual WTP per person is then divided by the average \# of days participating in the activity as given by the Apogee Research study (1996) and as referenced above in section 3.7.1.

$$
\mathrm{NMDWTP}_{\mathrm{R}, \text { Daily }}=\left(\mathrm{WTP}_{\text {Annual }} / \# \text { people per } \mathrm{HH}\right) /\left(\begin{array}{r}
\text { Avg \# of days } \\
\text { participating })
\end{array}\right.
$$

where: $\quad$ NMDWTP $_{\mathrm{R}, \text { Daily }}=$ resident daily nonmarket direct WTP

$\mathrm{WTP}_{\text {Annual }}=$ annual WTP values from equations 3.19 to 3.21 above

For non-residents, the WTP daily is derived by dividing the annual WTP per tourist party from equations 3.19 to 3.21 by the median \# of days participating in each activity as referenced above in section 3.7.1.

$$
\mathrm{NMDWTP}_{\mathrm{NR}, \text { Daily }}=\mathrm{WTP}_{\text {Annual }} / \text { Median \# of days participating }
$$

where: $\quad$ NMDWTP $_{\mathrm{NR} \text {, Daily }}=$ non-resident daily nonmarket direct WTP

$$
\mathrm{WTP}_{\text {Annual }}=\text { annual WTP values from equations } 3.19 \text { to } 3.21 \text { above }
$$

Once, the daily nonmarket direct WTP for residents and non-residents has been calculated, the nonmarket direct use benefits from increased trips and participation rates due to improvements in water quality caused by the IRLS restoration (following assumptions given in section 3.7.1) are calculated according to the following:

$$
\mathrm{NMD}_{\mathrm{R}}=\left(\mathrm{POP}_{\mathrm{i}}\right) \times\left(\% \mathrm{PART}_{\mathrm{R}, \mathrm{W}}\right) \times\left(\mathrm{NMDWTP}_{\mathrm{R}, \text { Daily }} \times \text { DayswQ }_{\mathrm{Q}}\right)
$$

where: $\quad \mathrm{NMD}_{\mathrm{R}}=$ resident nonmarket direct use benefit value $\mathrm{POP}_{\mathrm{i}}=$ adult population of county $\mathrm{i}$

$\% \mathrm{PART}_{\mathrm{R}, \mathrm{wQ}}=\%$ of the resident adult population participating in the IRL given increase in water quality 
Days $_{W_{Q}}=$ average number of days participating given increased water quality

$$
\mathrm{NMD}_{\mathrm{NR}}=(\mathrm{TP}) \times\left(\% \mathrm{PART}_{\mathrm{NR}}, \mathrm{WQ}\right) \times\left(\mathrm{NMDWTP}_{\mathrm{NR}, \text { Daily }} \mathrm{x} \text { Days } \mathrm{WQ}_{\mathrm{W}}\right)
$$

where: $\quad \mathrm{NMD}_{\mathrm{NR}}=$ non-resident nonmarket direct use benefit value $\mathrm{TP}=$ estimated \# of tourist parties to IRL net of Volusia County

$\% \mathrm{PART}_{\mathrm{NR}, \mathrm{WQ}}=\%$ of the non-resident adult population participating in the IRL given increase in water quality

Days $_{W Q}=$ average number of days participating given increased water quality

The above methodology is employed in order to estimate nonmarket direct use values for fishing, swimming, and boating given a 50\% improvement of impaired waters. These nonmarket direct and passive use benefit estimates as just described in this section are combined with the market benefit estimates of section 3.7.1 for a total benefit estimation given the proposed nitrogen and phosphorus reductions. The total benefit estimation is combined with the costs for an economic analysis of the restoration as described in the next section.

\subsection{Cost-Benefit Analysis}

As per section 3.1, the difference between an upper value of benefits given the completion of the restoration effort and the lower value of benefits given the absence of the restoration effort from the baseline value is the "net" benefit value to be used in the cost-benefit analysis. The upper value of benefits for the IRLS is obtained by following the methodology described in section 3.7. Given the absence of the IRLS restoration, "as a result of ongoing watershed management programs, water quality in the Upper East 
Coast (IRLS) is expected to improve slightly in the future" (USACE/SFWMD, 2002). Furthermore, "The estimates of 2050 phosphorus loads are very close to today's estimates. This is because the increase in load caused by growth in urban lands is offset by decreases in loads from urban and agricultural lands that are expected to occur as a result of the best management practices' implementation" (USACE/SFWMD, 2002). Based on this information, the lower value of benefits due to the absence of the restoration is expected to be as least as great as the baseline values, and therefore for purposes of this study the net benefits will be the difference between the upper values estimated as per section 3.7 , and the baseline value estimated as per section $3.2-3.5$, as shown in the figure below.

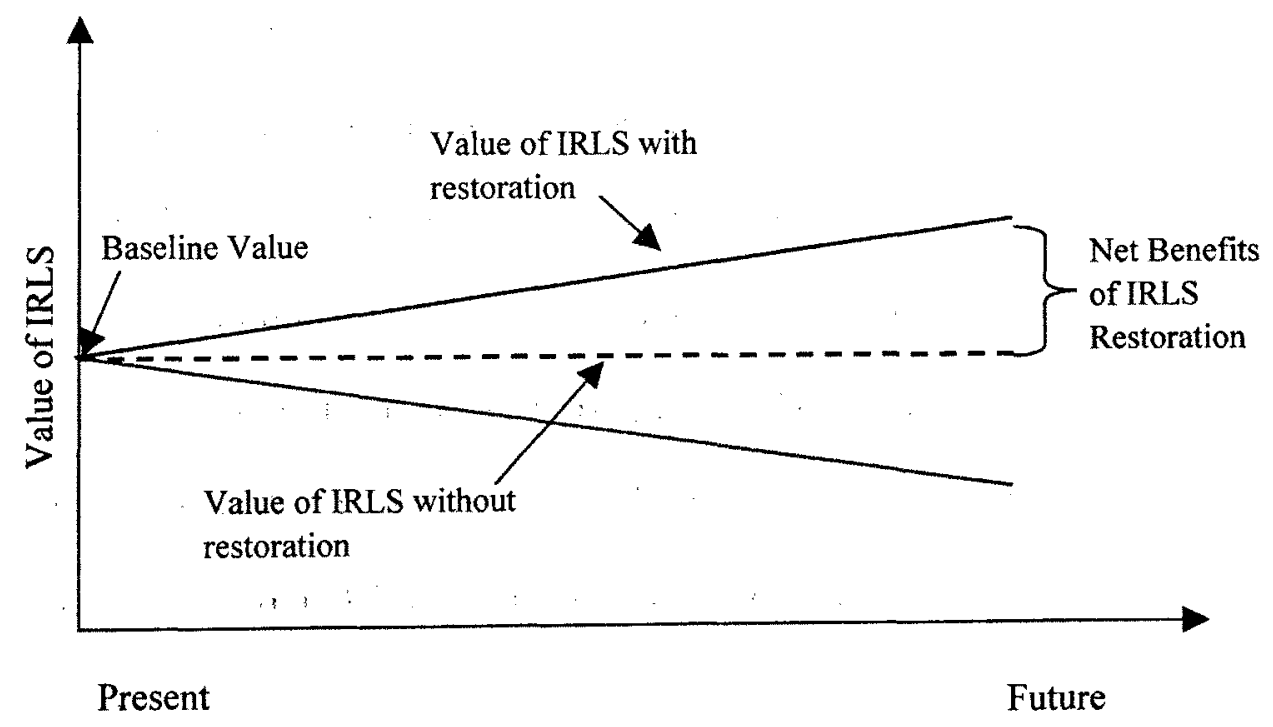

Figure 3.6: Net Benefits of IRLS Restoration 
As per section 2.3, net present value (NPV) is the difference between the present value of the stream of benefits minus the present value of the stream of costs, and therefore estimated by the following equation:

$$
\mathrm{NPV}=\sum_{\mathrm{t}=0}^{\mathrm{T}}\left[1 /(1+\mathrm{r})^{\mathrm{t}}\right] \times[\text { Benefits }(\mathrm{t})-\operatorname{Costs}(\mathrm{t})]
$$

where: $\quad t=$ time periods

$\mathrm{r}=$ interest rate

NPV for the IRLS is estimated by equation (3.26) where a positive NPV estimation equates to an acceptance of the IRLS project from an economic perspective, while a negative NPV estimation leads to its rejection from an economic perspective.

Costs for the IRLS, given and discussed in section 2.4 , have already been discounted at a rate of $6.125 \%$ (USACE/SFWMD, 2002), and therefore, the $6.125 \%$ discount rate is also used to estimate the present value of the section 3.7 IRLS benefits following the above NPV equation 3.26. A total 30-year time period is used, with initial construction costs phased in from 2002 to 2010 as given by table 2.8, and ongoing operations and maintenance costs of $\$ 4.2$ million for the remaining years. Following Russell et al. (2001) initiation of benefits usually occurs five years after initiation of construction, and therefore benefits for the IRLS begin to accrue starting in year six of the analysis. It is assumed that benefits will accrue at a rate of $10 \%$ per year, therefore reaching full value in ten years time, or 15 years from the initiation of construction. And for years 16-30, it is assumed that full benefits are achieved each year. Due to a lack of reliable projected population and visitor data, as well as concerns of extrapolating survey participation 
results from 1995 thirty plus years forward, future benefits are only based on the baseline adult population, \# of household, and \# of visitors as presented in section 3.4.

Table 3.2: Benefit-Cost Analysis Overview

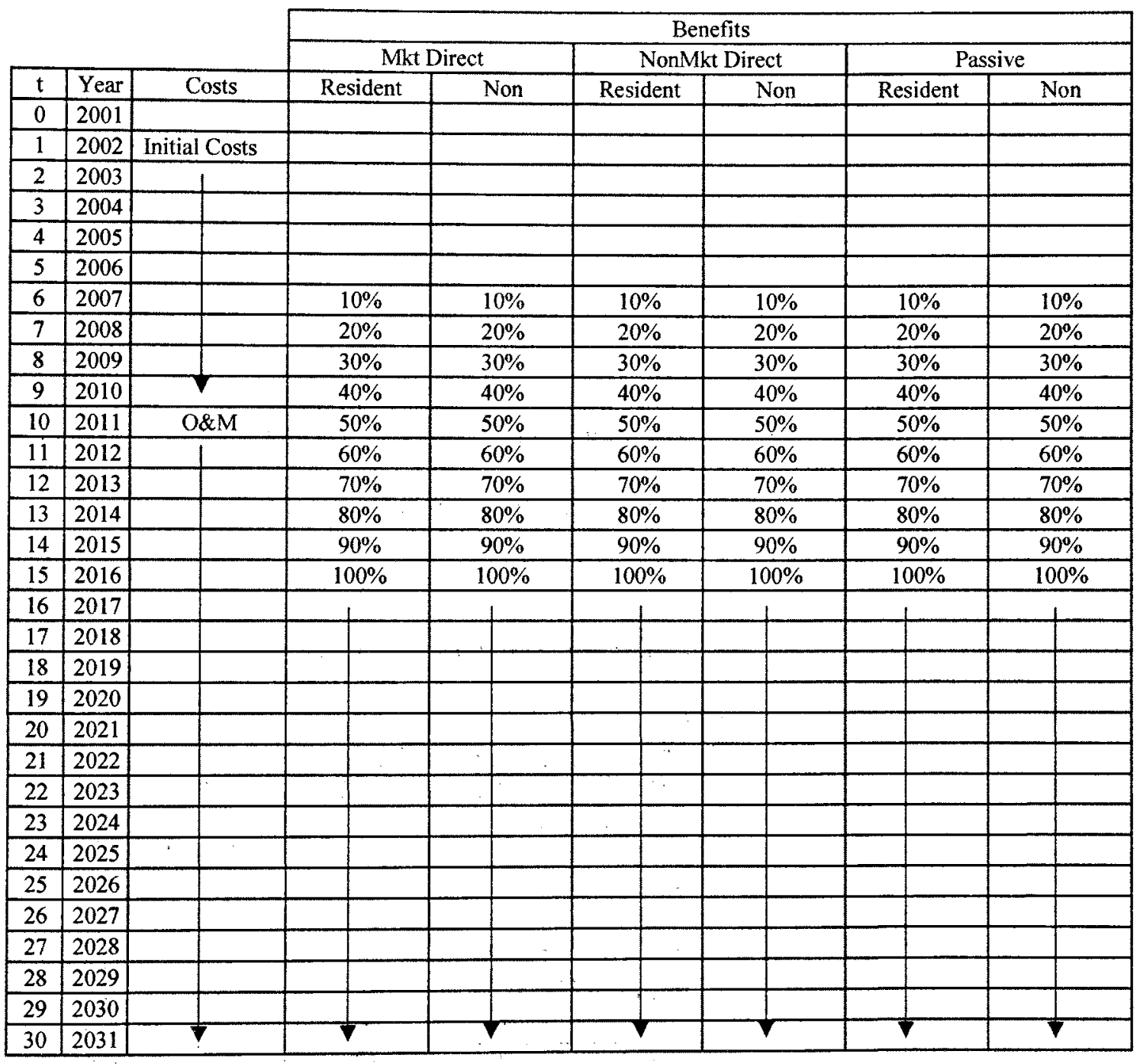

To account for the uncertainty inherent in the NPV analysis, a sensitivity analysis as described in section 2.3 is conducted around key variables in the NPV estimation including: 
- $20 \%$ increase in average annual days participating

- $1 \%$ increase in overall absolute $\%$ participating

- $50 \%$ improvement of impaired waters

- Cost and benefit timing as discussed above

To further account for the uncertainty inherent in the NPV analysis, a Monte Carlo risk analysis is conducted with \% values drawn randomly from the assumed uniform distribution of the three main variables and their identified value ranges as defined:

- $\%$ increase in average annual days participating - [0-25\%]

- $\%$ increase in overall absolute $\%$ participating - $[0-2 \%]$

- $\%$ improvement of impaired waters - $[0-100 \%]$

10,000 random draws are generated for each of the three variables and associated benefits and NPV are estimated for each draw. The various NPV results are compared and conclusions drawn concerning the economic feasibility of the IRLS restoration.

\section{RESULTS AND DISCUSSION}

\subsection{Identified Service Flows}

Recreational service flows generated from the IRLS are the most relevant to this analysis. This coincides with Bockstael et al.'s statements (1987) that greater than 50\% of returns from water quality improvements accrue to recreational users, $95 \%$ of benefits derived from water quality improvements to a Delaware estuary are attained by 
recreationists, and water based recreators would be the major beneficiaries of the 1972 Federal Water Pollution Control Act. The economic importance of recreational uses is clearly shown in sections 4.2 and 4.3 to follow. A benefit estimate for agricultural uses was estimated as part of the original IRLS study (USACE/SFWMD, 2002) as given in section 2.2.3.3. Municipal and industrial uses rely on the Floridian aquifer are expected to continue to rely on this aquifer through 2050 and would not be impacted by the IRLS restoration (USACE/SFWMD, 2002). Other identified uses of the IRLS such as commercial fishing, navigation, and flood protection would have minimal benefits from the restoration as already discussed in this report. The ecological service flows provided by the IRLS is a use that should be looked at further, but is outside the scope of this initial analysis.

\subsection{Baseline Estimate}

The following sections present the results of the Apogee Research (1996) IRL baseline estimate by value derived. All values are in 1995 dollars.

\subsubsection{Market Direct Use Values}

Following the methodology in section 3.3.1, total annual expenditures, i.e., market direct use expenditures, by recreational activity were estimated for residents. Boating, with a total value of $\$ 49.1$ million, is shown as an example below: 
Table 4.1: IRL Resident Market Direct Use Value for Boating

\begin{tabular}{|c|c|c|c|c|}
\hline & $\begin{array}{c}\text { Estimated } \\
\text { Population } \\
(18 \& \text { over })\end{array}$ & $\begin{array}{c}\% \\
\text { Participating } \\
\text { in Lagoon }\end{array}$ & $\begin{array}{c}\text { Total Average } \\
\text { Annual } \\
\text { Expenditures } \\
\text { of Respondents }\end{array}$ & $\begin{array}{c}\text { Estimated Total } \\
\text { Annual } \\
\text { Expenditures }\end{array}$ \\
\hline Volusia & 312,243 & $7 \%$ & $\$ 256.56$ & $\$ 5,607,634$ \\
\hline Brevard & 332,430 & $18 \%$ & $\$ 459.60$ & $\$ 27,501,269$ \\
\hline Indian River & 77,223 & $21 \%$ & $\$ 226.40$ & $\$ 3,671,490$ \\
\hline St. Lucie & 125,168 & $17 \%$ & $\$ 229.50$ & $\$ 4,883,430$ \\
\hline Martin & 87,149 & $21 \%$ & $\$ 408.80$ & $\$ 7,481,567$ \\
\hline Total & & & & $\$ 49,145,391$ \\
\hline
\end{tabular}

(Source: Apogee Research, 1996)

Applying this methodology across all the recreational activities yielded a total resident annual value of $\$ 257$ million, with fishing accounting for nearly $60 \%$ of the total value. Fishing and boating had the highest participation rates.

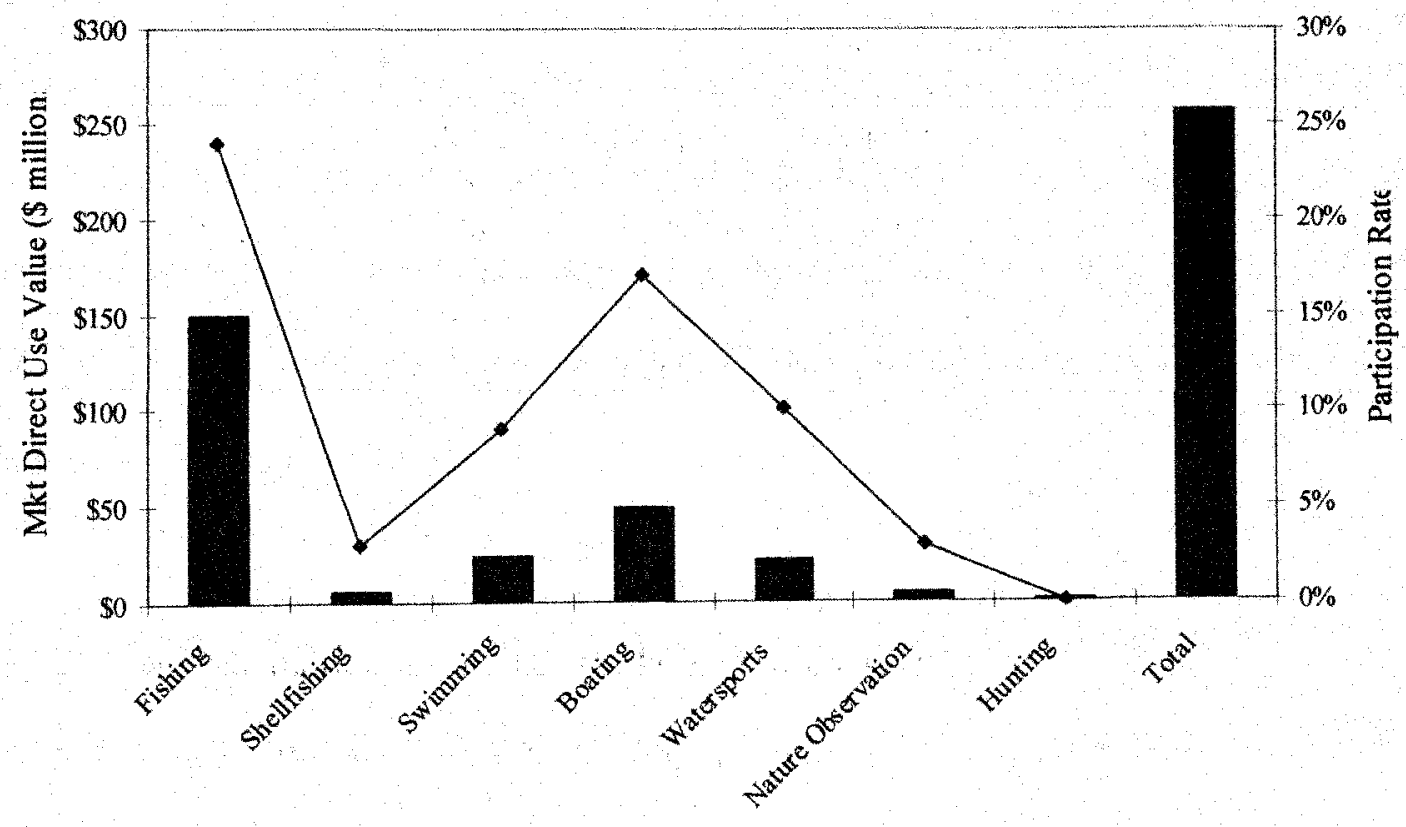

Recreational Activity

Mkt Direct Use - Participation Rate

(Source: Adapted from Apogee Research, 1996)

Figure 4.1: IRL Total Resident Market Direct Use Values 
Following the methodology described in section 3.3.1, total annual expenditures, i.e., market direct use expenditures, by recreational activity were estimated for non-residents. Swimming, with a total value of $\$ 112$ million, is shown as an example below:

Table 4.2: IRL Non-Resident Market Direct Use Value for Swimming

\begin{tabular}{|c|c|c|c|c|}
\hline County & $\begin{array}{c}\text { Estimated \# } \\
\text { of tourist } \\
\text { parties }\end{array}$ & $\begin{array}{c}\text { \%otal Average } \\
\text { Tourist } \\
\text { in Lagoon }\end{array}$ & $\begin{array}{c}\text { Expenditures per } \\
\text { party per trip }\end{array}$ & $\begin{array}{c}\text { Estimated Total } \\
\text { Annual } \\
\text { Expenditures }\end{array}$ \\
\hline Volusia & $1,196,503$ & $2.8 \%$ & $\$ 206.82$ & $\$ 6,928,903$ \\
\hline All Other & 978,957 & $52 \%$ & $\$ 206.82$ & $\$ 105,283,336$ \\
\hline Total & $2,175,461$ & & & $\$ 112,212,240$ \\
\hline
\end{tabular}

(Source: Apogee Research, 1996)

Applying this methodology across all the recreational activities yielded a total nonresident annual value of $\$ 231$ million, with swimming representing nearly half of this figure. Swimming and nature observation had the highest participation rates. The high participation rate in swimming, especially compared to the resident rate, indicated potential problems with this value in terms of non-residents swimming in the IRL or the ocean. See figure 4.2 below

Combining the above resident and non-resident market direct use values for all recreational activities give an annual total market direct use value of $\$ 487$ million as shown in figure 4.3 below. 


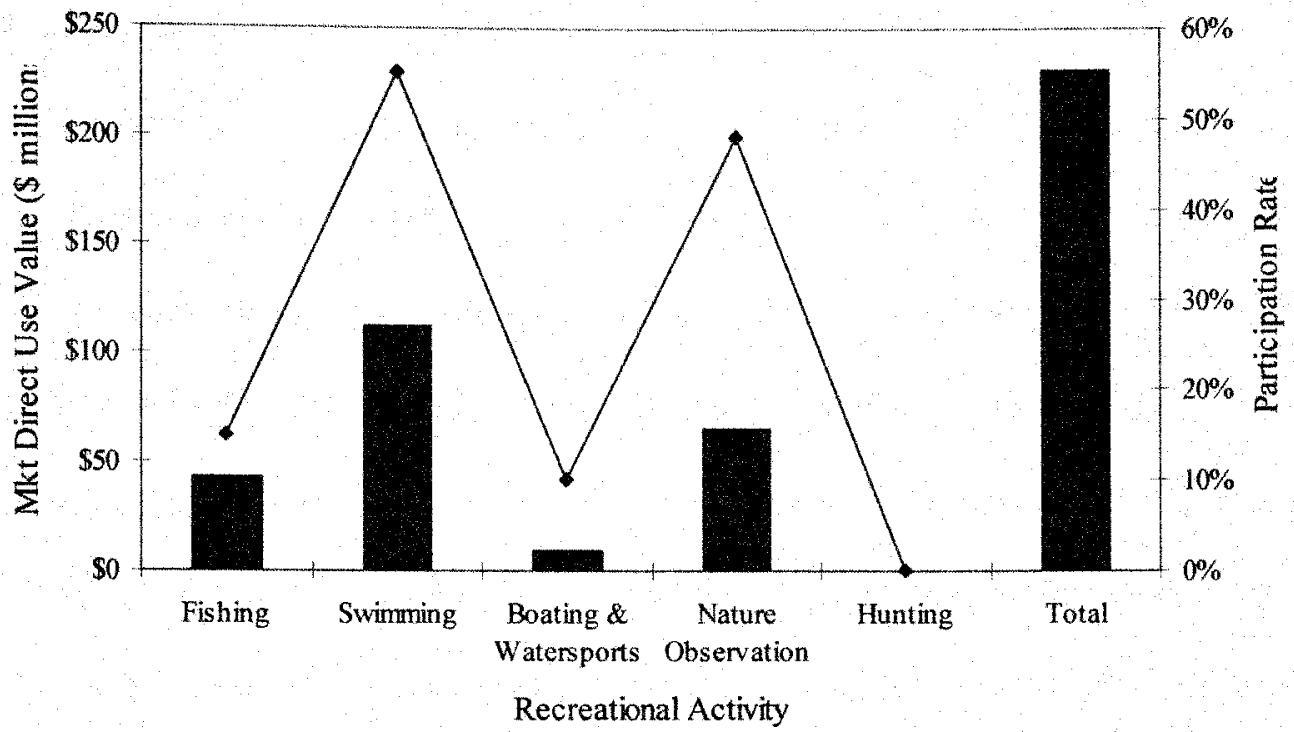

Mkt Direct Use - Participation Rate

(Source: Adapted from Apogee Research, 1996)

Figure 4.2: IRL Total Non-Resident Market Direct Use Values

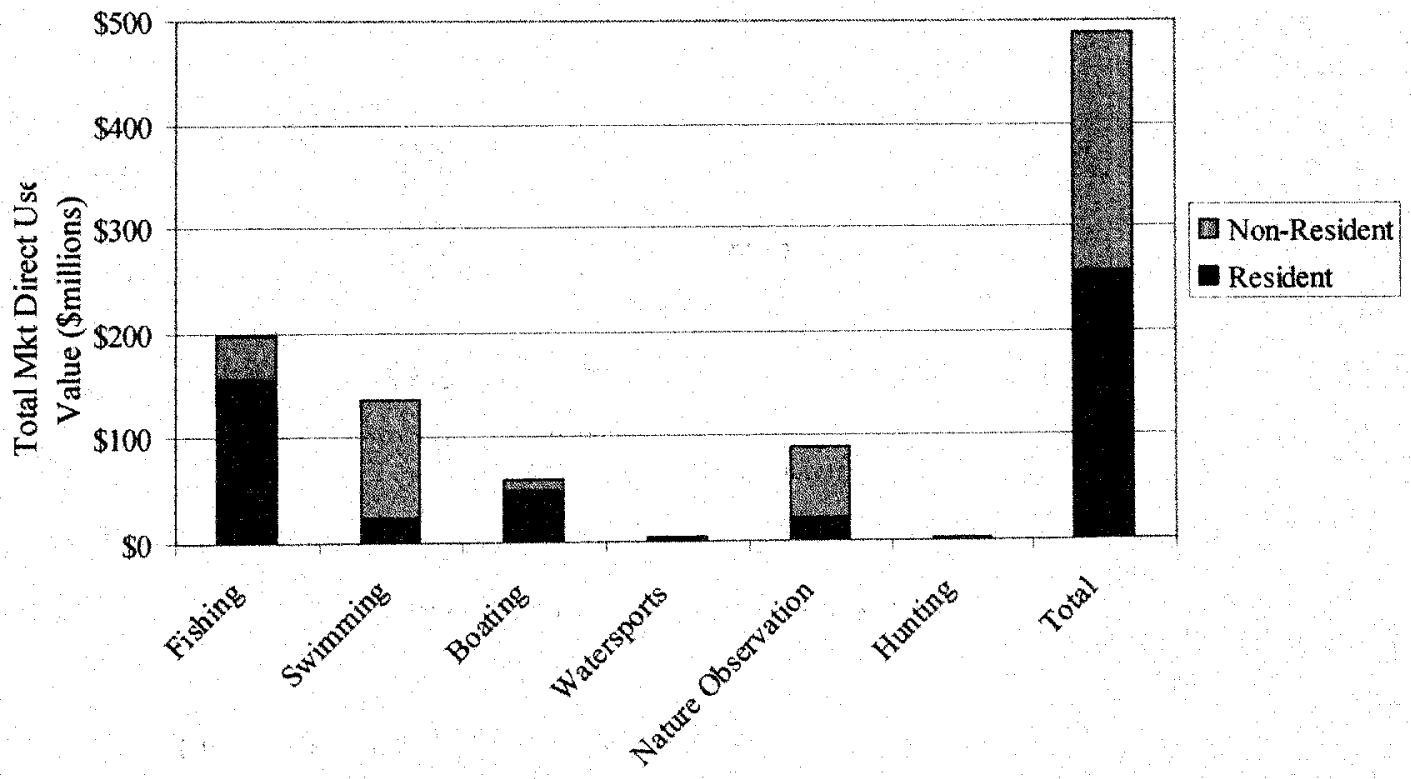

Recreational Activity

(Source: Adapted from Apogee Research, 1996)

Figure 4.3: IRL Total Resident \& Non-resident Market Direct Use Value 


\subsubsection{Nonmarket Passive Use Values}

Following the methodology described in section 3.3.2 nonmarket passive use values were estimated for residents. Mean WTP and median WTP values of $\$ 53.32$ and $\$ 30.00$ were derived respectively for residents. The bivariate probit regression analysis indicated that resident WTP values are only weakly related to current uses of the lagoon, which indicates that nearly all of the estimated resident WTP can be classified as passive use value. The results also indicated some starting point bias, which means the median WTP may be a more appropriate value to use for estimation. Resident mean passive use values were estimated at $\$ 25.9$ million annually, while resident median passive use values were estimated at $\$ 14.6$ million annually as shown in the following table:

Table 4.3: IRL Resident Nonmarket Passive Use Values

\begin{tabular}{|c|c|c|c|r|c|}
\hline County & $\begin{array}{c}\text { \# of } \\
\text { Households }\end{array}$ & $\begin{array}{c}\text { Mean } \\
\text { WTP }\end{array}$ & $\begin{array}{c}\text { Median } \\
\text { WTP }\end{array}$ & $\begin{array}{c}\text { Aggregate Using } \\
\text { Mean WTP }\end{array}$ & $\begin{array}{c}\text { Aggregate } \\
\text { Using Median } \\
\text { WTP }\end{array}$ \\
\hline Volusia & 162,489 & $\$ 53.32$ & $\$ 30.00$ & $\$ 8,663,913$ & $\$ 4,874,670$ \\
\hline Brevard & 173,102 & $\$ 53.32$ & $\$ 30.00$ & $\$ 9,229,799$ & $\$ 5,193,060$ \\
\hline Indian River & 40,551 & $\$ 53.32$ & $\$ 30.00$ & $\$ 2,162,179$ & $\$ 1,216,530$ \\
\hline St. Lucie & 63,410 & $\$ 53.32$ & $\$ 30.00$ & $\$ 3,381,021$ & $\$ 1,902,300$ \\
\hline Martin & 45,602 & $\$ 53.32$ & $\$ 30.00$ & $\$ 2,431,499$ & $\$ 1,368,060$ \\
\hline Total & 485,154 & & & $\$ 25,868,411$ & $\$ 14,554,620$ \\
\hline
\end{tabular}

(Source: Apogee Research, 1996)

Following the methodology described in section 3.3.2 nonmarket passive use values were estimated for non-residents. Mean WTP and median WTP values of \$23.37 and \$25.11 were derived respectively for non-residents.. The bivariate probit regression analysis 
indicated that non-resident WTP values were not as weakly related to current uses of the lagoon as they were for residents, which indicates that some portion of the estimated nonresident WTP may not be classified as passive use value. Non-resident mean passive use values were estimated at $\$ 29.8$ million annually, while median passive use values were estimated at \$32.1 million annually.

Table 4.4: IRL Non-Resident Nonmarket Passive Use Values

\begin{tabular}{|c|c|c|c|c|c|}
\hline County & $\begin{array}{c}\text { Estimated \# of } \\
\text { tourist parties }\end{array}$ & $\begin{array}{c}\text { Mean } \\
\text { WTP }\end{array}$ & $\begin{array}{c}\text { Median } \\
\text { WTP }\end{array}$ & $\begin{array}{c}\text { Aggregate Using } \\
\text { Mean WTP }\end{array}$ & $\begin{array}{c}\text { Aggregate } \\
\text { Using Median } \\
\text { WTP }\end{array}$ \\
\hline Volusia & 299,126 & $\$ 23.37$ & $\$ 25.11$ & $\$ 6,990,571$ & $\$ 7,511,050$ \\
\hline All Other & 978,957 & $\$ 23.37$ & $\$ 25.11$ & $\$ 22,878,233$ & $\$ 24,581,618$ \\
\hline Total & $1,278,083$ & & & $\$ 29,868,804$ & $\$ 32,092,669$ \\
\hline
\end{tabular}

(Source: Apogee Research, 1996)

\subsubsection{Nonmarket Direct Use Values}

Following the methodology described in section 3.3 .3 average annual access values per angler in county of residence and for the IRL as a whole were estimated and shown in figure 4.4 below. These annual access vàlues per angler were than aggregated for the county of residence and the entire IRL based on 1995 population and participation rates.

Table 4.5: Total IRL Nonmarket Direct Use Value

\begin{tabular}{|c|c|c|c|c|}
\hline $\begin{array}{c}\text { County of } \\
\text { Residence }\end{array}$ & $\begin{array}{c}\text { Estimated } \\
\text { Population (18 \& } \\
\text { over) }\end{array}$ & $\begin{array}{c}\% \\
\text { Participating } \\
\text { in Lagoon }\end{array}$ & $\begin{array}{c}\text { Access Value for } \\
\text { IRL in County of } \\
\text { Residence }\end{array}$ & $\begin{array}{c}\text { Access Value } \\
\text { for IRL } \\
\text { System }\end{array}$ \\
\hline Volusia & 312,243 & $40 \%$ & $\$ 8,632,894$ & $\$ 33,392,515$ \\
\hline Brevard & 332,430 & $41 \%$ & $\$ 17,729,423$ & $\$ 65,618,491$ \\
\hline
\end{tabular}




\begin{tabular}{|c|c|c|c|c|}
\hline $\begin{array}{c}\text { County of } \\
\text { Residence }\end{array}$ & $\begin{array}{c}\text { Estimated } \\
\text { Population (18 \& } \\
\text { over) }\end{array}$ & $\begin{array}{c}\% \\
\text { Participating } \\
\text { in Lagoon }\end{array}$ & $\begin{array}{c}\text { Access Value for } \\
\text { IRL in County of } \\
\text { Residence }\end{array}$ & $\begin{array}{c}\text { Access Value } \\
\text { for IRL } \\
\text { System }\end{array}$ \\
\hline Indian River & 77,223 & $40 \%$ & $\$ 1,946,020$ & $\$ 8,506,886$ \\
\hline St. Lucie & 125,168 & $42 \%$ & $\$ 1,637,047$ & $\$ 5,765,939$ \\
\hline Martin & 87,149 & $47 \%$ & $\$ 3,824,028$ & $\$ 24,128,734$ \\
\hline Total $^{45}$ & & & $\$ 33,769,412$ & $\$ 137,412,565$ \\
\hline
\end{tabular}

(Source: Apogee Research, 1996)

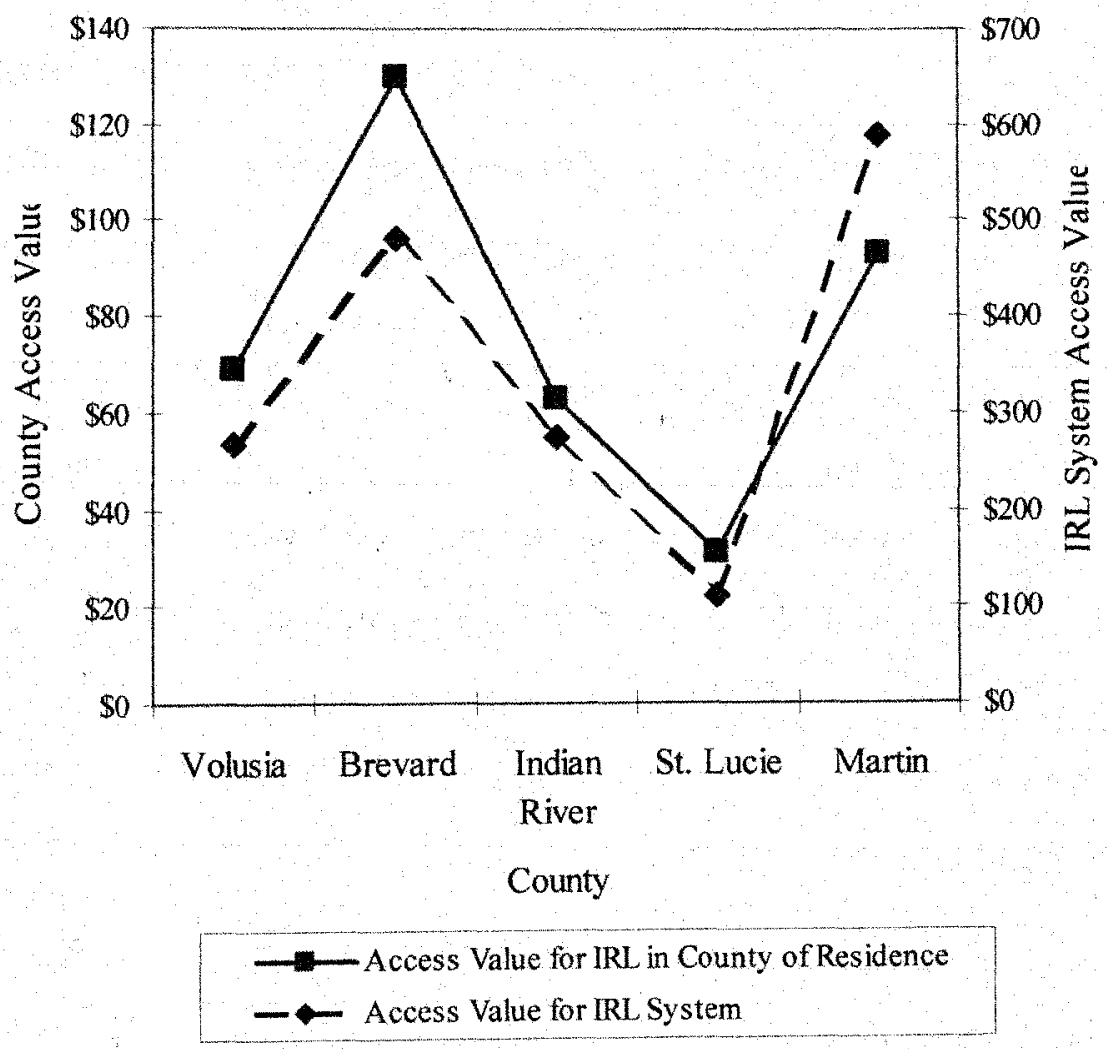

(Source: Adapted from Apogee Research, 1996)

Figure 4.4: IRL Nonmarket Access Values Per Angler

${ }^{45}$ Total value in the study is $\$ 140$ million, incorporating Orange, Lake, Osceola and Seminole counties value of $\$ 2.6$ million 
Lack of data and project scope issues dictated that similar analyses for non-residents as well as the other recreational activities of the lagoon; swimming, boating, nature observation, water sports, and hunting, were not conducted as part of this study. Therefore, the nonmarket direct use values for these activities are not included and the values for recreational fishing can be considered a lower bound for the total nonmarket direct use values of the IRL.

\subsubsection{Riverfront Residential Land Values}

Following the methodology described in section 3.3.4 a total capitalized market value of $\$ 824$ million was generated as shown in the below table:

Table 4.6: IRL Capitalized Market Value of Riverfront Land

\begin{tabular}{|c|c|c|c|c|c|}
\hline $\begin{array}{c}\text { County - } \\
\text { (Riverfront / } \\
\text { Nonriver Parcel } \\
\text { Count) }\end{array}$ & $\begin{array}{c}\text { Riverfront } \\
\text { Average } \\
\text { Parcel Value }\end{array}$ & $\begin{array}{c}\text { Non-riverfront } \\
\text { Average } \\
\text { Parcel Value }\end{array}$ & $\begin{array}{l}\text { Average Parcel } \\
\text { Difference in } \\
\text { Value }\end{array}$ & $\begin{array}{l}\text { Value of Land } \\
\text { Attributable to } \\
\text { Riverfrontage }\end{array}$ & Market Value \\
\hline \begin{tabular}{|l|} 
Volusia $(587 /$ \\
$205,080)$
\end{tabular} & $\$ 132,919$ & 15,937 & 116,982 & $\$ 100,077,000$ & $\$ 117,737,647$ \\
\hline $\begin{array}{l}\text { Brevard }(3,654 / \\
142,098)\end{array}$ & $\$ 106,351$ & 23,174 & 83,177 & $\$ 303,930,000$ & $\$ 357,564,706$ \\
\hline \begin{tabular}{|l|} 
Indian River \\
$(442 / 51,550)$
\end{tabular} & $\$ 237,197$ & 31,429 & 205,768 & $\$ 90,949,000$ & $\$ 106,998,824$ \\
\hline $\begin{array}{l}\text { St. Lucie }(1,163 / \\
113722)\end{array}$ & $\$ 71,928$ & 12,578 & 59,350 & $\$ 69,025,000$ & $81,205,882$ \\
\hline \begin{tabular}{|l|} 
Martin (798/ \\
$46,016)$ \\
\end{tabular} & $\$ 212,136$ & 40,389 & 171,747 & $\$ 137,066,000$ & $\$ 161,254,118$ \\
\hline Total & & & & $\$ 701,047,000$ & $\$ 824,761,176$ \\
\hline
\end{tabular}

(Source: Apogee Research, 1996)

The capitalized values were than converted into annual values for analytical purposes as described in section 3.3.4. A total annualized value of $\$ 33$ million was generated, and as 
the study did not factor in proximity into the analysis nor improvement values, the $\$ 33$ million annualized value can be considered a lower bound estimate.

(\$ millions)

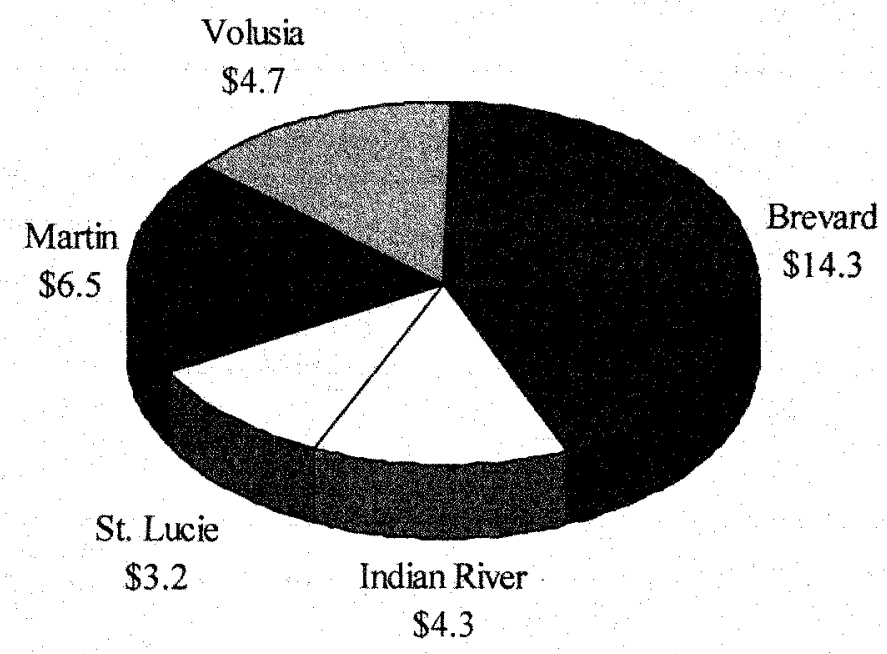

(Source: Adapted from Apogee Research, 1996)

Figure 4.5: IRL Total Annualized Value of Riverfront Land

\subsubsection{Commercial Fishing Value}

Annual dockside values of landings of both shellfish and finfish were $\$ 12.8$ million in 1992 and $\$ 17.0$ million in 1994 . However, in 1995 gill and entangling nets became prohibited in Florida. Therefore, this study only considered the market value of commercial species that can be legally harvested, namely shellfish. Shellfish represented $\$ 8.4$ million of the 1992 landing and $\$ 12.6$ million of the 1994 landings. The $\$ 12.6$ million was the annual value used for this study and was not segmented by county. 


\subsubsection{IRL Total Economic Value}

Apogee Research (1996) estimated the total economic value of the Indian River Lagoon (IRL) to be $\$ 717$ - $\$ 731$ million annually in 1995 dollars.

Table 4.7: IRL 1995 Total Economic Value ${ }^{46}$

(\$millions)

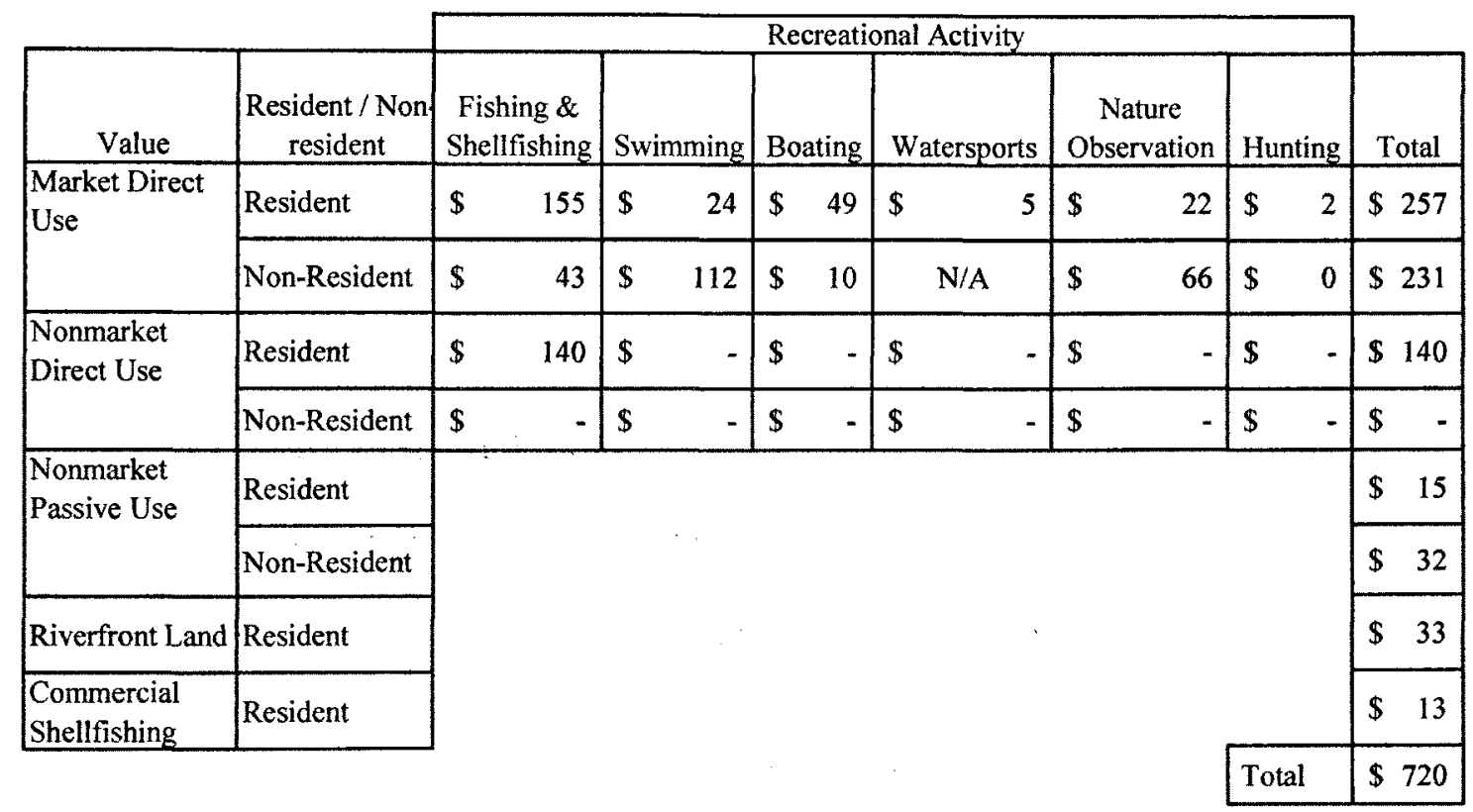

(Source: Apogee Research, 1996)

\subsection{Updated Baseline Estimate}

The following sections present the results of segmenting out the baseline estimate from section 4.2 specifically to St. Lucie and Martin counties, updating the numbers for recent demographics, and adjusting the estimates for inflation.

${ }^{46}$ This total value estimate was derived using median WTP passive use values as suggested in section 4.1.2, and falls within the range given in the report of $\$ 717$ to $\$ 731$ million. 


\subsubsection{Socioeconomic Comparison}

As described in section 3.4 .1 , table 4.8 compares the resident socioeconomic characteristics collected from the Apogee Research telephone survey (1996) to 2000 census data, while table 4.9 compares the non-resident socioeconomic characteristics collected from the Apogee Research intercept survey (1996) to 2001 Florida visitor survey where available. Apogee research concluded from their comparison that the survey sample was representative of the 1990 census population with some minor differences, and therefore the sample results for residents could be directly extrapolated to the IRL regional population. Given that the above comparison with 2000 census data produces results that are similar to the original study's comparison to the 1990 census data, leads to the conclusion that the survey results are able to be extrapolated to the updated populations for St. Lucie and Martin Counties.

Table 4.8: Resident Socioeconomic Characteristic Comparison

\begin{tabular}{|c|c|c|c|c|}
\hline & \multicolumn{2}{|c|}{ Survey Sample } & \multicolumn{2}{|c|}{2000 Census Data ${ }^{47}$} \\
\hline Socioeconomic Characteristic & St. Lucie & Martin & St. Lucie & Martin \\
\hline $\begin{array}{r}18-65 \text { years } \\
\text { Over } 65 \text { years } \\
\text { Refused }\end{array}$ & $\begin{array}{c}74.5 \% \\
25.5 \% \\
0.0 \% \\
\end{array}$ & $\begin{array}{c}70.0 \% \\
30.0 \% \\
0.0 \% \\
\end{array}$ & $\begin{array}{c}70.7 \% \\
29.3 \% \\
\text { N/A } \\
\end{array}$ & $\begin{array}{c}65.3 \% \\
34.7 \% \\
\text { N/A } \\
\end{array}$ \\
\hline $\begin{array}{r}\text { Male } \\
\text { Female }\end{array}$ & $\begin{array}{l}51.5 \% \\
48.5 \% \\
\end{array}$ & $\begin{array}{l}50.5 \% \\
49.5 \% \\
\end{array}$ & $\begin{array}{l}48.1 \% \\
51.9 \% \\
\end{array}$ & $\begin{array}{l}48.5 \% \\
51.5 \% \\
\end{array}$ \\
\hline $\begin{array}{r}\text { White } \\
\text { Black } \\
\text { Hispanic }\end{array}$ & $\begin{array}{c}85.0 \% \\
8.5 \% \\
3.0 \%\end{array}$ & $\begin{array}{c}91.5 \% \\
2.5 \% \\
1.0 \%\end{array}$ & $\begin{array}{c}78.0 \% \\
12.7 \% \\
7.0 \%\end{array}$ & $\begin{array}{c}88.4 \% \\
4.3 \% \\
5.9 \%\end{array}$ \\
\hline
\end{tabular}

47 Percentages are computed from 2000 U.S. Census counts as reported at www.factfinder.census.gov/servlet/BasicFactsServlet 


\begin{tabular}{|c|c|c|c|c|}
\hline & \multicolumn{2}{|c|}{ Survey Sample } & \multicolumn{2}{|c|}{2000 Census Data ${ }^{47}$} \\
\hline Socioeconomic Characteristic & St. Lucie & Martin & St. Lucie & Martin \\
\hline $\begin{array}{r}\begin{array}{r}\text { Other } \\
\text { Refused }\end{array} \\
\end{array}$ & $\begin{array}{l}2.5 \% \\
1.0 \%\end{array}$ & $\begin{array}{l}4.0 \% \\
1.0 \%\end{array}$ & $\begin{array}{l}2.2 \% \\
\text { N/A }\end{array}$ & $\begin{array}{l}1.3 \% \\
\mathrm{~N} / \mathrm{A}\end{array}$ \\
\hline \begin{tabular}{|l|} 
Household Data \\
Average \# per household \\
\end{tabular} & 2.66 & 2.52 & 2.47 & 2.23 \\
\hline \begin{tabular}{|r|} 
Education \\
Grade School (K-8) \\
Some high school \\
High school grad \\
Some college \\
College graduate \\
Post graduate \\
Refused
\end{tabular} & $\begin{array}{c}3.0 \% \\
4.5 \% \\
28.5 \% \\
33.5 \% \\
19.5 \% \\
10.0 \% \\
1.0 \%\end{array}$ & $\begin{array}{c}0.0 \% \\
4.5 \% \\
24.5 \% \\
38.5 \% \\
16.0 \% \\
16.0 \% \\
0.5 \%\end{array}$ & $\begin{array}{c}6.7 \% \\
15.6 \% \\
32.7 \% \\
22.9 \% \\
16.8 \% \\
5.2 \% \\
\text { N/A }\end{array}$ & $\begin{array}{c}4.4 \% \\
10.3 \% \\
28.3 \% \\
24.2 \% \\
24.0 \% \\
8.9 \% \\
\text { N/A }\end{array}$ \\
\hline $\begin{array}{r}\text { Income } \\
<\$ 25,000 \\
\$ 25,000-\$ 50,000 \\
\$ 50,000-\$ 75,000 \\
\text { Over } \$ 75,000 \\
\text { Refused }\end{array}$ & $\begin{array}{c}21.5 \% \\
41.5 \% \\
20.0 \% \\
10.5 \% \\
6.5 \%\end{array}$ & $\begin{array}{l}20.5 \% \\
33.0 \% \\
19.5 \% \\
13.5 \% \\
13.5 \%\end{array}$ & $\begin{array}{c}31.6 \% \\
35.4 \% \\
19.0 \% \\
14.1 \% \\
\text { N/A }\end{array}$ & $\begin{array}{c}26.8 \% \\
30.2 \% \\
18.1 \% \\
24.9 \% \\
\text { N/A }\end{array}$ \\
\hline \begin{tabular}{|l|} 
Average \# of years in FL \\
Average \# of years in Region
\end{tabular} & $\begin{array}{l}19.2 \\
13.3\end{array}$ & $\begin{array}{l}18.8 \\
12.9\end{array}$ & $\begin{array}{l}\text { N/A } \\
\text { N/A }\end{array}$ & $\begin{array}{l}\mathrm{N} / \mathrm{A} \\
\mathrm{N} / \mathrm{A}\end{array}$ \\
\hline
\end{tabular}

(Survey Sample Source: Apogee Research, 1996)

(2000 Census Data Source: US Census Bureau, 2003)

Table 4.9: Non-Resident Socioeconomic Characteristic Comparison

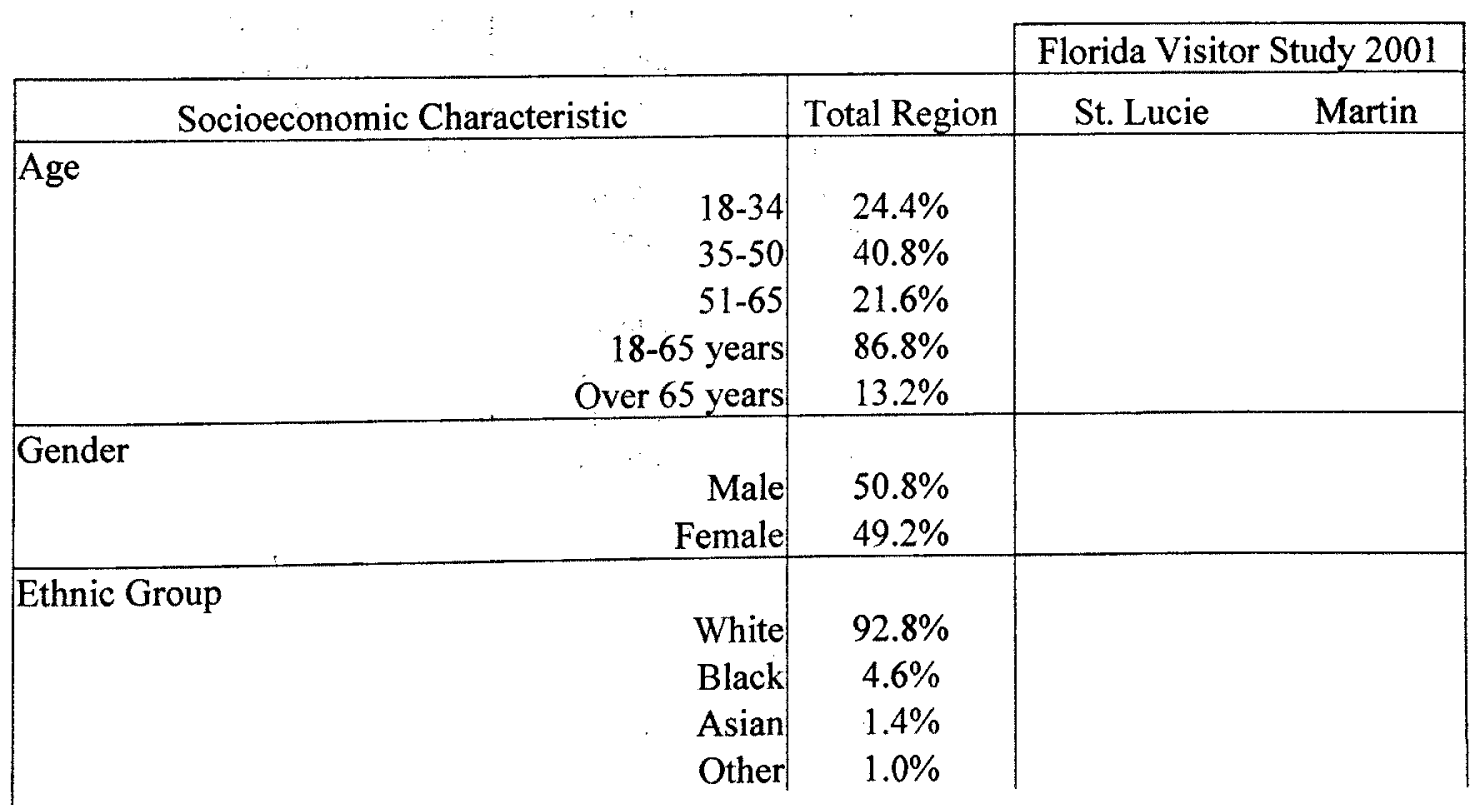




\begin{tabular}{|c|c|c|}
\hline & & Florida Visitor Study 2001 \\
\hline Socioeconomic Characteristic & Total Region & St. Lucie Martin \\
\hline Don't know & $0.2 \%$ & \\
\hline \multicolumn{3}{|l|}{ Traveling Party Data } \\
\hline Average \# per party & 2.75 & 2.9 \\
\hline Average \# under 18 & 0.72 & \\
\hline Average \# over 18 & 2.28 & \\
\hline \multicolumn{3}{|l|}{ Income } \\
\hline$<\$ 25,000$ & $9.8 \%$ & $12 \%$ \\
\hline$\$ 25,000-\$ 50,000$ & $34.2 \%$ & $25 \%$ \\
\hline$\$ 50,000-\$ 75,000$ & $22.0 \%$ & $26 \%$ \\
\hline Over $\$ 75,000$ & $21.6 \%$ & $37 \%$ \\
\hline Refused & $12.4 \%$ & \\
\hline$\%$ of respondents on 1st trip to Region & 35.4 & \\
\hline $\begin{array}{l}\text { Avg length of stay for respondents on first trip to } \\
\text { region }\end{array}$ & 6 days & 6.3 \\
\hline $\begin{array}{l}\text { Avg length of stay for respondents having } \\
\text { previously visited the region }\end{array}$ & 18 days & \\
\hline
\end{tabular}

(Survey Sample Source: Apogee Research, 1996)

(2001 Florida Visitor Source: Visit Florida Research Office, 2001)

\subsubsection{Updated Market Direct Use Values}

Following the methodology described in section 3.4.2, updated market direct use values for residents and non-residents were estimated. Adult populations of 160,739 in St. Lucie county and 108,689 in Martin county, representing population increases of $28 \%$ and $25 \%$ respectively, increased resident total market direct use values to $\$ 113$ million.

Table 4.10: IRLS Resident Market Direct Use Values

(\$ millions)

\begin{tabular}{|l|c|c|c|c|c|c|}
\cline { 2 - 7 } \multicolumn{1}{c|}{} & \multicolumn{3}{|c|}{ Apogee Baseline (1995 Dollars) } & \multicolumn{3}{c|}{ Updated (Oct 2001 Dollars) } \\
\hline Use Category & St. Lucie & Martin & Total & St. Lucie & Martin & Total \\
\hline Fishing & $\$ 25.5$ & $\$ 26.7$ & $\$ 52.1$ & $\$ 38.1$ & $\$ 38.8$ & $\$ 76.9$ \\
\hline Shellfishing & $\$ 0.2$ & $\$ 0.1$ & $\$ 0.3$ & $\$ 0.3$ & $\$ 0.1$ & $\$ 0.4$ \\
\hline Swimming & $\$ 2.8$ & $\$ 3.5$ & $\$ 6.3$ & $\$ 4.1$ & $\$ 5.1$ & $\$ 9.2$ \\
\hline
\end{tabular}




\begin{tabular}{|c|c|c|c|c|c|c|}
\hline \multirow[b]{2}{*}{ Boating } & \multicolumn{3}{|c|}{ Apogee Baseline (1995 Dollars) } & \multicolumn{3}{|c|}{ Updated (Oct 2001 Dollars) } \\
\hline & $\$ 4.9$ & $\$ 7.5$ & $\$ 12.4$ & $\$ 7.3$ & $\$ 10.9$ & $\$ 18.2$ \\
\hline Watersports & $\$ 1.1$ & $\$ 0.5$ & $\$ 1.6$ & $\$ 1.7$ & $\$ 0.7$ & $\$ 2.4$ \\
\hline Nature Observation & $\$ 2.1$ & $\$ 2.1$ & $\$ 4.2$ & $\$ 3.2$ & $\$ 3.0$ & $\$ 6.2$ \\
\hline Hunting & $\$ 0.0$ & $\$ 0.0$ & $\$ 0.0$ & $\$ 0.0$ & $\$ 0.0$ & $\$ 0.0$ \\
\hline Total & $\$ 36.6$ & $\$ 40.3$ & $\$ 76.8$ & $\$ 54.7$ & $\$ 58.6$ & $\$ \quad 113.3$ \\
\hline
\end{tabular}

(Apogee Baseline Source: Apogee Research, 1996)

The total number of non-resident visitors to Florida for all of 2002, was 76.2 million. This significant increase of $91 \%$ from 1995, generated non-resident market direct use values of $\$ 51$ million.

Table 4.11: IRLS Non-Resident Market Direct Use Values (\$ millions)

\begin{tabular}{|l|c|c|c|c|c|c|}
\cline { 2 - 7 } \multicolumn{1}{c|}{} & \multicolumn{3}{c|}{ Apogee Baseline (1995 Dollars) } & \multicolumn{3}{c|}{ Updated (Oct 2001 Dollars) } \\
\hline Use Category & St. Lucie & Martin & Total & St. Lucie & Martin & Total \\
\hline Fishing & $\$ 3.9$ & $\$ 1.1$ & $\$ 5.0$ & $\$ 8.7$ & $\$ 2.5$ & $\$ 11.2$ \\
\hline Shellfishing & & & $\$ 0.0$ & & & $\$ 0.0$ \\
\hline Swimming & $\$ 8.9$ & $\$ 1.2$ & $\$ 10.1$ & $\$ 19.8$ & $\$ 2.7$ & $\$ 22.6$ \\
\hline Boating & $\$ 1.1$ & $\$ 0.4$ & $\$ 1.5$ & $\$ 2.5$ & $\$ 0.8$ & $\$ 3.3$ \\
\hline Watersports & & & $\$ 0.0$ & & & $\$ 0.0$ \\
\hline Nature Observation & $\$ 6.0$ & $\$ 0.3$ & $\$ 6.3$ & $\$ 13.3$ & $\$ 0.6$ & $\$ 13.9$ \\
\hline Hunting & & & $\$ 0.0$ & & & $\$ 0.0$ \\
\hline & $\$ 19.9$ & $\$ 3.0$ & $\$ 22.9$ & $\$ 44.3$ & $\$ 6.6$ & $\$$ \\
\hline
\end{tabular}

(Apogee Baseline Source: Adapted from Apogee Research, 1996)

${ }^{48}$ The original study did not break down visitor values by county, this is done to show the magnitude of change in the updated value 


\subsubsection{Updated Nonmarket Passive Use Values}

Following the methodology described in section 3.4.3, updated nonmarket passive use values for residents and non-residents were estimated. A $28 \%$ increase in the number of households to 81,391 in St. Lucie county, and a $26 \%$ increase in the number of households to 57,382 in Martin county, generated an annual nonmarket passive use value of $\$ 5$ million $^{49}$. The total number of non-resident visitors to Florida for all of 2002, was 76.2 million. This significant increase of $91 \%$ from 1995 , generated non-resident nonmarket passive use values of $\$ 6$ million.

Table 4.12: IRLS Resident \& Non-Resident Nonmarket Passive Use Values (\$ millions)

\begin{tabular}{|l|c|c|c|c|c|c|}
\cline { 2 - 7 } \multicolumn{1}{c|}{} & \multicolumn{3}{c}{ Apogee Baseline (1995 Dollars) } & \multicolumn{3}{c|}{ Updated (Oct 2001 Dollars) } \\
\hline Median WTP & St. Lucie & Martin & Total & St. Lucie & Martin & Total \\
\hline Resident & $\$ 1.9$ & $\$ 1.4$ & $\$ 3.3$ & $\$ 2.8$ & $\$ 2.0$ & $\$ 4.9$ \\
\hline Non- Resident & $\$ 2.3$ & $\$ 0.3$ & $\$ 2.6$ & $\$ 5.2$ & $\$ 0.7$ & $\$ 5.9$ \\
\hline
\end{tabular}

(Apogee Baseline Source: Apogee Research, 1996)

\subsubsection{Updated Nonmarket Direct Use Values}

Following the methodology described in section 3.4.4, updated nonmarket direct use values for residents were estimated at $\$ 72$ million annually.

${ }^{49}$ Median WTP values as opposed to mean WTP values were chosen to be used as suggested in section 4.2 .2 
Table 4.13: IRLS Resident Nonmarket Direct Use Values

(\$ millions)

\begin{tabular}{|l|c|c|c|c|c|c|}
\cline { 2 - 7 } \multicolumn{1}{c|}{} & \multicolumn{9}{|c|}{ Apogee Baseline (1995 Dollars) } & \multicolumn{3}{|c|}{ Updated (Oct 2001 Dollars) } \\
\hline Activity & St. Lucie & Martin & Total & St. Lucie & Martin & Total \\
\hline Fishing & $\$ 26.5$ & $\$ 24.7$ & $\$ 51.2$ & $\$ 37.3$ & $\$ 34.6$ & $\$ 71.8$ \\
\hline
\end{tabular}

(Apogee Baseline Source: Adapted from Apogee Research, 1996)

\subsubsection{Updated Riverfront Residential Land Value}

Following the methodology described in section 3.4.5, updated riverfront residential land values for residents were estimated at $\$ 11$ million annually.

Table 4.14: IRLS Resident Riverfront Land Values

(\$ millions)

Apogee Baseline (1995 Dollars) Updated (Oct 2001 Dollars)

\begin{tabular}{|l|c|c|c|c|c|c|}
\hline Riverfront Land & St. Lücie & Martin & Total & St. Lucie & Martin & Total \\
\hline Market Value & $\$ 3.2$ & $\$ 6.5$ & $\$ 9.7$ & $\$ 3.8$ & $\$ 7.5$ & $\$ 11.3$ \\
\hline
\end{tabular}

(Apogee Baseline Source: Apogee Research, 1996)

\subsubsection{Updated Commercial Fishing Values}

Following the methodology described in section 3.3.6, updated commercial fishing values for residents were estimated at $\$ 144,000$ annually, with St. Lucie county representing nearly $\$ 140,000$. This is an activity that apparently does not provide much economic value to the IRLS.

${ }^{50}$ The original study did not break down nonmarket direct use values by county, this is done to show the magnitude of change in the updated value 


\subsubsection{IRLS Total Economic Value}

A combined annual value of $\$ 167$ million can be attributed to St. Lucie and Martin Counties from the original $\$ 720$ million total value estimated for the entire IRL in 1995. This represents approximately $23.2 \%$ of the total value and seems a reasonable estimate given the population in these two counties was $22.7 \%$ of the total five county 1995 population. Accounting for increases in population, number of visitors, and households, as well as adjusting expenditures and WTP estimates for inflation, yields a 2001 annual value of $\$ 258$ million attributable to St. Lucie and Martin Counties.

Table 4.15: IRLS Total Baseline Value for 1995 \& 2001

(\$ millions)

Original Study (1995 Dollars)

\begin{tabular}{|l|l|lr|rr|rr|c|}
\hline \multirow{2}{*}{ Value } & $\begin{array}{l}\text { Resident/Non- } \\
\text { Resident }\end{array}$ & St. Lucie & \multicolumn{1}{c|}{ Martin } & \multicolumn{2}{c|}{ Total } & $\begin{array}{c}\% \text { of } \\
\text { Total }\end{array}$ \\
\hline \multirow{2}{*}{ Market Direct Use } & Resident & $\$$ & 36.6 & $\$$ & 40.3 & $\$$ & 76.8 & $46 \%$ \\
\cline { 2 - 9 } & Non-Resident & $\$$ & 19.9 & $\$$ & 3.0 & $\$$ & 22.9 & $14 \%$ \\
\hline Nonmarket Direct Use & Resident & $\$$ & 26.5 & $\$$ & 24.7 & $\$$ & 51.2 & $31 \%$ \\
\hline Nonmarket Passive Use & Resident & $\$$ & 1.9 & $\$$ & 1.4 & $\$$ & 3.3 & $2 \%$ \\
\cline { 2 - 8 } & Non-Resident & $\$$ & 2.3 & $\$$ & 0.3 & $\$$ & 2.6 & $2 \%$ \\
\hline Riverfront Land & Resident & $\$$ & 3.2 & $\$$ & 6.5 & $\$$ & 9.7 & $6 \%$ \\
\hline Commercial Shellfishing & Resident & $\$$ & 0.1 & $\$$ & 0.0 & $\$$ & 0.1 & $0 \%$ \\
\hline Total & & $\$$ & 90.6 & $\$$ & 76.0 & $\$$ & 166.6 & $100 \%$ \\
\hline
\end{tabular}

(Source: Adapted from Apogee Research, 1996)

Updated (Oct 2001 Dollars)

\begin{tabular}{|c|c|c|c|c|c|}
\hline Value & $\begin{array}{l}\text { Resident/Non- } \\
\text { Resident }\end{array}$ & St. Lucie & Martin & Total & $\begin{array}{l}\% \text { of } \\
\text { Total } \\
\end{array}$ \\
\hline \multirow[t]{2}{*}{ Market Direct Use } & Resident & 54.7 & 58.6 & 113.3 & $44 \%$ \\
\hline & Non-Resident & 44.3 & 6.6 & 51.0 & $20 \%$ \\
\hline
\end{tabular}




\begin{tabular}{|l|l|rr|rr|rr|c|}
\hline & $\begin{array}{l}\text { Uesident/Non- } \\
\text { Value }\end{array}$ & Resident & St. Lucie & \multicolumn{2}{c|}{ Martin } & \multicolumn{2}{|c|}{ Total } & \multicolumn{1}{c|}{$\begin{array}{c}\% \text { of } \\
\text { Total }\end{array}$} \\
\hline Nonmarket Direct Use & Resident & $\$$ & 37.3 & $\$$ & 34.6 & $\$$ & 71.8 & $28 \%$ \\
\hline Nonmarket Passive Use & Resident & $\$$ & 2.8 & $\$$ & 2.0 & $\$$ & 4.9 & $2 \%$ \\
\cline { 2 - 9 } & Non-Resident & $\$$ & 5.2 & $\$$ & 0.7 & $\$$ & 5.9 & $2 \%$ \\
\hline Riverfront Land & Resident & $\$$ & 3.8 & $\$$ & 7.5 & $\$$ & 11.3 & $4 \%$ \\
\hline Commercial Shellfishing & Resident & $\$$ & 0.1 & $\$$ & 0.0 & 0.1 & $0 \%$ \\
\hline Total & & $\$$ & 148.3 & $\$$ & 110.0 & $\$$ & 258.3 & $100 \%$ \\
\hline
\end{tabular}

Much of this 33\% increase in value from 1995 (after adjusting for inflation) is attributable to the IRLS' continuing attraction to new residents. Port St. Lucie is the $12^{\text {th }}$ fastest growing city in Florida according to recent U.S. Census data (Staff and Wire reports, 2003). From the five-county IRL region, St. Lucie and Martin Counties had the highest and $3^{\text {rd }}$ highest growth rates respectively as shown in the below figure:

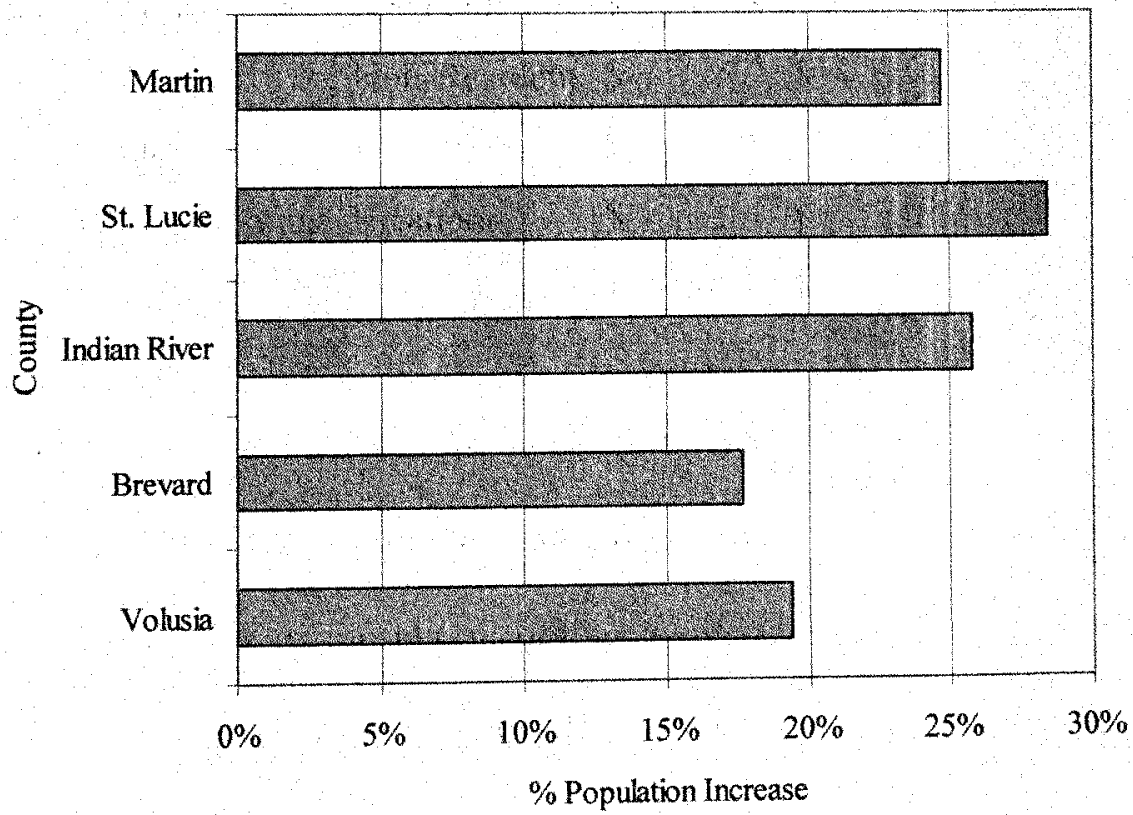

Figure 4.6: 1995 to 2002 IRL Adult Population Growth Rates 
Another important driver for this increase in value, was the increase in the number of visitors to Florida over this time period. From 1994 to 2002, the number of visitors to Florida increased by nearly $100 \%^{51}$ from 39.9 to 76.2 million, obviously generating a significant impact to any region in the state.

\subsection{Additional Baseline Values}

As per section 3.5, non-resident nonmarket direct use fishing values and resident and non-resident nonmarket direct use values for all other recreational activities excluding fishing are added to the updated baseline estimate of section 4.3.7. Incorporating these values adds an additional $\$ 62$ million in resident, and $\$ 23$ million in non-resident, nonmarket direct use values.

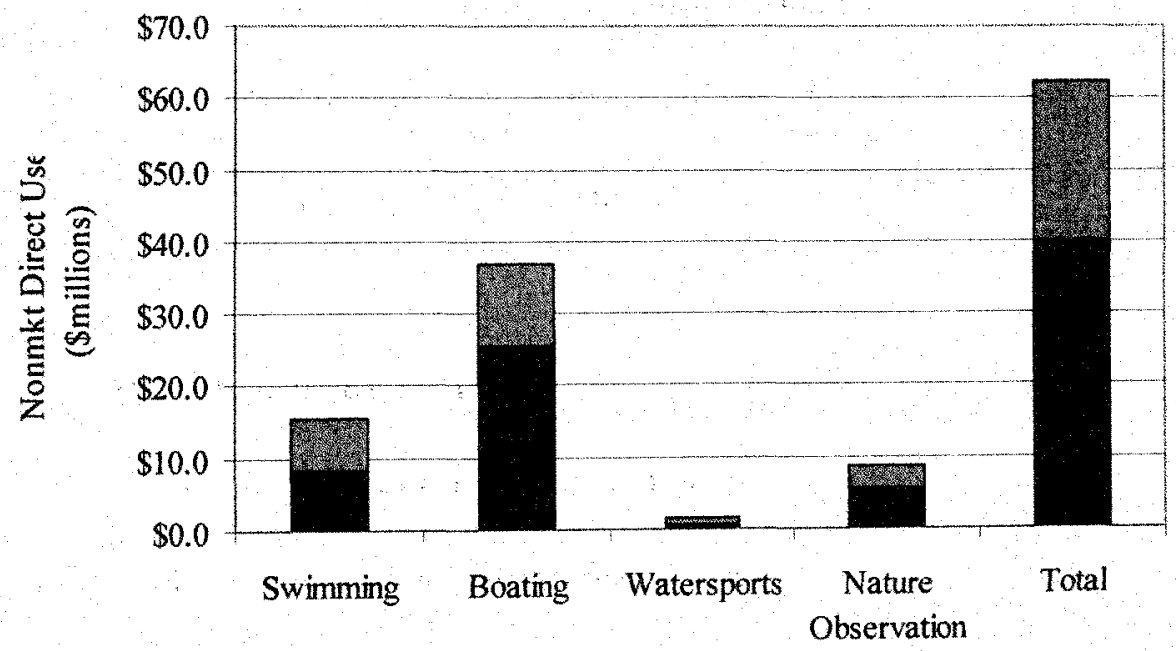

Recreation Activity

St. Lucie Martin

Figure 4.7: Resident Added Nonmarket Direct Use Values

s1 Again, this value may be attributable to the implementation of better visitor tracking mechanisms by Visit Florida 


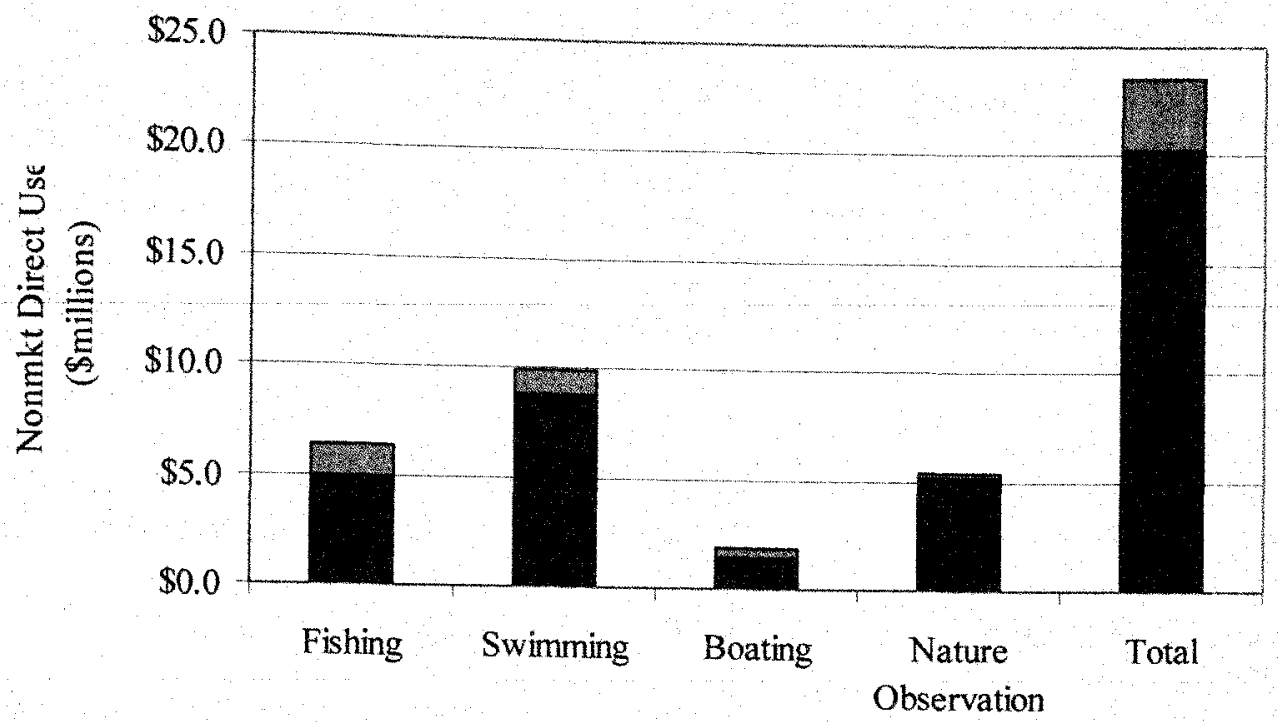

Recreation Activity

St. Lucie Martin

Figure 4.8: Non-resident Added Nonmarket Direct Use Values

Adding these values to the updated IRLS baseline of section 4.3 .7 , generates a new updated IRLS baseline of $\$ 344$ million:

Table 4.16: Updated Baseline with Additional Values

\begin{tabular}{|c|c|c|c|c|c|c|c|c|}
\hline & \multicolumn{8}{|c|}{ Updated (Oct 2001 Dollars) } \\
\hline Value & $\begin{array}{l}\text { Resident/Non- } \\
\text { Resident }\end{array}$ & & Lucie & & $\operatorname{artin}$ & & Total & $\%$ of Total \\
\hline \multirow[t]{2}{*}{ Market Direct Use } & Resident & \$ & 54.7 & $\$$ & 58.6 & $\$$ & 113.3 & $33 \%$ \\
\hline & Non-Resident & $\$$ & 44.3 & $\$$ & 6.6 & $\$$ & 51.0 & $15 \%$ \\
\hline \multirow[t]{2}{*}{ Nonmarket Direct Use } & Resident & $\$$ & 77.1 & $\$$ & 57.1 & $\$$ & 134.2 & $39 \%$ \\
\hline & Non-Resident & $\$$ & 20.3 & $\$$ & 3.3 & $\$$ & 23.6 & $7 \%$ \\
\hline \multirow[t]{2}{*}{ Nonmarket Passive Use } & Resident & $\$$ & 2.8 & $\$$ & 2.0 & $\$$ & 4.9 & $1 \%$ \\
\hline & Non-Resident & $\$$ & 5.2 & $\$$ & 0.7 & $\$$ & 5.9 & $2 \%$ \\
\hline
\end{tabular}




\begin{tabular}{|l|l|rr|rr|rr|r|}
\hline & $\begin{array}{l}\text { Resident/Non- } \\
\text { Resident }\end{array}$ & St. Lucie & Martin & \multicolumn{2}{c|}{ Total } & $\%$ of Total \\
\hline Riverfront Land & Resident & $\$$ & 3.8 & $\$$ & 7.5 & $\$$ & 11.3 & $3 \%$ \\
\hline Commercial Shellfishing & Resident & $\$$ & 0.1 & $\$$ & 0.0 & 0.1 & $0 \%$ \\
\hline Total & & $\$ 208.4$ & $\$$ & 135.8 & $\$$ & 344.2 & $100 \%$ \\
\hline
\end{tabular}

\subsection{Water Quality Baseline Assessment}

The mean concentration of total phosphorus for the IRLS over the period 19851998 was $0.170 \mathrm{mg} / \mathrm{l}$, while the mean total nitrogen concentration over the same period ranged from 1.0 to $1.7 \mathrm{mg} / 1$ (USACE/SFWMD, 2002). Comparing these values to the standards presented in section 2.5 shows that total phosphorus and total nitrogen baseline concentrations are at quality classification levels deemed to be bad and low respectively. Two separate target concentrations for total phosphorus were identified, $0.081 \mathrm{mg} / 1$ and $0.053 \mathrm{mg} / 1$ (USACE/SFWMD, 2002), along with a target concentration of $0.692 \mathrm{mg} / 1$ for total nitrogen (IRL SWIM, 2002). Assuming that the IRLS restoration achieves these concentration targets via the planned $41 \%$ phosphorus and $26 \%$ nitrogen load reductions, total phosphorus concentration levels would improve from bad to approaching fairly clean, and total nitrogen would improve from low to medium. These results are shown in the figures below. 


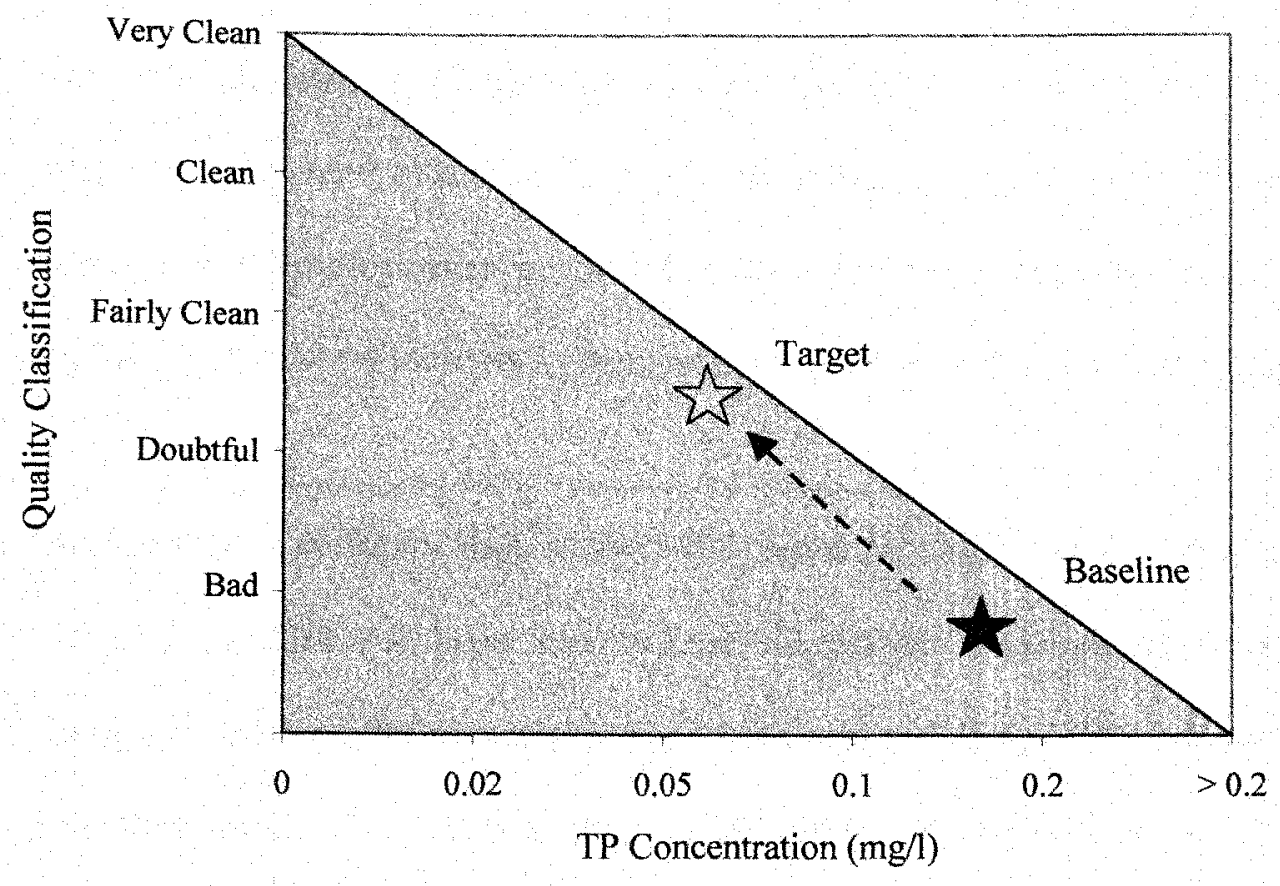

Figure 4.9: IRLS Total Phosphorus Concentration Baseline

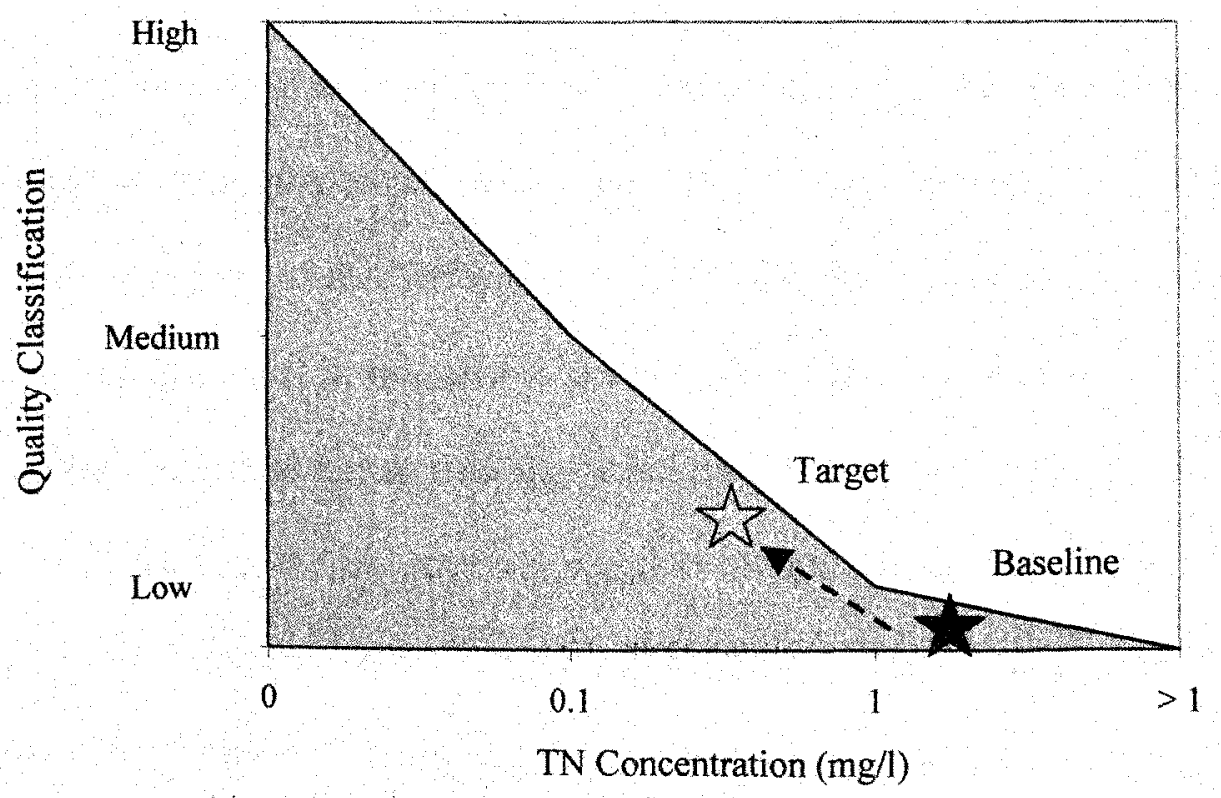

Figure 4.10: IRLS Total Nitrogen Concentration Baseline 
Other important results following the methodology presented in sections 3.6 and 3.7.1:

1) Given the diminishing marginal returns for water quality improvements hypothesis of figure 3.4 presented in section 3.7.1, the poor IRLS baseline levels presented above imply that an improvement in the water quality concentration levels could expect a relatively significant increase in demand associated with its implementation

2) Bricker et al.'s eutrophication study (1999) rated the whole IRL as having a moderate eutrophic condition with no impaired uses identified. However, this study did rate the IRL as having a future outlook that would worsen highly. One can conclude from this that immediate increases in demand may not occur from a water quality improvement, but over time the water quality improvement would have an important effect on the use of the IRLS for recreational activities.

3) Total phosphorus and total nitrogen concentrations for the Albemarle and Pamlico Sound were approximately $0.09 \mathrm{mg} / \mathrm{l}$ and $0.75 \mathrm{mg} / \mathrm{l}$ respectively (US EPA, 2002) around the time of the Whitehead et al (2000) study. This indicates that while the water quality level in this area is not considered clean compared to the standards, it can be considered better than the water quality level in the IRLS. As per section 2.2.3.2, the hypothetical scenario posed to respondents in the Whitehead et al. study called for bringing water quality levels to those of 1981. As per the 1979 Nutrient Sensitive Water Act, total phosphorus concentration limits were $0.01 \mathrm{mg} / \mathrm{l}$, and total nitrogen concentration limits were $0.03 \mathrm{mg} / \mathrm{l}$. Using the 1979 nutrient limits as a 
proxy for the 1981 level target concentrations of the Whitehead et al. study indicates target concentrations of clean for TP, and medium to high for TN. These target concentrations are at a higher quality level than those of the IRLS restoration. In summary, Whitehead's et al. study (2000) identified increases to demand from a higher initial water quality baseline moving toward higher target concentration levels as compared to the IRLS. This is factored into the benefit transfer value.

Also as per section 3.6, a baseline list of the \% of IRLS waterbodies impaired is developed. A total of 57.7 miles of rivers, 152 square miles of bays/estuaries, and 9,664 acres of lakes were assessed for St. Lucie and Martin counties in the 2000 305(b) list. From this assessment, $75 \%$ of rivers and $38 \%$ of bays/estuaries were determined to be impaired. A summary of these results are presented in the below table:

Table 4.17: IRLS \% Waterbody Impaired

\begin{tabular}{|l|l|c|c|}
\hline Waterbody Type & Total Assessed & $\%$ Good & $\%$ Not Good \\
\hline Stream/Creek/River & 57.7 Miles & $25.82 \%$ & $74.18 \%$ \\
\hline Bay/ Estuary & 152.1 SQ Miles & $61.74 \%$ & $38.26 \%$ \\
\hline Lake/Reservoir/Pond & 9664 Acres & $100.00 \%$ & $0.00 \%$ \\
\hline
\end{tabular}

The details of this assessment are presented in the following table: 
Table 4.18: Detailed IRLS Assessed Waterbodies

\begin{tabular}{|c|c|c|c|c|c|c|c|c|c|c|}
\hline Waterbody Name & Planning Unit & Class & \begin{tabular}{|c} 
Type \\
\end{tabular} & $\begin{array}{c}\text { Fully } \\
\text { Supported } \\
\end{array}$ & $\begin{array}{c}\text { Partially } \\
\text { Supported }\end{array}$ & $\begin{array}{c}\text { Not } \\
\text { Supported }\end{array}$ & $\begin{array}{c}\text { Good or } \\
\text { Not Good } \\
\end{array}$ & Miles & SQ Miles & Acres \\
\hline $\mathrm{C}-44$ & C.44 & & Stream/Creek/River & $\mathbf{X}$ & & & Good & 5 & & \\
\hline Martin Co. ICCW & Coastal & III M & Bay / Estuary & $\mathbf{X}$ & & & Good & & 8.7 & \\
\hline Martin Co. ICCW & Coastal & III M & Bay / Estuary & $\mathbf{X}$ & & & Good & & 6.1 & \\
\hline Moore Creek & Coastal & III M & Bay / Estuary & $\mathbf{X}$ & & & Good & & 5 & \\
\hline North Coastal & Coastal & III M & Bay / Estuary & $\mathbf{X}$ & & & Good & & 6.9 & \\
\hline South Indian River & Coastal & II & Bay / Estuary & $\mathbf{X}$ & & & Good & & 40.4 & \\
\hline South Indian River & Coastal & II & Bay / Estuary & $\mathbf{X}$ & & & Good & & 16.2 & \\
\hline South Indian River & Coastal & II & Bay / Estuary & $\mathbf{X}$ & & & Good & & 10.6 & \\
\hline Savannahs & North St. Lucie & III F & Lake/Reservoir/Pond & $\mathbf{X}$ & & & Good & & & 9664 \\
\hline Basin 2 & South St. Lucie & III F & Stream/Creek/River & $\mathbf{X}$ & $\therefore$ & & Good & 5 & & 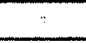 \\
\hline South Fork St. Lucie & South St. Lucie & III F & Stream/Creek/River & $\mathbf{X}$ & & & Good & 4.9 & & \\
\hline $\mathrm{C}-23$ & $\mathrm{C}-23$ & III F & Stream/Creek/River & & $\mathbf{X}$ & & Not Good & 5 & & \\
\hline $\mathrm{C}-24$ & $\mathrm{C}-24$ & III F & Stream/Creek/River & & $\mathbf{X}$ & & Not Good & 5 & & \\
\hline $\mathrm{C}-25$ & C-25/Basin 1 & III F & Stream/Creek/River & & $\mathbf{X}$ & & Not Good & 5 & & \\
\hline Manatee Pocket & Coastal & III M & Bay / Estuary & & $\mathbf{X}$ & & Not Good & & 6.9 & \\
\hline South Indian River & Coastal & II & Bay / Estuary & & $\mathbf{X}$ & & Not Good & & 7.8 & \\
\hline St Lucie River & Coastal & III $\mathrm{M}$ & Bay / Estuary & & $\mathbf{X}$ & & Not Good & & 19.5 & \\
\hline Five Mile Creek & North St. Lucie & III F & Stream/Creek/River & & $\mathbf{X}$ & & Not Good & 3.8 & & \\
\hline North St. Lucie & North St. Lucie & III M & Bay / Estuary & & $\mathbf{X}$ & & Not Good & & 12.4 & \\
\hline St. Lucie & North St. Lucie & III M & Bay / Estuary & & & $\mathbf{X}$ & Not Good & & 7.7 & \\
\hline Ten Mile Creek & North St. Lucie & III F & Stream/Creek/River & & $\mathbf{X}$ &. & Not Good & 7.9 & & \\
\hline Basin 6 & South St. Lucie & III F & Stream/Creek/River & & $\mathbf{X}$ & & Not Good & 5 & & \\
\hline Bessey Creek & South St. Lucie & III F & Stream/Creek/River & & $\mathbf{X}$ & & Not Good & 1.9 & & \\
\hline Bessey Creek & South St. Lucie & III F & Stream/Creek/River & & & $\mathbf{X}$ & Not Good & 3.6 & & \\
\hline St. Lucie Canal & South St. Lucie & III M & Stream/Creek/River & & $\mathbf{X}$ & & Not Good & 5.6 & & \\
\hline Tidal St. Lucie & South St. Lucie & III M & Bay / Estuary & & $\mathbf{X}$ & & Not Good & & 3.9 & \\
\hline Total & & & & & & & & 57.7 & 152.1 & 9664 \\
\hline
\end{tabular}




\subsection{Estimated Market Direct Use Benefits}

As discussed in section 4.5, water quality improvements to the IRLS baseline can be expected to lead to a fairly significant increase in demand for recreational activities in the IRLS. Whitehead et al. (2000) estimated a $32 \%$ increase in the number of trips (original participants and non-participants) for the water quality improvements in the Albemarle and Pamlico Sounds. As their study's increase in demand was identified for a similar waterbody with a higher initial water quality baseline and higher target concentration levels as compared to the IRLS, a more conservative $20 \%$ increase in the number of trips for current participants and $1 \%$ increase in the overall absolute level of participation is used in this analysis to account for the possible inaccuracy of a single point benefit transfer. These benefit transfer values are transferred to the following two equations as discussed in section 3.7.1 in order to generate the market direct use benefits.

$$
\mathrm{MD}_{\mathrm{R}}=\left(\mathrm{POP}_{\mathrm{i}}\right) \times\left(\% \mathrm{PART}_{\mathrm{R}}\right) \times\left(\mathrm{EXP}_{\mathrm{R}}\right)
$$

where: $\quad \operatorname{EXP}_{\mathrm{R}}=$ (average annual \# of days participating in activity) $\mathrm{x}$ (total average daily expenditure).

$$
\mathrm{MD}_{\mathrm{NR}}=(\mathrm{TP}) \times\left(\% \mathrm{PART}_{\mathrm{NR}}\right) \times\left(\mathrm{EXP}_{\mathrm{NR}}\right)
$$

where: $\quad \operatorname{EXP}_{\mathrm{NR}}=($ Median \# of days participating in activity) $\mathrm{x}$ (total average daily expenditure)

Using these $\%$ increases leads to a $\$ 30.3$ million net benefit from resident users, and a $\$ 48.1$ million net benefit from non-resident users as shown in the following two tables ${ }^{52}$ :

${ }^{52}$ As these are market values, their increase would also have a multiplier effect through the rest of the economy which are not estimated in this study, therefore this estimated value could be considered a lower bound 
Table 4.19: Resident Estimated IRLS Market Direct Use Benefits

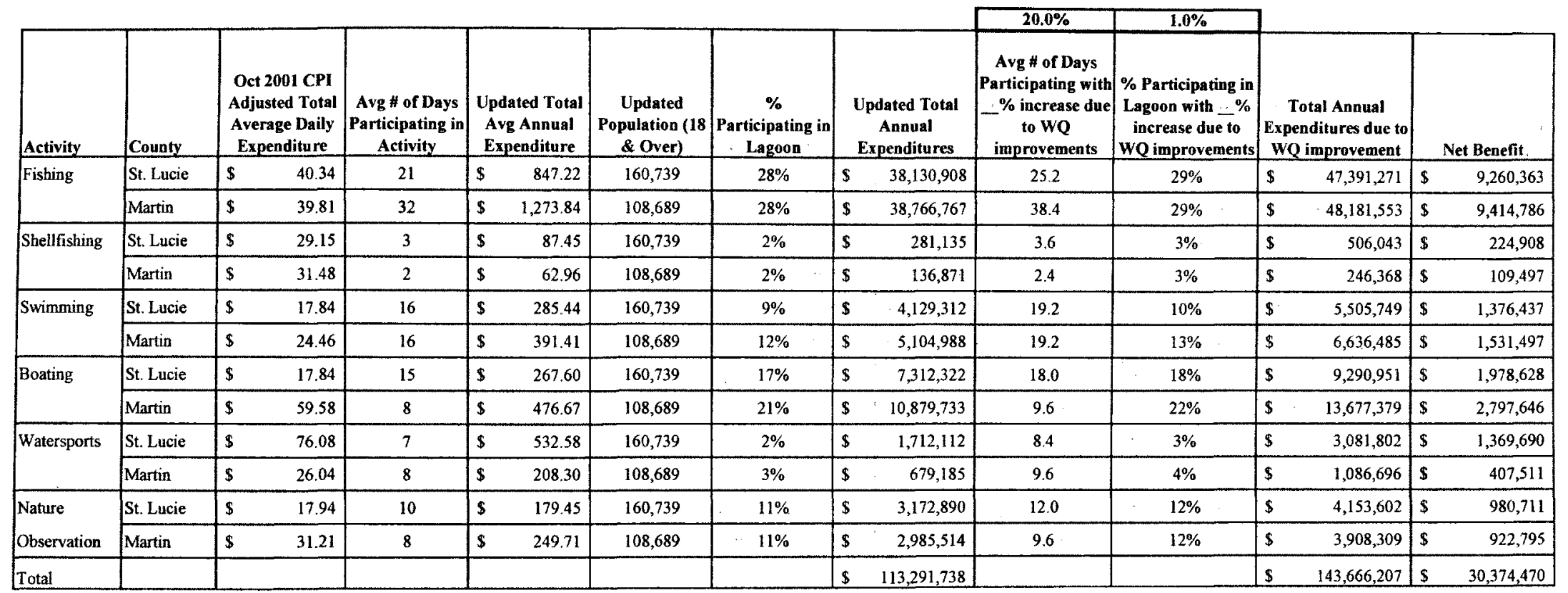


Table 4.20: Non-Resident Estimated IRLS Market Direct Use Benefits

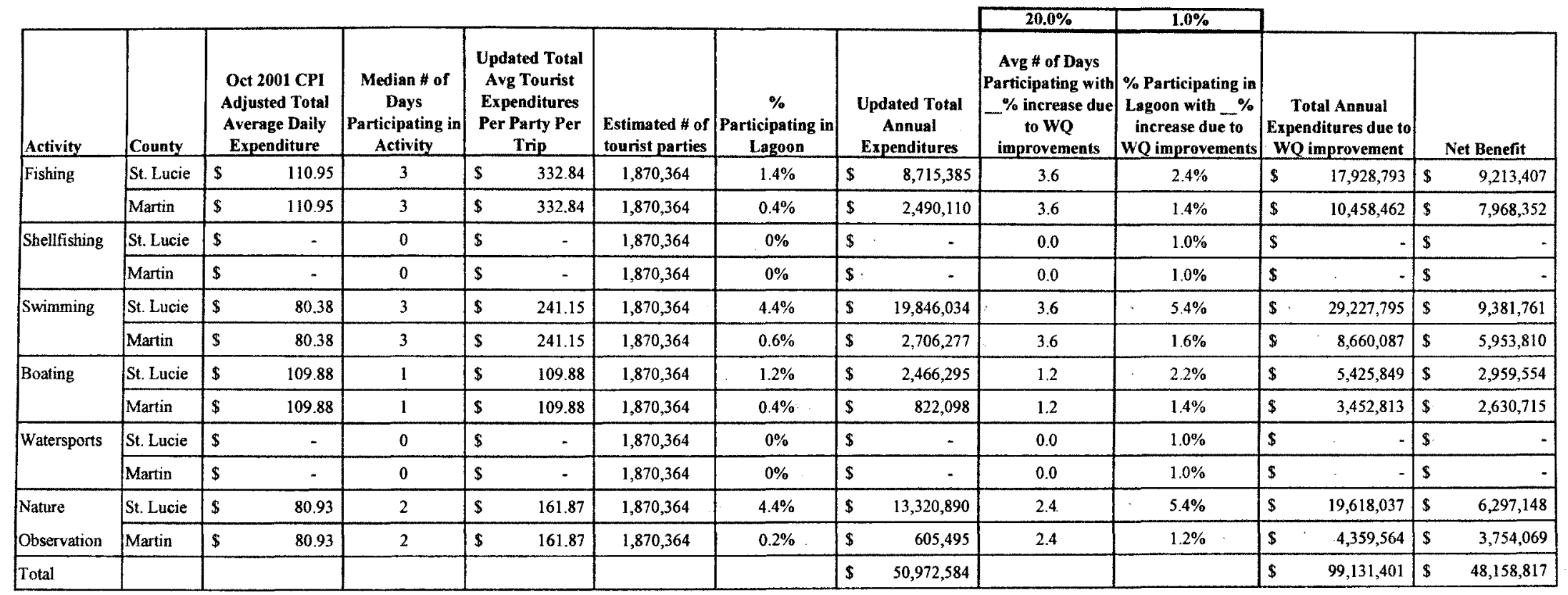




\subsection{Estimated Nonmarket Direct and Passive Use Benefits}

The 50\% improvement of impaired waters assumption as discussed in section 3.7 .2 is applied to the identified impaired waterbodies listed in section 4.5 in order to estimate the nonmarket passive use benefits according to equations 3.15 and 3.16 for residents and 3.17 and 3.18 for non-residents as discussed in section 3.7.2:

$$
\begin{aligned}
& \mathrm{NMP}_{\text {Rriver }}=\left(\mathrm{HH}_{\mathrm{i}}\right) \times(\$ 4.03) \times(\% \text { IRLS rivers impaired } \times 50 \%) \\
& \mathrm{NMP}_{\text {Restuary }}=\left(\mathrm{HH}_{\mathrm{i}}\right) \times(\$ 8.18) \times(\% \text { IRLS estuaries impaired } \times 50 \%) \\
& \mathrm{NMP}_{\text {NRriver }}=(\mathrm{TP}) \times(\$ 4.03) \times(\% \text { IRLS rivers impaired } \times 50 \%) \\
& \mathrm{NMP}_{\text {NRestuary }}=(\mathrm{TP}) \times(\$ 8.18) \times(\% \text { IRLS estuaries impaired } \times 50 \%)
\end{aligned}
$$

\begin{tabular}{|c|c|c|c|c|c|c|c|c|}
\hline \multirow[b]{2}{*}{ Waterbody Type } & \multirow[b]{2}{*}{ Total Assessed } & \multirow[b]{2}{*}{$\begin{array}{l}\% \text { Not } \\
\text { Good }\end{array}$} & \multirow[b]{2}{*}{$\begin{array}{c}50 \% \\
\text { Improvement }\end{array}$} & \multirow[b]{2}{*}{$\begin{array}{c}\text { Non-Use WTP } \\
\text { Per } 1 \% \\
\text { Improvement }\end{array}$} & \multicolumn{2}{|c|}{ \# of Households } & \multicolumn{2}{|c|}{ Total Passive Use Value } \\
\hline & & & & & St. Lucie & Martin & St. Lucie & Martin \\
\hline Stream/Creek/River & 57.7 Miles & $74.18 \%$ & 37.09 & 4.03 & 81,391 & 57,382 & $\$ 12,163,680$ & $\$ 8,575,596$ \\
\hline Bay / Estuary & 152.1 SQ Miles & $38.26 \%$ & 19.13 & 8.18 & 81,391 & 57,382 & $\$ 12,737,494$ & $\$ 8,980,144$ \\
\hline Lake/Reservoir/Pond & 9664 Acres & $0.00 \%$ & 0.00 & 8.18 & 81,391 & 57,382 & $\$ 0$ & $\$ 0$ \\
\hline Total & & & & & & & $\$ 24,901,175$ & $\$ 17,555,740$ \\
\hline
\end{tabular}

Resident nonmarket passive use benefits totaled $\$ 42$ million, while non-resident nonmarket passive use benefits total $\$ 18$ million as presented below:

Table 4.21: IRLS Resident Nonmarket Passive Use Value Benefits 
Table 4.22: IRLS Non-Resident Nonmarket Passive Use Value Benefits

\begin{tabular}{|c|c|c|c|c|c|c|c|c|}
\hline \multirow[b]{2}{*}{ Waterbody Type } & \multirow[b]{2}{*}{ Total Assessed } & \multirow[b]{2}{*}{$\begin{array}{l}\% \text { Not } \\
\text { Good }\end{array}$} & \multirow[b]{2}{*}{$\begin{array}{c}50 \% \\
\text { Improvement }\end{array}$} & \multirow[b]{2}{*}{$\begin{array}{c}\text { Non-Use WTP } \\
\text { Per } 1 \% \\
\text { Improvement }\end{array}$} & \multicolumn{2}{|c|}{$\begin{array}{l}\text { Estimated \# of } \\
\text { Tourist Parties }\end{array}$} & \multicolumn{2}{|c|}{ Total Passive Use Value } \\
\hline & & & & & St. Lucie & Martin & St. Lucie & Martin \\
\hline Stream/Creek/River & 57.7 Miles & $74.18 \%$ & 37.09 & $\begin{array}{ll}\$ & 4.03 \\
\end{array}$ & 53,305 & 7,481 & $\$ 7,966,353$ & $\$ 1,118,085$ \\
\hline Bay / Estuary & 152.1 SQ Miles & $38.26 \%$ & 19.13 & 8.18 & 53,305 & 7,481 & $\$ 8,342,160$ & $\$ 1,170,830$ \\
\hline Lake/Reservoir/Pond & 9664 Acres & $0.00 \%$ & 0.00 & 8.18 & 53,305 & 7,481 & $\$ 0$ & $\$ 0$ \\
\hline Total & & & & & & & $\$ 16,308,513$ & $\$ 2,288,914$ \\
\hline
\end{tabular}

The $50 \%$ improvement of impaired waters assumption as discussed in section 3.7 .2 is applied to the identified impaired waterbodies listed in section 4.5 , as well as to $20 \%$ increase in the number of trips for current participants and $1 \%$ increase in the overall level of participation presented above in section 4.6 , in order to estimate the nonmarket direct use benefits for fishing, swimming, and boating. These values are estimated according to the following equations as discussed in section 3.7.2

$$
\begin{aligned}
& \mathrm{NMD}_{\mathrm{R}}=\left(\mathrm{POP}_{\mathrm{i}}\right) \times\left(\% \mathrm{PART}_{\mathrm{R}, \mathrm{WQ}}\right) \times\left(\mathrm{NMDWTP}_{\mathrm{R}} \text {, Daily } \times \text { Days }_{\mathrm{WQ}}\right) \\
& \mathrm{NMD}_{\mathrm{NR}}=(\mathrm{TP}) \times\left(\% \mathrm{PART}_{\mathrm{NR}}, \mathrm{wQ}\right) \times\left(\mathrm{NMDWTP}_{\mathrm{NR}, \text { Daily }} \times \text { DayswQ }_{\mathrm{W}}\right)
\end{aligned}
$$

Total nonmarket direct use benefits for residents total $\$ 3.5$ million and non-residents total $\$ 15.7$ million as presented below: 
Table 4.23: IRLS Resident Nonmarket Direct Use Benefits

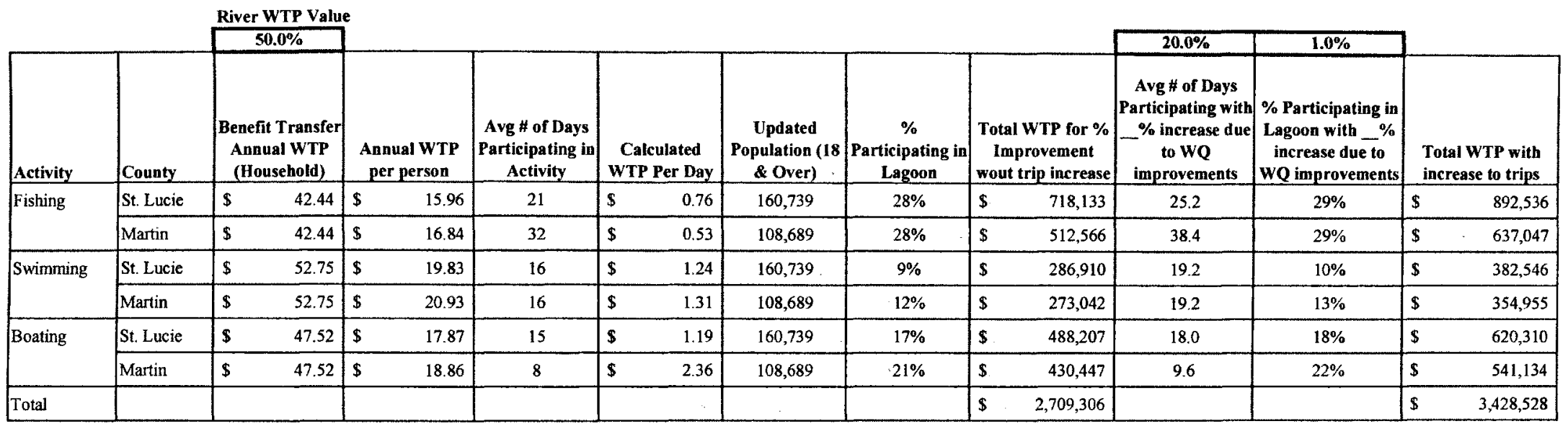


Table 4.24: IRLS Non-Resident Nonmarket Direct Use Benefits

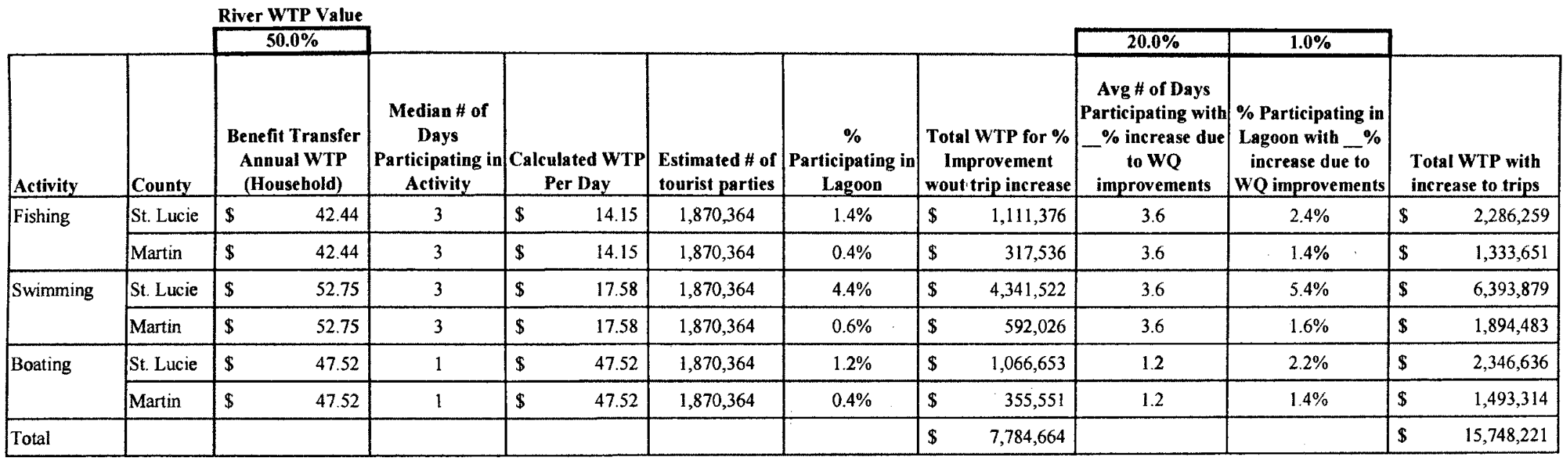




\subsection{Total Estimated IRLS Benefits}

This analysis has identified a total of approximately $\$ 159$ million in annual benefits due to the water quality improvements to total nitrogen and total phosphorus as proposed by the IRLS restoration. This represents a $46 \%$ improvement over the $\$ 344$ million baseline value.

Table 4.25: Total IRLS Estimated Benefits

\begin{tabular}{|l|rr|rr|rr|}
\hline \multicolumn{1}{|c|}{ Use Value } & \multicolumn{2}{|c|}{ Resident } & \multicolumn{2}{c|}{ Non-Resident } & \multicolumn{2}{c|}{ Total } \\
\hline Market Direct & $\$$ & 30.3 & $\$$ & 48.1 & $\$$ & 78.4 \\
\hline Nonmarket Passive & $\$$ & 42.5 & $\$$ & 18.6 & $\$$ & 61.1 \\
\hline Nonmarket Direct & $\$$ & 3.5 & $\$$ & 15.8 & $\$$ & 19.3 \\
\hline Total & $\$$ & 76.3 & $\$$ & 82.5 & $\$$ & 158.8 \\
\hline
\end{tabular}

Comparing the derived $\$ 159$ million benefit values to the $\$ 344$ million baseline values of Table 4.16 indicates a significant shift of the $\%$ of the total value between nonmarket passive use and nonmarket direct use values as shown in the figures 4.11 and 4.12 below:

Bockstael et al. (1989) estimated WTP benefits for a $20 \%$ improvement in phosphorus and nitrogen water quality for the Chesapeake Bay. A. CVM was used to estimate nonuser WTP for water quality improvements to make water acceptable for swimming, boating, and fishing. Mean WTP for nonusers, adjusted to October 2001 dollars, was estimated at $\$ 65$. Aggregating this mean WTP to the study population of approximately 620,000 yielded a total nonuser WTP value of $\$ 40.3$ million, adjusted for October 2001 


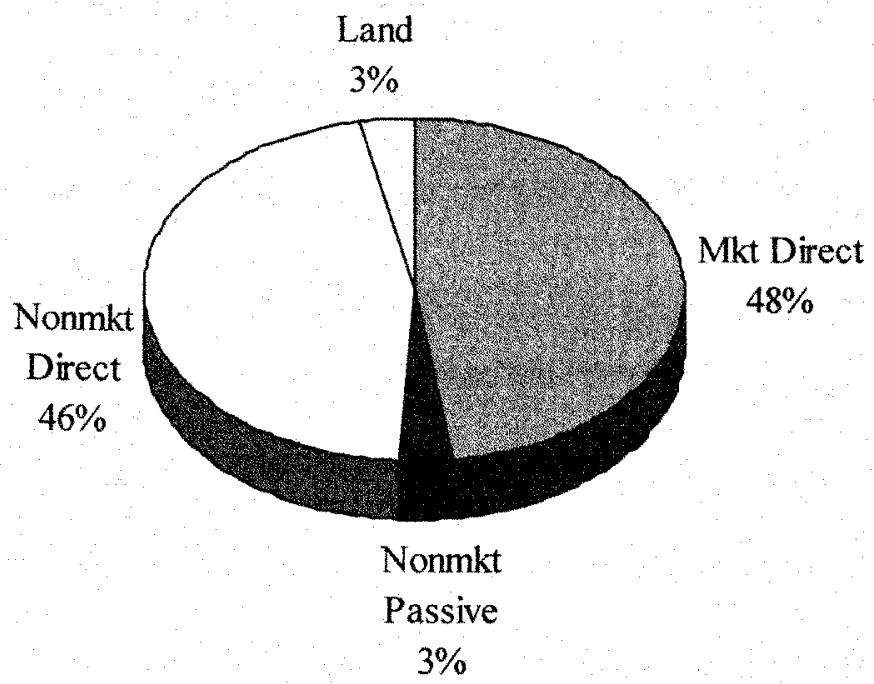

Figure 4.11: Use Values as a $\%$ of $\$ 344$ million Total Baseline

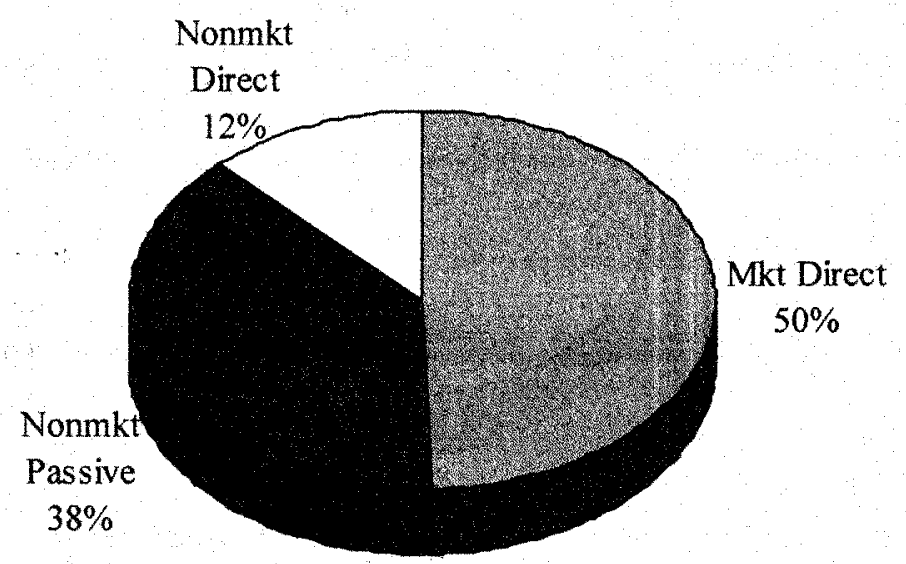

Figure 4.12: Use Values as a $\%$ of $\$ 159$ million Total Benefits

dollars. The above $\$ 61$ million passive use benefit estimated in this study was derived for a $50 \%$ improvement to impaired waters in the IRLS for an aggregated resident and 
non-resident population of approximately 200,000. Comparing these two results, and given the high $\%$ of waterbodies rated as impaired in the IRLS, this suggests that a $\$ 61$ million passive use WTP benefit derived for the IRLS may not be unreasonable.

At least a portion of the lower $\%$ total benefits from nonmarket direct uses can be attributed to benefit values being derived only for the three recreational activities of fishing, boating, and swimming. Bockstael et al (1989) also estimated nonmarket direct use values via non-traditional TCM techniques. Nonmarket direct use benefit estimates for a $20 \%$ improvement in phosphorus and nitrogen water quality across swimming, boating, and fishing totaled approximately $\$ 70$ million adjusted for inflation. Nonmarket WTP per day values were higher in the Bockstael et al. study compared to the values used in this study as described in section 4.7. This comparison suggests that the nonmarket direct use values derived in this analysis may underestimate the true values.

In summary, poor baseline water quality conditions indicate the potential for significant economic benefits due to improvements in water quality as evidenced by the $46 \%$ benefit improvement over the IRLS total economic baseline value. Following the methodology described in section 3.7 benefits were estimated at $\$ 159$ million, where nonmarket passive use benefits derived may be somewhat overestimated, and nonmarket direct use benefits derived may be somewhat underestimated. (Note: it is important to remember that the $\$ 159$ million benefit estimation given above is derived primarily from recreational and passive use benefit values and therefore may be considered a lower bound estimate. Other benefit values that were outside the scope of this analysis, but 
could be potentially incorporated into the overall benefit estimation due to the IRLS restoration include ${ }^{53}$ : indirect use values (e.g., ecological functions), waterfront real estate values, and other direct use values such as agriculture, flood control, etc.) The significance of the potential benefits as highlighted by this study, emphasizes the need for detailed primary research efforts to be employed.

\subsection{Cost-Benefit Analysis}

Following the cost-benefit methodology of section 3.8, the NPV was estimated for the "base case" scenario of a $20 \%$ increase in demand from current recreation participants, a $1 \%$ increase in the absolute overall level of participation, and a $50 \%$ improvement to identified impaired waters. Two other NPVs are estimated performing a sensitivity analysis around the base case variables. These results are given in the below table:

Table 4.26: IRLS NPV Results

\begin{tabular}{|c|c|c|c|c|c|c|}
\hline $\begin{array}{l}\text { Avg \# of Days } \\
\text { Participating } \\
\text { with \% } \\
\text { increase due to } \\
\text { WQ } \\
\text { improvements }\end{array}$ & $\begin{array}{c}\% \\
\text { Participating in } \\
\text { Lagoon with } \\
\% \text { increase } \\
\text { due to WQ } \\
\text { improvements }\end{array}$ & $\begin{array}{c}{ }_{\text {Improvement }}^{\%} \\
\text { of IRLS } \\
\text { Impaired } \\
\text { Waters }\end{array}$ & $\begin{array}{c}\text { PV of Total } \\
\text { Benefits }\end{array}$ & $\begin{array}{c}\text { PV of Total } \\
\text { Costs }\end{array}$ & & NPV \\
\hline $20 \%$ & $1.0 \%$ & $50 \%$ & $\$ 1,059,543,728$ & $\$ 1,085,099,000$ & $\$$ & $(25,555,272)$ \\
\hline $30 \%$ & $1.5 \%$ & $75 \%$ & $\$ 1,679,120,962$ & $\$ 1,085,099,000$ & $\$$ & $594,021,962$ \\
\hline $10 \%$ & $0.5 \%$ & $25 \%$ & $501,667,552$ & $\$ 1,085,099,000$ & $\$$ & $(583,431,448)$ \\
\hline
\end{tabular}

${ }^{53}$ Although possible to incorporate these other values, it is uncertain whether these values would simply be able to be summed to the values generated in this study, i.e., double-counting of benefits estimated across the various categories would need to be analyzed. 
The NPVs for the above three scenarios are viewed given cumulative present value costs and benefits over 30 years, showing the effect of the large amount of initial costs of the IRLS restoration (Note: the NPV in the below figure is represented by the difference between the PV benefit line and the PV cost line at any point in time):

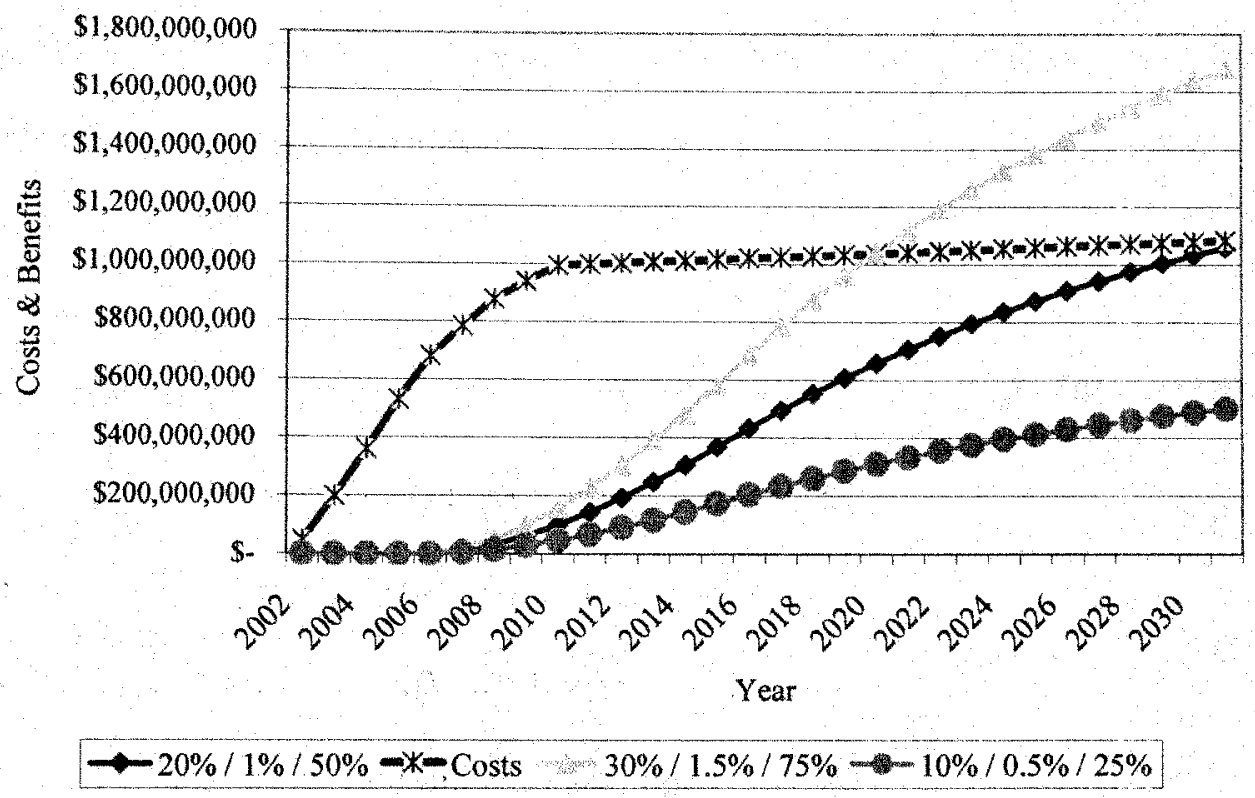

Figure 4.13: IRLS PV of Cumulative Costs \& Benefits

Table 4.26 above shows the NPV of the IRLS restoration given the base case scenario as negative $\$ 25$ million, indicating nearly the break-even point. Therefore, in order for the IRLS restoration to be economically justified, i.e., an NPV $>0$, it is indicated from this analysis that slight greater than a $20 \%$ increase in demand from current recreation participants, a $1 \%$ increase in the absolute overall level of participation, and a $50 \%$ improvement to identified impaired waters need to occur simultaneously. 
Results from the Monte Carlo analysis give an alternate view of the NPV estimations. 10,000 random draws for the specified three variables and their corresponding specified ranges as described in section 3.8 indicate that there is approximately a $64 \%$ chance that the IRLS restoration will produce a negative NPV (still maintaining a $6.125 \%$ discount rate and 30 year time period). The below histogram shows the frequency and cumulative $\%$ of negative and positive NPV results from the Monte Carlo analysis, with negative results clearly having higher frequencies.

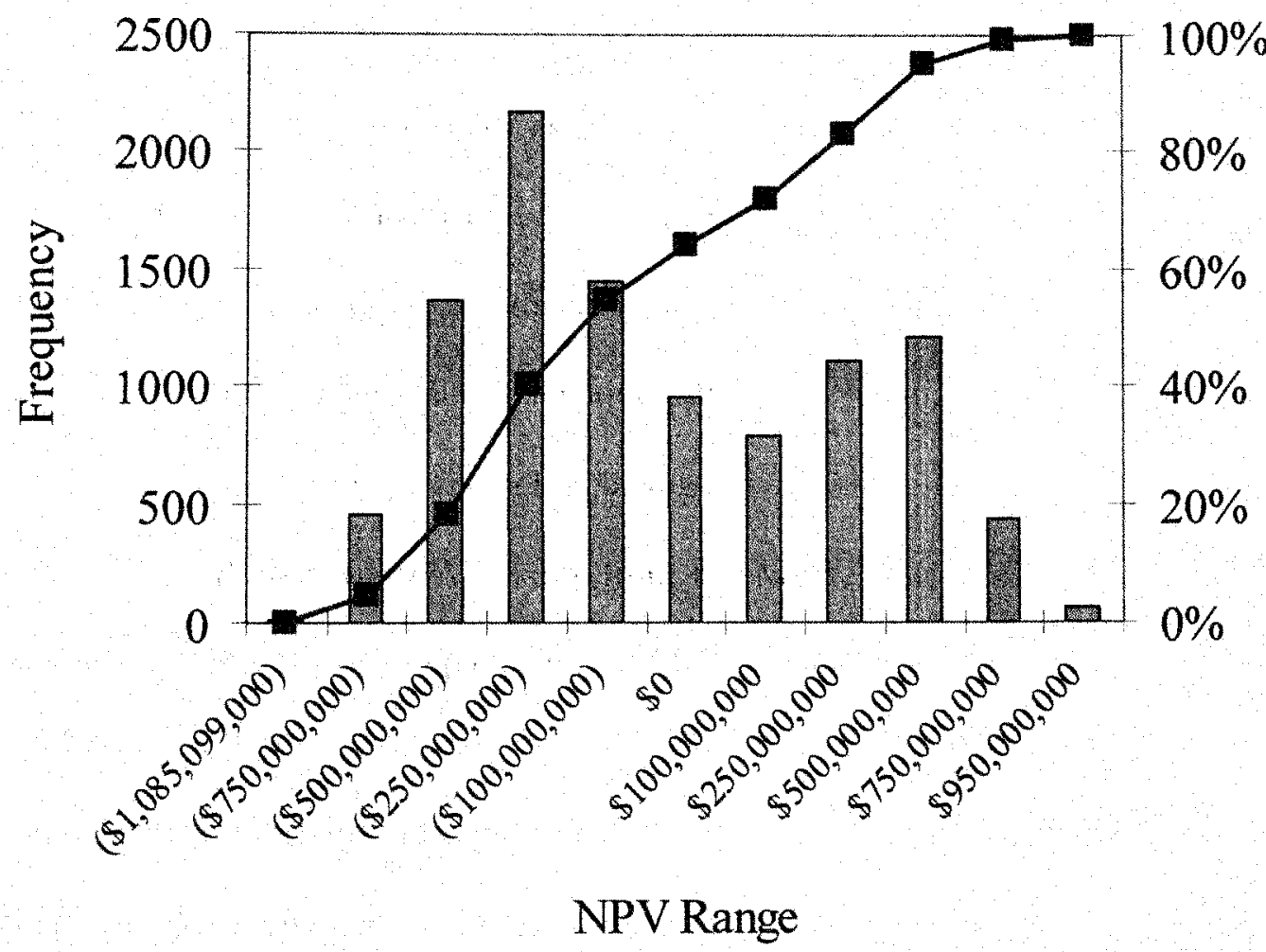

Frequency - -Cumulative $\%$

Figure 4.14: IRLS Monte Carlo NPV Histogram 
The expected loss of the IRLS restoration is the average of the negative NPVs, $-\$ 365$ million, multiplied by the probability of a loss, approximately $64 \%$, yielding an expected loss of $-\$ 234$ million. Similarly, the expected gain is the average of the positive NPVs, $\$ 269$ million, multiplied by the $36 \%$ probability of a gain, yielding an expected gain of $\$ 97$ million. The difference between the expected gains and losses is approximately the mean NPV generated by the Monte Carlo analysis, $-\$ 137$ million. The median NPV, of $-\$ 147$ million, closely approximates the mean value with other summary statistics of the NPV distribution given below:

Table 4.27: Monte Carlo Base Case Summary Statistics

\begin{tabular}{|l|r|}
\hline Summary Statistic & \multicolumn{1}{|c|}{ Result } \\
\hline Minimum & $-\$ 1,085,099,000$ \\
\hline Mean & $-\$ 136,800,439$ \\
\hline Median & $-\$ 147,984,776$ \\
\hline Maximum & $\$ 943,128,582$ \\
\hline Standard Deviation & $\$ 376,689,083$ \\
\hline
\end{tabular}

Given the uncertainty of the three variables that are primarily driving the total benefits estimation in this analysis, the Monte Carlo results are able to lend much richer information in regard to the economic feasibility of the project. The standard deviation indicates a relatively large spread around the mean NPV value, however this is still weighted more to the negative side due to the negative mean NPV.

The Monte Carlo analysis was also conducted by simultaneously fixing two of the three variables to their base case value, i.e., $20 \%, 1 \%, 50 \%$, and randomly drawing from the 
uniform distribution for the third. This analysis indicates the largest affect on NPV to be from variation in the $\%$ of improved waterbodies and also the $\%$ of increased participation suggesting more management focus may want to be directed in these areas.
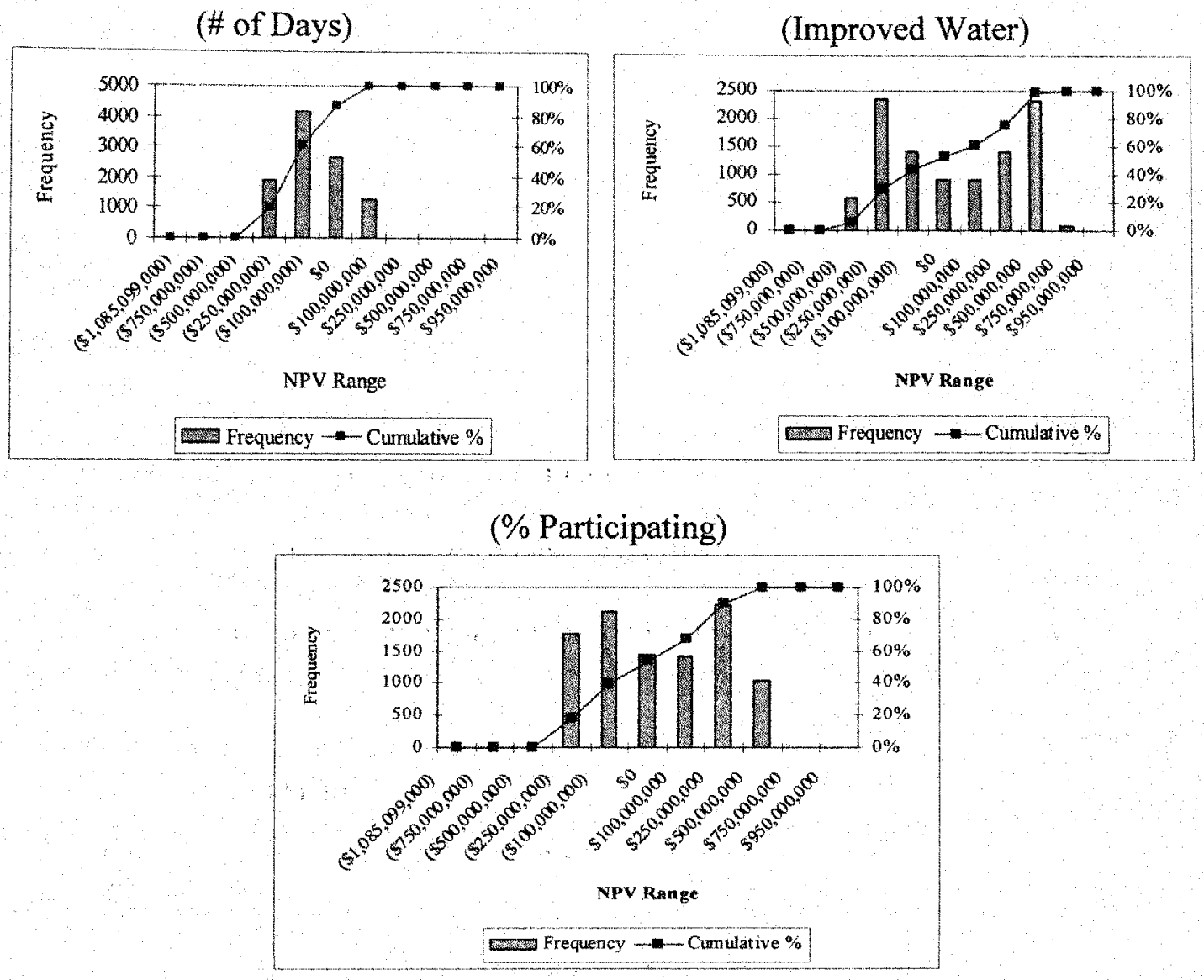

Figure 4.15: Monte Carlo NPV with One Random Variable

The below table presents the summary statistics for the random variable, showing the improved mean NPV values for \% participating and improved waters. 
Table 4.28: Monte Carlo Fixed Analysis Summary Statistics

\begin{tabular}{|l|c|c|c|}
\hline Summary Statistic & \# of Days & Improved Waters & \% Participating \\
\hline Minimum & $(316,944,407)$ & $(560,992,445)$ & $(374,351,563)$ \\
\hline Mean & $(136,939,096)$ & $(26,731,853)$ & $(24,296,901)$ \\
\hline Median & $(137,448,700)$ & $(29,303,332)$ & $(22,067,309)$ \\
\hline Maximum & $47,292,012$ & $509,881,902$ & $323,241,020$ \\
\hline Standard Deviation & $105,059,587$ & $310,930,497$ & $202,473,572$ \\
\hline
\end{tabular}

The effects of time can be factored into the analysis as well while simultaneously drawing random values for the three main variables. For purposes of this analysis, the $\$ 995$ million present value of initial construction costs is amortized over a 5 and 15 year time period ${ }^{54}$. Amortizing the $\$ 995$ million over 5 years at a $6.125 \%$ interest rate yields annual costs of $\$ 237$ million for 5 years. Amortizing the $\$ 995$ million over 15 years also at a rate of $6.125 \%$ yields annual costs of $\$ 103$ million for 15 years. Operations and maintenance expenses of $\$ 4.2$ million per year post construction are the same. Speeding up the construction from its original schedule to 5 years implies that benefits are realized sooner as well - specifically accruing $10 \%$ per year beginning in year 3 as opposed to year 6. Similarly, slowing down the construction implies that benefits are realized later $10 \%$ per year beginning in year 9 . Finally, altering the assumption of benefits accruing at $10 \%$ per year to $20 \%$ per year beginning in year 6 is also done with no change to the costs.

\footnotetext{
${ }^{54}$ Amortization typically applies to one-time costs that will be uniformly allocated into future periods. The IRLS initial construction costs are not necessarily one-time construction costs as they are spread over 9 years. Furthermore, these costs are not uniformly spread over the nine years. However, for purposes of this analysis, this is the assumption being used although possibly incorrectly.
} 
The following figure presents the NPV histograms for the four different construction time periods - 10 years of construction with benefits accruing $10 \%$ per year beginning in year $6(10 \mathrm{yrs}-10 \%), 5$ years of construction with benefits accruing $10 \%$ per year beginning in year $3(5 \mathrm{yrs}-10 \%), 15$ years of construction with benefits accruing $10 \%$ per year beginning in year $9(15 \mathrm{yrs}-10 \%)$, and 10 years of construction with benefits accruing $20 \%$ per year beginning in year $6(10 \mathrm{yrs}-20 \%)$ :
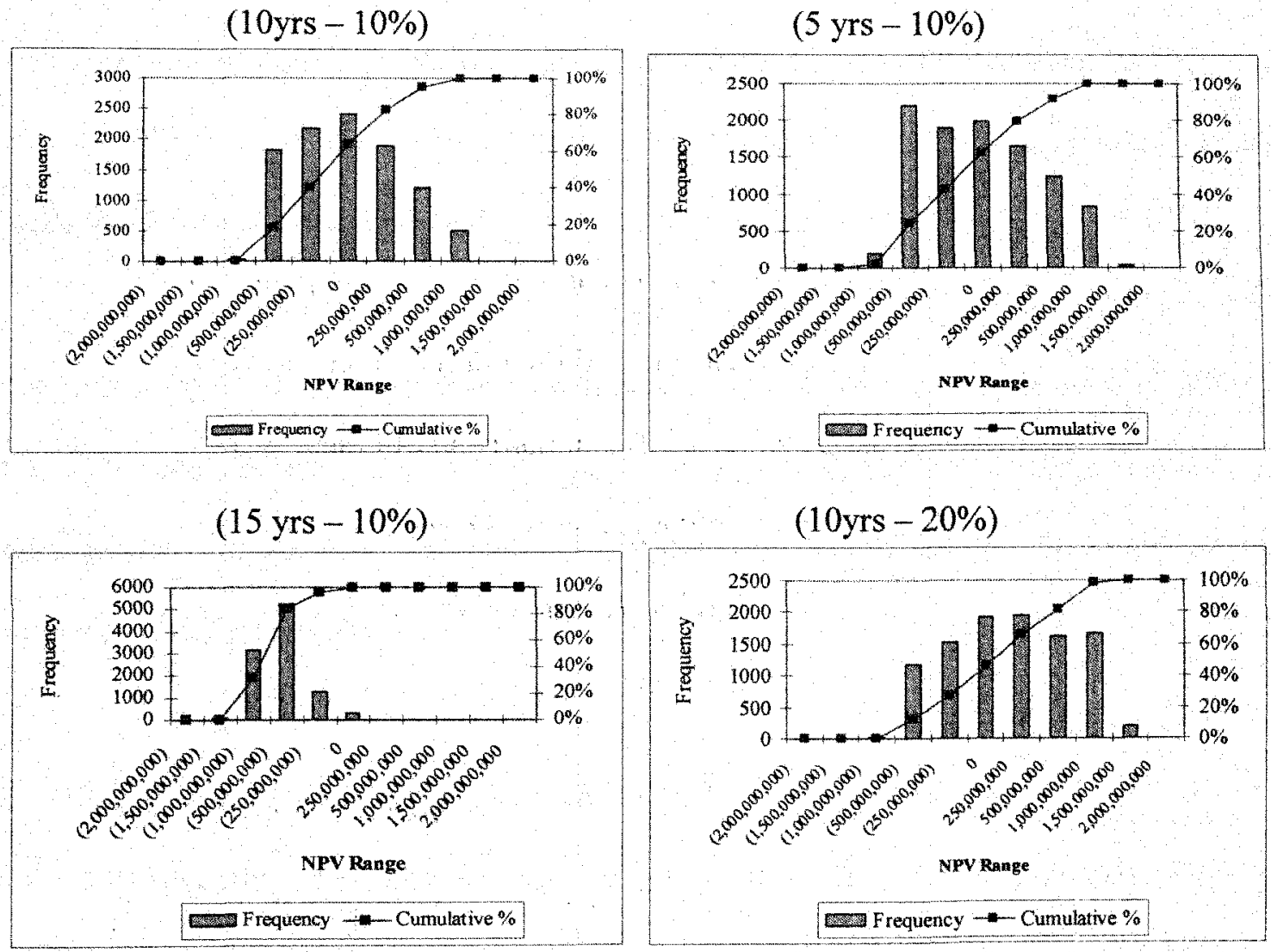

Figure 4:16: Monte Carlo Histogram Results Varying Time

As mentioned above, the expected loss in the base case scenario is $-\$ 234$ million with an expected gain of $\$ 97$ million, a mean NPV of $-\$ 137$ million, and an overall $64 \%$ chance 
of producing a negative NPV. From the above figure it can be clearly seen that slowing down the construction (15 yrs $-10 \%$ ) does not improve upon these results. What is interesting is that speeding up the construction ( $5 \mathrm{yrs}-10 \%$ ) does not necessarily equate to better results either. While there is a slightly better chance of producing a positive NPV, approximately $38 \%$ as compared to $36 \%$ in the base case, the mean NPV is actually lower at $-\$ 147$ million. This is attributed to increases in both the expected loss and expected gain of the project, $-\$ 270$ and $\$ 123$ million respectively, due to the larger range and variance of the NPV results. Lastly, altering the assumption of accruing benefits quicker, $20 \%$ vs. $10 \%$ annually (10 yrs $-20 \%$ ), without effecting the costs obviously leads to a better chance of a positive NPV, approximately $54 \%$.

Various analyses and results have been presented in this section in order to demonstrate the how cost benefit analysis allows for the evaluation of different courses of management action, and also provides insight into the economic feasibility of the proposed IRLS restoration.

\section{CONCLUSIONS \& FUTURE RESEARCH}

Implementing the methodology presented in section 3.1 has allowed for the confirmation of the two hypotheses stated in section 1.2 , i.e., that water quality benefits derived from the IRLS restoration can be monetized and that their monetization is able to ultimately provide much richer information to decision makers, including importantly whether the restoration effort is economically feasible. An updated IRLS baseline economic value, consisting of direct and passive use values only, was estimated utilizing 
the existing work by Apogee Research (1996). An IRLS water quality baseline was also established for nitrogen and phosphorus concentrations as well as the total amount of impaired waters.

Net benefits beyond the economic baseline value were estimated utilizing benefit transfer values from the existing studies of Whitehead et al. (2000) and Magat et al. (2000), and by importantly incorporating the results of the water quality baseline. Assuming these benefit transfer values hold true and are in fact applicable, net benefits resulting from this study amounted to a total of $\$ 159$ million annually, with market direct use values and passive use values representing the most significant portion of the total. Again, as mentioned in section 4.8 , the $\$ 159$ million amount can be considered a lower bound value as indirect values, waterfront real estate values, and other minimal direct use benefits were not incorporated into this analysis and the subsequent $\$ 159$ million benefit result. Nonetheless, it appears evident that the IRLS indeed already exhibits significant economic value and also has potential for further significant economic value to accrue given its relatively poor water quality baseline.

The $\$ 159$ million annual benefit value was analyzed from a cost-benefit analysis perspective over a 30 year time period. Under the specific assumptions for interest rates and $\%$ of benefits accruing per year as given in section 3.8, the IRLS restoration with its $\$ 159$ million annual value was shown to not be economically feasible, i.e., having a NPV value $<\$ 0$. However, as the NPV value was only slightly below $\$ 0$ and given the level 
of uncertainty in the benefit estimate ${ }^{55}$, a Monte Carlo probabilistic risk analysis was also conducted on the NVP results. Assigning specific ranges for the possible values of the key variables driving the benefit estimation, as described in section 3.8, 10,000 random draws were taken simultaneously for these variables. NPV results were then estimated from these 10,000 random draws. Results from the Monte Carlo analysis indicate that the IRLS restoration has approximately a $64 \%$ chance of producing a non-economically feasible result, i.e., a NPV $<\$ 0$, including mean and median values with negative NPVs.

Other Monte Carlo analyses were conducted which seemed to indicate that focus on the level of new recreation participants and the amount of non-impaired waters might be better served to decision makers as opposed to the timing of the construction itself. Importantly, given the uncertainty in the benefit estimates the Monte Carlo results ultimately give decision makers a way of incorporating the uncertainty into their decision-making process and a much richer view of the estimated results.

This study has not been meant to be a definitive proclamation on the economic feasibility of the IRLS restoration. Rather, it has been intended to show decision makers the theory behind economically valuing an environmental restoration effort such as the IRLS, and also to present a methodology that allows one to accomplish this. Furthermore, it presents the significant potential economic value of natural resources and thereby why it

\footnotetext{
${ }^{55}$ Any estimate relying on benefit transfers inherently has a relatively high level of uncertainty in the result
} 
is important to understand the scope of this value, especially in relation to costs intended to foster this value.

There are several areas for future research related to this study. As the results of this study have relied on many specific assumptions and benefit transfers, the quality of the results would be enhanced greatly by deriving formal economic models with primary source date to generate benefit estimates as discussed in section 3.7. The incorporation of recreation substitution effects, labor-leisure decisions by utility maximizers, and the behavioral role that objective water quality improvements in fact display could also play a more prominent role in these models. Other interesting and important possibilities include:

- Incorporating land values due to water quality improvements via a hedonic pricing analysis

- Incorporating indirect values related to the ecological function of the IRLS waterbodies

- Utilizing option-pricing models as opposed to cost-benefit analysis as suggested by Conrad and Lopez (2002)

- Modeling the effect of objectively clean and healthy environmental resources on economic growth for the region

- Game theory expected payoff analysis considering the other components of the total Everglades restoration effort 
Obviously, this type of natural resource restoration effort provides a very rich source of interesting economic research topics, as should be expected given the complexity, costs, and societal ramifications of such an effort. 


\section{REFERENCES}

Abdalla, C., 1990. "Measuring Economic Losses from Ground Water Contamination: An Investigation of Household Avoidance Costs." Water Resources Bulletin. 26:3 pgs 451-463.

Acharya, G., Barbier, E., 2002. "Using Domestic water analysis to value groundwater recharge in the Hadejia-Jama'are floodplain, Northern Nigeria" American Journal of Agricultural Economics v.84, 2, 415(12)

Adamowicz, W., Louviere, J., Williams, M., 1994. "Combining revealed and stated preference methods for valuing environmental amenities" Journal of environmental economics and management 26: 271-292

Apogee Research Inc., Resource Economics Consultants Inc., 1996. Economic Assessment and Analysis of the Indian River Lagoon.

Arrow, K., Daily, G., Dasgupta, P., Levin, S., Maler, K., Maskin, E., Starrett, D., Sterner, T., Tietenberg, T. 2000. "Managing Ecosystem Resources." Environmental Science \& Technology 34 (8): 1401-1406.

Bell, F., 1997. "The Economic Valuation of Saltwater Marsh Supporting Marine Recreational Fishing In the Southeastern United States." Ecological Economics 21:243-254.

Bergstrom, J., Boyle, K., Poe, G., 2001. The Economic Value of Water Quality Northampton, MA Edward Elgar Publishing, Inc.

Bhat, M., 2003. "Application of Non-Market Valuation to the Florida Keys Marine Reserve Management" Journal of Environmental Management 67 (4): 315-325

Boardman, A., Greenberg, D., Vining, A., Weimer, D., 2001. Cost-Benefit Analysis: Concepts and Practice Upper Saddle River, NJ, Prentice Hall Inc.

Bockstael, N., Hanemann, W., Kling, C., 1987. Estimating the Value of Water Quality Improvements in a Recreational Demand Framework" Water Resources Research. 23:5:951-960

Bockstael, N., McConnell, K., Strand, I., 1989. "Measuring the Benefits of Improvements in Water Quality: The Chesapeake Bay", Marine Resource Economics, 6: 1-18

Bockstael, N., Freeman III, A., Kopp, R., Portney, P., Smith, K. 2000. "On Measuring Economic Values for Nature." Environmental Science \& Technology 34 (8): 1384-1389. 
Bricker, S., Clement, C., Pirhalla, D., Orlando, S., Farrow, D., 1999. National estuarine eutrophication assessment: effects of nutrient enrichment in the Nation's estuaries. NOAA, National Ocean Service, Special Projects Office, and the National Centers for Coastal Ocean Science, Silver Spring MD.

Buchli, L., Filippini, M., Banfi, S., 2003. "Estimating the benefits of low flow alleviation in rivers: the case of the Ticino River", Applied Economics 35: 585-590.

Calloway, J., Schwartz, A., Thompson, R., 1974. "Industrial Economic Model of Water Use and Waste Treatment for Ammonia." Water Resources Research 10(4): 650658.

Carson, Richard 2000. "Contingent Valuation: A User's Guide." Environmental Science \& Technology 34 (8): 1413-1418.

Carson, R., Mitchell, R., 1993. "The Value of Clean Water: The Public's Willingness to Pay of Boatable, Fishable, and Swimmable Quality Water" Water Resources Research 29:7:2445-2454

Conrad, J., Lopez, A., 2002. "Stochastic Water Quality: Timing And Option Value Of Treatment." Water Resources Research. 38:5.

Eiswerth, M., Englin, J. Fadali, E., Shaw, D., 2000. "The Value of water levels in waterbased recreation: a pooled revealed preference/contingent behavior model" Water Resource Research 36:4:1079-1086

Englehardt, J. 1998. "Ecological and Economic Risk Analysis of Everglades: Phase I Restoration Alternatives." Risk Analysis 18 (6): 755-771.

Englin, J., Lambert, D., Shaw W., 1997. "A Structural Equations Approach to Modeling Consumptive Recreation Demand" Journal of Environmental Economics and Management 33:33-43.

Farber, S., Griner, B. 2000. "Using Conjoint Analysis To Value Ecosystem Change." Environmental Science \& Technology 34 (8): 1407-1412.

Faux, J., Perry, G., 1999. "Estimating Irrigation Water Value Using Hedonic Price Analysis" Land Economics 75(3): 440-453.

Florida Bureau of Economic and Business Research, 2003. "Number of Households and Average Household Size in Florida: April 1, 2002" Florida Population Studies 36:2, Bulletin 135 .

FDEP (Florida Department of Environmental Protection) Division of Water Resource Management, 2003. Group 2 Basin Status Report: St. Lucie and Loxahatchee 
FDEP, 2002. Florida's Water Quality Assessment 2002 305(b) Report

Florida Office of Economic and Demographic Research Retrieved July 17, 2003 from http://www.state.fl.us/edr/population.htm

Frederick, K.D., VandenBerg, T., Hanson, J. 1996. Economic Valuation of Freshwater In the United States. Washington D.C.: Resources for the Future.

Freeman, A.M. 1993. The Measurement of Environmental and Resource Values Washington D.C., Resources For the Future

Freeman, A.M. 2003. The Measurement of Environmental and Resource Values, $2^{\text {nd }}$ Edition Washington D.C., Resources For the Future

Griffin, R., Mjelde, J., 2000. "Valuing Water Supply Reliability." American Journal of Agricultural Economics 82:414-426.

Hamilton, J., Whittlesey, N., Robison, H., Willis, D., 2002. "Measuring Direct And Indirect Costs Of Land Retirement In An Irrigated River Basin." Water Resources Research. 38:8

Hanley, N., Shogren, J., White, B., 1997. Environmental Economics In Theory and Practice New York, Oxford University Press.

Hanley, N., Bell, D., Alvarez-Farzio, B., 2003. "Valuing the Benefits of Coastal Water Quality Improvements Using Contingent and Real Behavior" Environmental and Resource Economics 24: 273-285.

Hazen and Sawyer, 2002. "Natural Resource Analysis of Lake Okeechobee Phosphorus Management Strategies" Contract C-11677 Phase 1 Summary Report and Documentation Report.

Heathcote, I., W., 1998. Integrated Watershed Management: Principles and Practice New York, John Wiley and Sons, Inc.

ICEMECS (International Center for the Environmental Management of Enclosed Coastal Seas), Retrieved September 5, 2003 from http://www.emecs.or.jp/01cd-rom/section 3 e/sec3 fset e3 2.html

IRL SWIM (Indian River Lagoon 2000-2005 Surface Water Improvement and Management Plan Update), 2002.

Jain, R., Urban, L., Stacey, G., Balbach, H., 1993. Environmental Assessment New York, McGraw-Hill 
Jenkins, M., Lund, J., Howitt, R., 2003. "Using Economic Loss Functions to Value Urban Water Scarcity in California." Journal AWWA 95:2.

Johnston, R., Swallow, S., Allen, C., Smith, L., 2002. "Designing Multidimensional Environmental Programs: Assessing Tradeoffs And Substitution In Watershed Management Plans." Water Resources Research. 38:7

Kaoru, Y., 1995. "Measuring Marine Recreation Benefits of Water Quality Improvements by the Nested Random Utility Model" Resource and Energy Economics 17:119-136

Kaoru, Y., Smith, V.K., Liu, J., 1995. "Using Random Utility Models to estimate the recreational value of estuarine resources" American Journal of Agricultural Economics 77:141-151

King, D.M., Mazzotta, M., (n.d.) Ecosystem Evaluation. Retrieved October 21, 2002 from http://www.ecosystemvaluation.org

Kramer, R., Eisen-Hecht, J., 2002. "Estimating the economic value of water quality Protection in the Catawba River Basin." Water Resources Research. 38:9.

Leeworthy, V., Wiley, P., 2003. "Socioeconomic Impact Analysis of Marine Reserve Alternatives for the Channel Islands National Marine Sanctuary" National Oceanic and Atmospheric Administration

Letson, D., 2002. Economic Valuation and Analysis. In D. Letson and J.W. Milon (Ed.), Florida Coastal Environmental Resources A Guide to Economic Valuation and Impact Analysis (pgs. 1-38). Florida Sea Grant College Program.

Loomis, J., Kent, P., Strange, L., Fausch, K., Covich, A., 2000. "Measuring the total economic value of restoring ecosystem services in an impaired river basin: results from a contingent valuation survey", Ecological Economics 33: 103-117.

Lupi F., Hoehn, J., 1998. "A Partial Benefit-Cost Analysis of Sea Lamprey Treatment Options on the St. Marys River". A Report Submitted to the Great Lakes Fishery Commission, July 1998

Lynee, G., Luppold, W., Kiker, C., 1978. "Water Price Responsiveness of Commercial Establishments", Water Resources Bulletin 14, 3: 719-729.

Magat, W., Huber, J., Viscusi, K., Bell, J., 2000. “An Iterative Choice Approach to Valuing Clean Lakes, Rivers, and Streams" Journal of Risk and Uncertainty 21:1:7-43. 
Milon, J.W., 2002. Natural Resource Valuation of the Indian River Lagoon. In D. Letson and J.W. Milon (Ed.), Florida Coastal Environmental Resources A Guide to Economic Valuation and Impact Analysis (pgs. 77-84). Florida Sea Grant College Program.

Munasinghe, M., 1993. Environmental Economics and Sustainable Development, World Bank Environment Paper Number 3, The World Bank, Washington D.C. ISBN 081213-2352-0

NRC (National Research Council) Committee on Valuing Ground Water, 1997. Valuing Ground Water Washington D.C., National Academy Press.

NRC (National Research Council), 2000. Clean Coastal Waters: Understanding and Reducing the Effects of Nutrient Pollution. Washington DC, National Academy Press.

Ortolano, L., 1997. Environmental Regulation and Impact Assessment New York, John Wiley and Sons.

Pearce, David W., Seccombe-Hett, Tannis. 2000. "Economic Valuation and Environmental Decision-Making in Europe." Environmental Science \& Technology 34 (8): 1419-1425.

Pretty, J., Mason, C., Nedwell, D., Hine, R., Leaf, S., Dils, R., 2003. "Environmental Costs of Freshwater Eutrophication in England and Wales." Environmental Science \& Technology 37 (2): 201-208.

Raucher, R., 1983. "A Conceptual Framework for Measuring the Benefits of Groundwater Protection." Water Resources Research. 19:2 pgs 320-326.

Renzetti, S., 2002. The Economics of Water Demands. Norwell, MA, Kluwer Academic Publishers

Rosenberger, R., Loomis, J., 2001. "Benefit Transfer of Outdoor Recreation Use Values: A Technical Document Supporting the Forest Service Strategic Plan (2000 Revision)." Gen. Tech. Rep. RMRS-GTR-72. Fort Collins, CO: U.S. Department of Agriculture, Forest Service, Rocky Mountain Research Station.

Russell, C., Vaughan, W., Clark, C., Rodriguez, D., Darling, A., 2001. Investing in Water Quality Measuring Benefits, Costs and Risks, Inter-American Development Bank, Washington D.C.

Sagoff, Mark. 2000. "Environmental Economics and the Conflation of Value and Benefit.” Environmental Science \& Technology 34 (8): 1426-1432. 
Schiffler, M., 1998. The Economics of Groundwater Management in Arid CountriesTheory, International Experience and a Case Study of Jordan Portland, Frank Class Publishers

Shultz, S.D., Leitch, J.A., 2003. "The Feasibility of Restoring Previously Drained Wetlands to Reduce Flood Damage." Journal of Soil and Water Conservation $58: 3$, pgs 21-29.

Shultz, S.D., Lindsay, B., 1990. "The Willingness to Pay for Groundwater Protection." Water Resources Research. 26:9 pgs 1869-1875.

Solley, W., Pierce, R., Perlman, H., 1998. "Estimated Use of Water In the United States in 1995." U.S. Geological Survey Circular 1200.

SFERTF (South Florida Ecosystem Restoration Task Force), 2000. Coordinating Success: Strategy for Restoration of the South Florida Ecosystem

Staff and Wire Reports, 2003. "Port St. Lucie Among Fastest Growing Cities In State" Stuart News July 10, 2003 Page A1.

Stewart, W. 1996. "Economic Assessment of the Ecosystem." Sierra Nevada Ecosystem Project: Final Report to Congress, vol. III, University of California, Centers for Water and Wildland Resources.

Tay, R., McCarthy, P., 1994. "Benefits of improved water quality: a discrete choice analysis of freshwater recreational demands" Environment and Planning 26:16251638

Thomas, J., Syme, G., 1988. "Estimating Residential Price Elasticity of Demand for Water: A Contingent Valuation Approach." Water Resources Research. 24:11 pgs 1847-1857.

USACE/SFWMD (United States Army Corps of Engineers, South Florida Water Management District), 1999. Central and Southern Florida Project Comprehensive Review Study: Socio-Economics, Appendix E.

USACE/SFWMD (United States Army Corps of Engineers, South Florida Water Management District), 2002. Central and Southern Florida Project Indian River Lagoon - South (IRLS) Feasibility Study, Final Integrated Feasibility Report and Supplemental Environmental Impact Statement.

United States Census Bureau, American Fact Finder, Retrieved July 17, 2003 from www.factfinder.census.gov/servlet/BasicFactsServlet 
US EPA (United States Environmental Protection Agency), 2000A. Ambient Water Quality Criteria Recommendations Information Supporting the Development of State and Tribal Nutrient Criteria For Lakes and Reservoirs in Nutrient Ecoregion XII, Office of Water, Washington D.C. EPA 822-B-00-013

US EPA (United States Environmental Protection Agency), 2000B. Ambient Water Quality Criteria Recommendations Information Supporting the Development of State and Tribal Nutrient Criteria For Lakes and Reservoirs in Nutrient Ecoregion XIII. Office of Water, Washington D.C. EPA 822-B-00-014

US EPA (United States Environmental Protection Agency), 2001. Nutrient Criteria Technical Guidance Manual: Estuarine and Coastal Marine Waters. Office of Water, Washington D.C., EPA-822-B-01-003

US EPA (United States Environmental Protection Agency) 2002. Mid-Atlantic Integrated Assessment 1997-98 Summary Report, EPA/620/R-02/003. U.S. Environmental Protection Agency, Atlantic Ecology Division, Narragansett, RI.

Visit Florida Research Office, 2001. "Year-in-brief Visitors to Florida in 2001"

Von Haefen, R., Phaneauf, D., 2003. "Estimating preferences for outdoor recreation: a Comparison of continuous and count data demand system frameworks" Journal of Environmental Economics and Management 45: 612-630.

Walsh, R., Johnson, D., McKean, J., 1992. "Benefit Transfer of Outdoor Recreation Demand Studies, 1968-1988", Water Resources Research 28,3: 707-713.

Ward, K., Duffield, J., 1992. Natural Resource Damages: Law and Economics New York, John Wiley \& Sons, Inc.

Weber, J., 1989. "Forecasting Demand and Measuring Price Elasticity." Journal AWWA 81:5:57.

Weisskoff, R., 2000. "Missing Pieces in Ecosystem Restoration: The Case of the Florida Everglades." Economic Systems Research, Vol. 12, No. 3., Pgs 271-303.

Whitehead, J., Haab, T., Huang, J., 2000. "Measuring Recreation Benefits of quality improvements with revealed and stated behavior data." Resource and Energy Economics. 22: 339-354. 